\title{
Bronchus-associated macrophages are positioned for soluble antigen capture from the airway lumen and for local Th2 cell activation
}

Xin-Zi Tang 1,2,3,5, Lieselotte S. M. Kreuk ${ }^{1,2}$, Cynthia Cho ${ }^{1,2,6}$, Ross J. Metzger ${ }^{4,7}$, and Christopher D. C. Allen ${ }^{1,2,4, *}$

${ }^{1}$ Cardiovascular Research Institute, University of California, San Francisco, San Francisco, CA, USA

${ }^{2}$ Sandler Asthma Basic Research Center, University of California, San Francisco, San Francisco, CA, USA

${ }^{3}$ Biomedical Sciences Graduate Program, University of California, San Francisco, San Francisco, CA, USA

${ }^{4}$ Department of Anatomy, University of California, San Francisco, San Francisco, CA, USA

${ }^{5}$ Present address: Molecular Engineering Laboratory, Institute of Bioengineering and

Nanotechnology, Agency for Science, Technology and Research, Singapore

${ }^{6}$ Present address: RAPT Therapeutics, South San Francisco, CA, USA

7Present address: Department of Pediatrics (Cardiology), Stanford University School of Medicine, Stanford, CA, USA

${ }^{\star}$ Correspondence should be addressed to:

Christopher D. C. Allen, Ph.D.

Address: UCSF

CVRI, Box 3122

555 Mission Bay Blvd S

San Francisco, CA 94143, USA

Email: $\quad$ Chris.Allen@ucsf.edu

Phone: $\quad$ 415-476-5178 


\begin{abstract}
The aberrant activation of immune responses at barrier surfaces may lead to pathological inflammation. In allergic asthma, allergen inhalation leads to peri-bronchial inflammation and the activation of antigen-specific Th2 cells critical for disease pathogenesis. However, the mechanisms for local allergen capture and antigen presentation remain unclear. By two-photon laser scanning microscopy, we established that soluble antigens that deposited along the bronchial airways were primarily captured and presented by a population of interstitial macrophages with high CX3CR1-GFP and surface MHC class II expression. These cells were strategically positioned underneath the bronchial epithelium and were enriched in collagen-rich regions near some airway branchpoints, where inhaled antigens are likely to deposit. We refer to these cells as Bronchus-Associated Macrophages (BAMs) based on their localization. BAMs efficiently captured, processed, and presented antigen; activated effector Th2 cells; formed extended interactions with T cells in vivo; and remained lung resident after exposure to inflammatory stimuli. In contrast, classical DCs migrated to draining lymph nodes and were not necessary for the induction of allergic lung inflammation in sensitized mice, suggesting that BAMs act as local antigen presenting cells in the lung.
\end{abstract}

\title{
Introduction
}

Immune surveillance of barrier surfaces is essential for the maintenance of tissue homeostasis and defense against pathogens. Within the lung, the conducting bronchial airways represent one of the first sites of exposure to inhaled substances and infectious agents. In allergic asthma, the inhalation of harmless environmental allergens leads to peri-bronchial inflammation, in which the local activation of type 2 helper T cells (Th2 cells) results in effector cytokine production that promotes pathogenesis (Holgate, 2012; Lambrecht et al., 2019). The Th2 cells are activated by antigen presenting cells (APCs) that survey the epithelial barrier and capture and present antigen. However, the types of APCs contributing to surveillance of the conducting airways are not fully characterized, and the anatomical organization that couples antigen capture to Th2 cell activation remains unclear.

The lung tissue regions around the conducting airways may be ideal sites for antigen surveillance and the initiation of immune responses. Unlike alveolar spaces, the conducting airways do not participate in gaseous exchange but serve to conduct and filter air. As inspired air passes through airway branchpoints, changes in the direction of airflow promote the deposition of particulates and the dissolution of soluble substances in the overlying mucus layer (Carvalho et al., 2011; Clarke and Yeates, 1994). In allergic asthma, eosinophils and lymphocytes are recruited to regions around the conducting airways, resulting in peri-bronchial inflammation (Jeffery, 1992). In several mouse models of airway infections, T and B cells accumulate in organized foci near the airways, forming induced Bronchus-Associated Lymphoid Tissue (BALT) structures (Fleige and Forster, 2017; Randall, 2010). The accumulation of immune cells in tissue regions near the conducting airways may allow streamlined access to inhaled antigens that have become deposited.

Antigen capture and immune activation at the airways are thought to be coordinated primarily by dendritic cells (DCs) (Wikstrom and Stumbles, 2007), based initially on observations that MHC$\mathrm{II}^{+}$cells with dendritic morphology were abundant along both human and rodent airways at baseline (Demedts et al., 2005; Huh et al., 2003; Lambrecht et al., 1998; von Garnier et al., 2007). Flow cytometric analysis of lung-draining lymph nodes as well as dissociated lung tissue enriched for the conducting airways also showed that DCs, gated as CD11 $\mathrm{c}^{+} \mathrm{MHC}-\mathrm{II}^{+}$cells, were able to capture and process fluorescent ovalbumin (OVA) administered via the 
airways (del Rio et al., 2007; Hammad et al., 2010; Huh et al., 2003; von Garnier et al., 2007). However, time-lapse microscopy studies of CD11c-YFP reporter mice found that DCs near the conducting airways did not capture inhaled particulate antigen in the form of beads (Thornton et al., 2012; Veres et al., 2011). Instead, DCs were reported to capture beads at the alveoli in a mouse model of asthma, and were proposed to subsequently migrate to tissue regions proximal to the bronchial airways, where T cells are activated (Thornton et al., 2012). This mechanism may describe the uptake and presentation of particulate antigens that reach the alveoli, but a direct assessment of whether soluble antigen is captured and presented at the conducting airways remains lacking. The presentation of soluble antigens is pertinent, because a recent study indicated that individuals allergic to aeroallergens had an increased frequency of Th2 cells that preferentially recognized soluble antigen components of aeroallergens, whereas regulatory T cells preferentially recognized particulate antigen components (Bacher et al., 2016). Developing a better understanding of the uptake and presentation of soluble antigens may therefore be of significant relevance to Th2 cell responses in asthma.

Despite conflicting evidence for antigen capture by DCs at the conducting airways, much of the literature supports a crucial role for DCs in the induction and maintenance of allergic responses in the lung. DCs sorted from the airways were shown to activate T cells in co-culture experiments (Huh et al., 2003). Imaging studies of the rodent trachea demonstrated close contacts between T cells and DCs, with DCs identified by MHC-II+ labeling and dendritiform morphology (Huh et al., 2003). DC depletion and reconstitution strategies using CD11cdiphtheria toxin receptor (DTR) mice indicated that DCs were necessary and sufficient to induce inflammation for allergic recall responses in mouse models of allergic asthma (Hammad et al., 2010; Plantinga et al., 2013; van Rijt et al., 2005). However, CD11c is expressed by other cell types of the mononuclear phagocyte system, such as alveolar macrophages, interstitial macrophages (IMs), and some monocytes (Hume, 2008), which could also potentially contribute to allergic asthma. Studies in the intestine confirmed that the CD11c-DTR also depletes macrophages in addition to DCs (Schreiber et al., 2013). Since some lung IMs express CD11C and high amounts of MHC-II (Gautier et al., 2012; Schlitzer et al., 2013), these cells would also have been included in the populations of 'DCs' sorted in co-culture experiments and labelled by MHC-II antibody in microscopy studies. In the intestinal lamina propria, CD11 $\mathrm{C}^{+} \mathrm{MHC}-\mathrm{II}^{+}$ macrophages were found to be distinct from classical DCs (cDCs) based on functional and behavioral differences and were reported to contribute to local intestinal immunity (Hadis et al., 2011; Mazzini et al., 2014; Schreiber et al., 2013; Schulz et al., 2009). Whether lung CD11c ${ }^{+}$ MHC-II+ IMs exhibit behaviors and functions similar to intestinal macrophages has not been tested.

Here we show that in the steady state in naïve mice, lung myeloid APCs are primarily positioned underneath the bronchial airway epithelium and are strategically enriched near some airway branchpoints where inhaled allergens are likely to deposit. We found that at these regions the majority of inhaled soluble antigens were captured by CX3CR $1+\mathrm{CD} 11 \mathrm{C}^{+} \mathrm{MHC}-\mathrm{II}^{+} \mathrm{IMs}$ rather than DCs. Allergic lung inflammation remained robust when cDCs were selectively depleted prior to allergen challenge, supporting a role for these IMs in antigen capture and T cell activation at the airways. CX3CR1 + CD11 ${ }^{+} \mathrm{MHC}-\mathrm{II}^{+}$IMs were capable of antigen processing and presentation, activated T cells in vitro, and interacted with $\mathrm{T}$ cells recruited to the airways in an asthma model. Unlike DCs, CX3CR1 ${ }^{+} \mathrm{CD} 11 \mathrm{C}^{+} \mathrm{MHC}-\mathrm{II}^{+} \mathrm{IMs}$ did not migrate to the draining lymph node and remained lung resident. We therefore propose that $\mathrm{CX} 3 \mathrm{CR} 1+\mathrm{CD} 11 \mathrm{C}^{+} \mathrm{MHC}-\mathrm{Il}^{+}$ IMs located near the bronchial airways are tissue-resident sentinel APCs that are able to drive local allergic inflammation independently of DCs. 


\section{Results}

\section{Myeloid cells are enriched near bifurcating airways prior to the induction of inflammation}

Peribronchial inflammation is a hallmark of asthma that is recapitulated in mouse models of allergic airway disease. Foci of leukocytes can be observed near the bronchi that include numerous eosinophils. In our own studies of mouse models of allergic airway disease, such as in a classical model with OVA as an allergen (Daubeuf and Frossard, 2013), we observed in thin cryosections that these foci were not evenly distributed along the airway, but rather were typically located near airway branchpoints and associated with large blood vessels (Fig 1A). In parallel studies, we had noted a corresponding region near some airway branchpoints with a dense accumulation of collagen surrounding blood vessels (Fig 1B and Video 1). These regions likely represent bronchovascular bundles which are known to contain bronchi and arteries in a common adventitial sheath (Townsley, 2012). These areas were visualized in agarose-inflated, thick lung sections that were precision cut with a vibratome and imaged by two-photon laser scanning microscopy (hereafter referred to as two-photon microscopy). Collagen was detected by second harmonic generation. Bronchial airway epithelial cells were revealed by GFP expression when we combined Sonic hedgehog (Shh)-Cre (Harfe et al., 2004) with the ROSA26-mTmG reporter, in which Cre-mediated recombination leads to the expression of membrane-bound GFP (Muzumdar et al., 2007). Alveolar epithelial cells also express GFP in these mice, with alveolar type II cells appearing more prominently due to their cuboidal shape, whereas all other cells express membrane-bound tdTomato. Bifurcating blood vessels, visualized by membrane-bound tdTomato, were also visible at some collagen-rich sites in which the airways appeared to undergo planar bifurcation (Metzger et al., 2008) (Fig 1B and Video 1).

Various myeloid cells are known to accumulate in peribronchial regions during inflammation. Indeed, at the collagen-rich regions near some bifurcating airways, we observed dense accumulations of myeloid cells with the MacGreen (CSF1R-GFP) reporter (Sasmono et al., 2003) in both OVA and house dust mite (HDM) models of allergic airway disease by two-photon microscopy of thick lung sections (Fig 1C, 1D). In MacGreen mice, we observed that most myeloid cells including macrophages, monocytes, neutrophils, and CD11b+ DCs brightly expressed the GFP reporter, although eosinophils exhibited much lower GFP expression (data not shown). As some B cells were also found to express GFP in these mice (unpublished observations), we crossed the MacGreen mice to B-cell deficient $\mu \mathrm{MT}$ mice so that GFP expression was restricted to myeloid cells. Interestingly, in naïve mice, a sparse population of MacGreen+ cells were also observed at these collagen-rich regions near bifurcating airways (Fig $1 \mathrm{E})$, suggesting that myeloid cells may localize to these areas prior to the formation of foci of leukocytes during inflammation. Notably, these myeloid cells were best visualized in naïve mice in thick lung sections by two-photon microscopy, as in thin cryosections the very low density of cells made it difficult to discern their distribution.

To further evaluate the types of myeloid cells located at these sites in the steady state, we imaged IMs and DCs using the CX3CR1-GFP (Jung et al., 2000) and CD11C-YFP (Lindquist et al., 2004) reporters, respectively, in thick lung sections by two-photon microscopy. Our analysis focused on cells with bright expression of these fluorescent reporters using limiting laser power, as other cell types have lower expression of these fluorescent reporters as we elaborate on further below. In order to visualize airway epithelial cells, we combined these reporters with the E-cadherin-mCFP reporter (Snippert et al., 2010), or with a combination of Shh-Cre with a ROSA26-loxP-STOP-loxP-tdTomato (Ai14) reporter (Madisen et al., 2010), such that airway epithelial cells expressed mCFP or tdTomato, respectively. In naïve mice, we observed clusters of bright CX3CR1-GFP+ IMs and CD11C-YFP+ DCs at some airway bifurcations in collagen-rich regions (Fig $1 \mathrm{~F}$ and $1 \mathrm{H}$, Videos 2 and 3). Scattered bright CX3CR1-GFP+ IMs were also 
observed underneath the entire bronchial airway epithelium (Fig $1 \mathrm{~F}$ and Video 2). Bright CX3CR1-GFP+ cells were more abundant at the airways than at the alveoli (Fig 1G), and bright CD11C-YFP+ DCs were only rarely observed at the alveoli in naïve mice (Fig 1I). Alveolar macrophages, which express high amounts of surface CD11c protein, are known to have low expression of the CD11c-YFP transgene in naïve mice (Rodero et al., 2015; Thornton et al., 2012). Taken together, these findings indicate that in the steady-state in the absence of inflammation, both IMs and DCs are located near bronchial airways and may be particularly enriched in collagen-rich regions near bifurcations. These regions correspond to the sites where eosinophils and other leukocytes accumulate in allergic airway disease, suggesting a potential role for these IMs and/or DCs in the initiation of the local inflammatory response.

\section{CX3CR1-GFP+ macrophages capture antigen from the bronchial airways}

Our above findings regarding the positioning of CX3CR1-GFP+ IMs and CD11C-YFP+ DCs at some airway branchpoints may be significant, as antigen is likely to deposit on the walls of the airways at branchpoints where airflow changes directions. In addition, the distribution of CX3CR1-GFP+ IMs underneath the entire bronchial airway epithelium suggests that these cells may generally be involved in surveillance of the airways. While previous studies have shown uptake of beads by monocytes and DCs located near the alveoli (Rodero et al., 2015; Thornton et al., 2012), we considered whether inhaled soluble antigens could be captured by the IMs and DCs located near the bronchial airways. Recent evidence suggests that Th2 responses are often directed against soluble components of common allergens (Bacher et al., 2016). In order to visualize the uptake of soluble protein antigens from the airway lumen, we instilled fluorescent OVA intranasally and prepared precision-cut lung slices 1-2 $\mathrm{h}$ later for imaging by two-photon microscopy. A short time point was chosen to ensure that the antigen capturing cells identified had not migrated from a different anatomical location, as had been proposed by Thornton et al (Thornton et al., 2012). Airway epithelial cells were visualized by the E-cadherinmCFP reporter. Our analysis revealed numerous bright CX3CR1-GFP+ IMs located near the bronchial airways that had taken up fluorescent OVA (Fig 2A, 2B). These bright OVA+ CX3CR1GFP+ IMs had a dendritic morphology, extending long processes under the bronchial airway epithelium. As expected, soluble antigen was also taken up at the alveoli, primarily by alveolar macrophages which had a distinct spherical appearance (Suppl. Fig 1). Thus, CX3CR1-GFP+ IMs with a dendritic morphology readily captured soluble antigen from the bronchial airway lumen and were distinct from alveolar macrophages.

In contrast to the CX3CR1-GFP+ IMs near the bronchial airways, the CD11C-YFP+ DCs at these sites did not appear to capture OVA by microscopy (Fig 2C). To confirm preferential uptake in CX3CR1-GFP+ IMs rather than CD11C-YFP+ DCs, we administered fluorescent OVA intranasally to mice simultaneously expressing both CX3CR1-GFP and CD11C-YFP reporters. This combination of fluorescent reporters has been helpful in the intestine to distinguish DC and macrophage subsets by two-photon microscopy (Farache et al., 2013; McDole et al., 2012). When we examined the airways of precision-cut lung slices by two-photon microscopy, we found indeed that OVA uptake was preferentially observed in bright CX3CR1-GFP+ IMs rather than bright CD11C-YFP+ DCs (Fig 2D). We made similar observations when we instilled fluorescently labelled extracts from HDM, a relevant aeroallergen (Fig 2E). By optimizing methodology to minimize the spectral overlap of GFP and YFP (see Methods section for details), we confirmed that bright CX3CR1-GFP+ and bright CD11C-YFP ${ }^{+}$cells were largely nonoverlapping populations. When we increased the image contrast, we observed that some of the bright CX3CR1-GFP + cells did have dim expression of CD11c-YFP, and vice versa, as expected from previous studies (Jung et al., 2000; Sen et al., 2016) (Suppl. Fig. 2A). 
Occasionally, we also observed rare cells that were bright for both the CX3CR1-GFP and CD11c-YFP reporters, yet the majority of cells in the naïve state appeared to be only bright for only one of these reporters suggesting they were distinct cell types (Suppl. Fig. 2B). Indeed, while CX3CR1-GFP+ IMs had a dendritic morphology, CD11C-YFP+ DCs were rounder and did not appear to extend long processes. We quantified these morphologic features by measuring sphericity as well as the length of the longest axis of each cell to characterize the dendritic projections. CX3CR1-GFP+ IMs had lower sphericity values and increased mean lengths of their longest axes compared to CD11C-YFP+ DCs (Fig 2F). The disparity in morphology and antigen uptake capacity suggests that CX3CR1-GFP+ IMs and CD11C-YFP+ DCs are two distinct cell populations present in airway-adjacent areas in the steady state, and that CX3CR1-GFP+ IMs are the primary antigen capturing cell type at the airways.

Our findings that OVA+ CD11C-YFP+ DCs were rarely observed by microscopy seemed somewhat surprising, as DCs are thought to be capable of antigen sampling. To further assess whether DCs captured antigen, we analyzed CD11c-YFP+ DCs isolated from the lung by flow cytometry. We were able to detect OVA ${ }^{+}$CD11c-YFPbright cells, though the intensity of fluorescent OVA was much lower in CD11C-YFP+ DCs than in CX3CR1-GFPbright IMs (Fig 2G, $2 \mathrm{H})$. Microscopy detects a comparably narrower dynamic range of fluorescent signals than flow cytometry, and thus we most likely only visualized CX3CR1-GFPbright IMs that carried the most OVA. Indeed, when we gated specifically on OVA bright $\mathrm{MHC}-\mathrm{II}^{+}$cells by flow cytometry, the majority of cells were CX3CR1-GFPbright but not CD11C-YFP+ (Suppl. Fig 3A-B). Therefore, our results suggest that DCs also take up soluble antigen from the bronchial airway lumen, but that the majority of antigen is taken up by a distinct population of CX3CR1-GFP+ IMs.

\section{$D C s$ are not necessary for allergic recall responses in the lung}

Our findings above that CX3CR1-GFP+ IMs more efficiently captured soluble antigens from the airway lumen than CD11C-YFP+ DCs prompted us to reexamine the role of DCs in the initiation of lung inflammation. Mouse models of allergic airway disease consist of two distinct phases: a sensitization or priming phase in which an initial adaptive immune response to an antigen is generated, followed by a challenge or effector phase in which allergic inflammation is elicited in the lung (Haspeslagh et al., 2017). During the priming phase, antigen-specific naïve T cells are activated in lymphoid organs, such as lymph nodes, and undergo expansion and Th2 differentiation; then during the challenge phase, the effector/memory Th2 cells are recruited to the lung and activated locally to induce an inflammatory response. DCs have been considered to be the major antigen presenting cells (APCs) responsible for both priming T cells in lymph nodes as well as activating effector/memory T cells in the lung (Hammad et al., 2010; Plantinga et al., 2013; van Rijt et al., 2005). However, it seems plausible that different subsets of APCs could present antigen to $T$ cells in the sensitization versus challenge phases. One of the key pieces of evidence establishing the critical role of DCs in antigen presentation in these contexts was conditional DC depletion with the CD11c-DTR transgene. As described above, however, this CD11c-DTR approach has also been shown to deplete other APCs that are not of the DC lineage, yet may express CD11c, such as macrophages. We thus considered the possibility that


lung to initiate allergic airway inflammation.

To test the specific contribution of DCs versus other CD11c-expressing cells, we took advantage of the high expression of the transcription factor Zbtb46 in cDCs, but not in macrophages and monocytes (Meredith et al., 2012; Satpathy et al., 2012). Specifically, we made bone marrow chimeras using Zbtb46-DTR (zDC-DTR) mice versus CD11c-DTR mice as bone marrow donors, as reported (Meredith et al., 2012). In zDC-DTR chimeras, DCs are 
specifically depleted upon diphtheria toxin (DT) administration, whereas in CD11c-DTR mice, most CD11c-expressing cells are depleted (Meredith et al., 2012). We assessed the impact of depletion of these APCs in the context of a mouse model of allergic airway disease in which allergic inflammation is driven by the adaptive immune response involving the local activation of effector/memory Th2 cells in the lung, rather than by innate inflammatory stimuli. In particular, we used the aforementioned classical OVA model of allergic airway disease (Daubeuf and Frossard, 2013), in which mice were primed by intraperitoneal injections with OVA in alum adjuvant and then challenged intranasally with OVA alone. Very low endotoxin preparations of OVA were used to ensure the inflammatory response in the lung was initiated by the adaptive immune response, in which APCs present antigen to OVA-specific Th2 cells. In order to specifically test the role of DCs versus all CD11c-expressing cells only during the challenge phase, DT was administered by intraperitoneal injection to deplete APCs after priming but prior to OVA challenge (Fig 3A). Similar to previous reports (van Rijt et al., 2005), our analysis of CD11c-DTR chimeras showed reduced allergic lung inflammation as measured by eosinophilic accumulation in the bronchoalveolar lavage (BAL) fluid. In contrast, zDC-DTR chimeras showed robust eosinophilia equivalent to wild-type mice (Fig 3B). These findings indicate that cDCs are not necessary for driving allergic recall responses and suggest that other CD11 $\mathrm{C}^{+}$cells are capable of antigen presentation and $T$ cell activation in the lung tissue.

To gain insight into which types of CD11 $\mathrm{c}^{+}$cells were depleted prior to allergen challenge, we treated unimmunized DTR mice with DT. Although alveolar macrophages express high amounts of CD11c, these cells in the alveolar space were largely spared from the intraperitoneal injection of DT in CD11c-DTR chimeras, suggesting that the depletion of other CD11 $\mathrm{c}^{+}$cells led to reduced eosinophilia in these mice (Suppl. Fig 4A). To confirm that alveolar macrophages were not required for eosinophilia, we achieved more efficient depletion of alveolar macrophages by the intranasal administration of DT to CD169-DTR mice, as reported (Hashimoto et al., 2013; Purnama et al., 2014) (Suppl. Fig 4B). However, robust eosinophilia was observed in immunized CD169-DTR mice treated with DT (Suppl. Fig 4E). These findings indicate that alveolar macrophages do not serve as critical APCs in allergic airway disease, consistent with the low expression of MHC-II on alveolar macrophages (Gautier et al., 2012; Schlitzer et al., 2013).

In comparing the CD11 $\mathrm{C}^{+} \mathrm{MHC}-\mathrm{II}^{+}$cells present after the administration of $\mathrm{DT}$ to unimmunized CD11c-DTR and zDC-DTR chimeras, we identified a population of CD11 $\mathrm{c}^{+} \mathrm{MHC}-\mathrm{II}^{+}$cells that remained in the zDC-DTR chimeras but that was depleted in CD11c-DTR chimeras. The residual $\mathrm{CD}_{11 \mathrm{C}^{+}} \mathrm{MHC}-\mathrm{II}^{+}$cells in the $\mathrm{zDC}$-DTR chimeras had high surface expression of MHCII, comparable to cDCs; however, these cells expressed the macrophage marker CD64 and had low to undetectable surface expression of the DC marker CD24 (Fig 3C-F). This surface marker profile is characteristic of some IMs or monocyte-derived cells (Gautier et al., 2012; Guilliams et al., 2013; Schlitzer et al., 2013). In our experimental design, very few monocyte-derived cells would have been present in the lung at the time of the initial intranasal challenge with OVA, since the priming was done via the intraperitoneal route, thus favoring a contribution of the resident IMs to antigen presentation. An exception was in CD169-DTR mice treated with DT, which resulted in the recruitment of Ly6Chi monocyte-derived cells (Suppl. Fig 4C). In these mice, the abundance of MHC-II+ IMs was unchanged after DT treatment, indicating the majority of these cells are not depleted efficiently by the CD169-DTR (Suppl. Fig 4D). To confirm that monocyte-derived cells were not required as APCs, we immunized monocyte-deficient Ccr2 ${ }^{-/}$ mice (Boring et al., 1997), and observed robust eosinophilia, with some increase in eosinophil numbers compared with control mice (Suppl Fig. 4F), as had been reported (Kim et al., 2001). Taken together, our depletion experiments suggest that CD11 $\mathrm{C}^{+} \mathrm{MHC}-\mathrm{II}^{+}$IMs serve as APCs to activate effector/memory $T$ cells in the lung, as we explore further below. 


\section{CX3CR1-GFPbright antigen capturing cells are Bronchus-Associated Macrophages (BAMs)}

Given our findings establishing a potential role for CD11 + MHC-II+ IMs as APCs in the initiation of allergic lung inflammation, we next verified that these macrophages corresponded to the bright CX3CR1-GFP+ antigen-capturing cells we had visualized by microscopy under the bronchial airway epithelium. This was important given that CX3CR1-GFP is also expressed in other cell types, such as monocytes, a subset of DCs, and some lymphocytes (Jung et al., 2000). By flow cytometry, we evaluated whether the CX3CR1-GFP+ cells that captured soluble inhaled antigen expressed MHC-II and confirmed their macrophage identity. For this analysis, we excluded alveolar macrophages using the marker Siglec- $F$, as these cells often confound the gating of GFP ${ }^{+}$cells by flow cytometry due to their autofluorescence, yet based on their round morphology and alveolar localization were clearly distinct from the antigen-capturing CX3CR1$\mathrm{GFP}^{+}$cells near the airways (Suppl. Fig. 1). After administering fluorescent OVA intranasally and then isolating and enzymatically digesting the lungs, our flow cytometric analysis showed that the CX3CR1-GFP bright OVA bright cells were predominantly MHC-II hi and CD11 $\mathrm{C}^{\text {mid }}$ (Fig 4A). The presence of these cells in naïve mice and high MHC-Il expression suggested they were not derived from inflammatory monocytes. The CX3CR1-GFPbright OVA ${ }^{\text {bright }}$ cells also predominantly expressed the macrophage markers CD64 and MerTK, and had relatively low to undetectable staining for the CDC marker CD24 (Fig 4A, 4B), consistent with surface markers previously established for IMs (Gautier et al., 2012; Guilliams et al., 2013; Schlitzer et al., 2013). This population matched the cell surface marker phenotype of the residual CD11 $\mathrm{c}^{+} \mathrm{MHC}-\mathrm{Il}^{+}$cells we had identified in zDC-DTR chimeras depleted of DCs, as shown in Fig 3C. Conversely, the majority of the CD11c-YFPbright cells were CD11 $\mathrm{c}^{\text {mid-hi }}$ and CD24 ${ }^{\text {hi }}$ but did not express CD64 and MerTK, thus representing cDCs (Fig 4A, 4B). Notably, CD64+ OVA ${ }^{\text {bright }}$ cells were largely CD11C-YFP- but did express surface CD11c by antibody staining (Suppl. Fig 5A), albeit with reduced abundance compared to $\mathrm{CDCs}$, indicating the expression of the CD11c-YFP transgene is more restricted to DCs than the CD11c protein, consistent with a prior study (Rodero et al., 2015). The small fraction of CD64+ OVA ${ }^{\text {bright }}$ cells that were also CD11C-YFPbright (Suppl. Fig. 5A) may correspond to the rare cells we had observed by microscopy that were bright for both CX3CR1-GFP and CD11C-YFP (Suppl. Fig. 2B). We found that monocytes, which resolve into two subsets based on CX3CR1-GFP expression (Geissmann et al., 2003), and the CX3CR1$\mathrm{GFP}^{+}$subset of cDC2s, all had lower CX3CR1-GFP expression than the MHC-II+ CD64+ MerTK cells (Suppl. Fig 5B), consistent with our imaging data (Suppl. Fig. 2A). Again, as microscopy has a more limited dynamic range than flow cytometry and we had focused our imaging on bright cells using limiting laser power, this likely favored our specific visualization of CX3CR1GFPbright cells. To indeed verify that the CX3CR1-GFPbright cells we had observed near the bronchial airway epithelium by microscopy were represented by the CX3CR1-GFPbright CD64+ MHC-II+ IMs identified by flow cytometry, we stained precision-cut thick lung slices from CX3CR1-GFP and CD11C-YFP mice with antibodies against CD64 and MHC-II. By two-photon microscopy, we observed that both CD64 and MHC-II staining co-localized with the CX3CR1GFPbright cells located in collagen-rich tissue regions near the bronchial airways, whereas the CD11c-YFPbright cells were CD64-negative (Fig 4C, 4D, 4E). Taken together, these findings indicate that the CX3CR1-GFPbright cells localized near the bronchial airway epithelium that capture soluble inhaled antigens are $\mathrm{MHC}-\mathrm{II}^{+} \mathrm{IMs}$.

To validate the identification of these cells as $\mathrm{MHC}-\mathrm{II}^{+} \mathrm{IMs}$, we further evaluated CD64+ $\mathrm{MHC}-\mathrm{II}^{+}$ cells in the lung by flow cytometry. These cells had high surface expression of CD11b and were uniformly MerTK+ ${ }^{+}$, but had only minimal expression of a Zbtb46 reporter that was nearly 10-fold lower than CD24+ DCs (Fig 4F, Suppl. Fig 6A-C), further confirming these cells are not DCs despite sharing similar markers to CDC2s. Whereas alveolar macrophages are known to highly 
express CD169 and Siglec-F, CD64+ MHC-II+ cells showed weak CD169 expression and did not express Siglec-F (Fig 4F, Suppl. Fig 6D), further supporting that these are two distinct macrophage populations. Previous studies have reported IMs can be divided into subsets based on CD206 expression (Chakarov et al., 2019; Gibbings et al., 2017; Schyns et al., 2019); our analysis showed that most CD64+ MHC-II+ cells had intermediate CD206 surface expression in a Gaussian distribution (Fig 4F, Suppl. Fig 6E). Given that multiple subsets of IMs have been described at various locations in the lung, and that IMs were originally thought to reside in the alveolar interstitium (Bedoret et al., 2009), we propose that the bright CX3CR1-GFP+ MHC-II+ cells located near the bronchial airways that capture soluble antigen be referred to as BronchusAssociated Macrophages (BAMs).

\section{BAMs primarily capture lower molecular weight soluble proteins}

We next further characterized the ability of BAMs to take up antigens from the airway lumen. To compare the antigen uptake capacities of BAMs to individual subsets of DCs and monocytes, fluorescent OVA was administered to mice intranasally $2 \mathrm{~h}$ before lungs were digested and dissociated into single cell suspensions for flow cytometric analysis. We gated on CD45+ CD19Ly6G- Siglec-F- CD11 $\mathrm{C}^{+} \mathrm{MHC}-\mathrm{II}^{+} \mathrm{CD} 11 \mathrm{~b}^{+} \mathrm{CD} 24^{-/ \mathrm{lo}} \mathrm{CD} 64^{+}$cells as a reasonable representation of BAMs, as we had established based on our marker analysis above. Indeed, a large majority $(\sim 80 \%)$ of BAMs gated by these markers had taken up OVA, whereas a smaller proportion $(\sim 50 \%)$ of cDC2s and less than $5 \%$ of monocytes were OVA ${ }^{+}$(Fig $\left.5 \mathrm{~A}\right)$. By microscopy, we observed that in addition to soluble OVA and HDM extract, CX3CR1-GFP+ BAMs took up other soluble fluorescent molecules of a range of sizes, such as TRITC-dextran molecules that were $10 \mathrm{kDa}$ or $155 \mathrm{kDa}$, as well as phycoerythrin (PE), a $240 \mathrm{kDa}$ molecule (Fig 5B-D). To quantify whether antigen size affected the efficiency of antigen capture by BAMs, we administered FITCdextran (FITC-DX) of various sizes ranging from $10 \mathrm{kDa}$ to $2 \mathrm{MDa}$, and then assessed the frequency of FITC-DX+ cells among BAMs (left) and cDC2s (right) by flow cytometry. To exclude the possibility that FITC-DX was taken up during the lung digestion process, lungs from congenic mice that were not exposed to FITC-DX (control lung) were processed in the same digestion reaction as the lungs from the mice that had received FITC-DX (host lung). Very few (or less than $5 \%$ of) BAMs from the control lungs of congenic mice that were co-digested were FITC-DX+, confirming that minimal FITC-DX uptake occurred during the digestion procedure. We found that a greater proportion of BAMs were FITC-DX+ when smaller molecules were instilled compared to larger molecules (Fig 5E). Therefore, the magnitude of antigen uptake by BAMs is inversely related to the antigen size.

It has been reported that DCs in the alveolar interstitium send projections into the alveolar space to capture fluorescent bead particles (Thornton et al., 2012). To assess whether BAMs captured particulate antigens, we intranasally instilled fluorescent beads and analyzed the lungs by microscopy. However, we rarely observed bead capture by CX3CR1-GFP+ BAMs or CD11c$\mathrm{YFP}^{+}$DCs near the airways (Fig 5F). In contrast, in the alveolar space, beads were taken up by highly spherical cells that were dimly CD11c-YFP+ (Fig 5F). By location and morphology, we conclude that these cells are alveolar macrophages, not DCs. In summary, BAMs preferentially captured soluble antigens, whereas both BAMs and DCs residing at the airway interstitium showed minimal capture of beads. 


\section{BAMs activate local effector T cells}

Based on our findings that BAMs readily captured soluble antigens from the bronchial airways and had high surface expression of MHC-II comparable to DCs, we considered whether BAMs are capable of activating T cells at these sites. In order to activate T cells, APCs need to process antigen and present antigen peptides on MHC-II on their cell surface. We used the $\mathrm{Y}$ Ae antibody to test whether BAMs were able to process and present antigen. The Y-Ae antibody specifically recognizes the $\mathrm{E} \alpha$ peptide, a peptide fragment of the I-E MHC-II molecule, presented on the I-A ${ }^{b}$ MHC-II molecule (Murphy et al., 1992). C57BL/6 mice do not express I-E and thus E $\alpha$ represents a foreign peptide. The E $\alpha$ peptide was fused to OVA, administered intranasally together with fluorescent OVA to label antigen-capturing cells, and then OVA+ lung APCs were analyzed 17-18 $\mathrm{h}$ later to allow time for antigen processing and presentation. Both BAMs and cDC2s stained with the Y-Ae antibody by flow cytometry (Fig 6A), demonstrating that BAMs processed and presented antigen, like DCs, rather than simply degrading it. Minimal YAe staining was observed 15 min after OVA-E $\alpha$ was administered, confirming that antigen processing and presentation were needed for detection of MHC-II:E $\alpha$ complexes on the cell surface (data not shown). Brighter Y-Ae staining was observed on BAMs compared with cDC2s (Fig 6A), consistent with the superior soluble antigen uptake we had observed (Figures 2 and 5). Alveolar macrophages, with low MHC-II expression and a high degradative capacity, showed negligible Y-Ae staining (Suppl. Fig 7), confirming these are not the relevant APCs for CD4 T cells. We also tested whether BAMs could provide the necessary co-stimulatory signals for $T$ cell activation and found that BAMs had higher surface expression of the co-stimulatory molecules CD80 and CD86 compared to CDC2s (Fig 6B). To determine whether BAMs were able to activate CD4 T cells, BAMs were sorted by FACS and co-cultured with OT-II TCR transgenic T cells, which respond to an OVA peptide presented on I-A $A^{b}$ by APCs. As a positive control for APC function in cell culture, cDC2s were sorted and co-cultured with OT-II T cells. When cultured in the presence of OVA peptide, BAMs induced the robust proliferation of naïve OT-II T cells, albeit somewhat less efficiently than cDC2s, as expected, given the high efficiency of naïve T cell activation by DCs (Fig 6C). Interestingly, BAMs and CDC2s equivalently induced IL-13 production when co-cultured with Th2 polarized, effector OT-II cells and OVA peptide (Fig 6D). These findings indicate that BAMs possess the necessary machinery for antigen presentation and activation of T cells, and further suggest that BAMs may equivalently activate effector T cells compared with DCs.

We hypothesized that the primary function of MHC-II expression on BAMs might be to activate local effector/memory $T$ cells that have been recruited to the lung tissue. To test this hypothesis, we utilized time-lapse two-photon microscopy to determine whether BAMs encountered and interacted with effector T cells in the lungs. Naïve OT-II T cells expressing CFP ( $\beta$-actin CFP) or tdTomato (CD4-Cre Ai14) were adoptively transferred into CX3CR1-GFP X CD11c-YFP mice and then primed in vivo, which resulted in expansion and recruitment to the lungs. Mice were subsequently rechallenged with intranasal OVA alone, lungs were excised $4 \mathrm{~h}$ later, and precision-cut lung slices were prepared for imaging. We observed sustained interactions between OT-II T cells and CX3CR1-GFP+ BAMs in the lung (Fig 6E and 6F, Videos 4 and 5), comparable to the interactions reported during antigen-specific T cell activation by DCs in the lymph nodes (Mempel et al., 2004). Some OT-II T cells were also observed to engage in sustained interactions with CD11c-YFP+ DCs near the airways (data not shown). These observations suggest that both BAMs and DCs can serve as APCs for the local activation of effector T cells in lung peribronchial regions. 


\section{BAMs are non-migratory while DCs are migratory}

Although BAMs and DCs both exhibited the capacity to serve as APCs for T cells, time-lapse imaging by two-photon microscopy revealed fundamental differences in cellular dynamics. BAMs had dendrites that were continuously extended and probing, but their cell bodies showed very minimal displacement over time. In contrast, DCs were surveying their surroundings by moving their entire cell bodies and traversed greater distances than BAMs (Fig 7A-D and Video 6 ). Therefore, DCs were highly migratory whereas BAMs were probing by extending dendrites with little net movement.

Based on our observations of their distinct migratory behavior, we hypothesized that BAMs may remain at the airways, whereas DCs would migrate to the draining lymph node to prime T cells, after antigen capture that leads to an inflammatory response. However, in other studies, cells with similar markers as BAMs, referred to as monocyte-derived DCs, had been observed in the draining lymph node harboring antigen (Plantinga et al., 2013). We therefore tested whether BAMs were able to migrate to the right posterior mediastinal lymph node that drains the lung. We first considered the expression of the chemokine receptor CCR7, which is necessary for migration to lymph nodes and is upregulated following exposure to inflammatory stimuli. We analyzed the cell surface expression of CCR7 on DCs and BAMs after administering LPS or $\mathrm{HDM}$ as inflammatory stimuli. After $4 \mathrm{~h}$, we found that CCR7 was upregulated on a significant proportion of DCs in a dose dependent manner, but not on BAMs (Fig 7E, 7F). We also tested whether OVA, which does not have intrinsic inflammatory properties, would induce CCR7 upregulation in previously sensitized mice in which OVA-specific effector/memory $\mathrm{T}$ cells could induce maturation of the APCs (Fig 7G). Indeed, after OVA challenge, DCs upregulated CCR7 expression in previously sensitized mice but not in naïve mice exposed to OVA for the first time (Fig 7G). Conversely, BAMs did not upregulate CCR7 in either sensitized or naïve mice (Fig 7G). As such, the expression of CCR7 only on the DCs, but not BAMs, would likely allow DCs to selectively migrate to the lymph node. To further assess whether DCs or BAMs entered and migrated in lymphatic vessels within the lung by two-photon microscopy, we visualized lymphatics by breeding Prox1-tdTomato transgenic mice (Truman et al., 2012) to CD11c-YFP or CX3CR1-GFP mice. After intranasal instillation of HDM or LPS, we frequently observed CD11C$\mathrm{YFP}^{+}$cells, but not CX3CR1-GFP+ cells, migrating within lung lymphatics (Fig $7 \mathrm{H}$, Videos 7 and 8). To determine which cells carried antigen into the lymph node, we intranasally instilled PE. With a molecular weight of $240 \mathrm{kDa}, \mathrm{PE}$ is too large to enter the conduit system of the lymph node (Roozendaal et al., 2009) and thus can only reach the lymph node parenchyma when carried by APCs. As an inflammatory stimulus to promote APC trafficking to the lymph node, we administered HDM extract together with the PE. This led to the recruitment of a population of $\mathrm{CD} 44^{+} \mathrm{MHC}-\mathrm{II}^{+}$cells that were $\mathrm{Ly} 6 \mathrm{C}^{+}$to the draining mediastinal lymph node $1 \mathrm{~d}$ later. However, these $\mathrm{CD}^{2} 4^{+} \mathrm{MHC}-\mathrm{II}^{+} \mathrm{Ly} 6 \mathrm{C}^{+}$cells were $\mathrm{PE}^{-}$, whereas we were readily able to identify a fraction of DCs that were $\mathrm{PE}^{+}$(Fig 7I, 7J). Thus, the CD64+ $\mathrm{MHC}-\mathrm{II}^{+} \mathrm{Ly} 6 \mathrm{C}^{+}$cells were not transporting $\mathrm{PE}$ from the lung to the lymph node. The high surface expression of Ly6C on the CD64+ MHC$\mathrm{II}^{+}$cells also suggests that they were not BAMs, which have low to moderate surface expression of Ly6C (Suppl. Fig 8). Instead, the high expression of Ly6C suggests that the CD64+ MHC-II+ cells were derived from monocytes that were recruited to the lymph node from the bloodstream and had upregulated CD64 and MHC-II in response to the inflammatory conditions. Taken together, these findings indicate that BAMs capture antigen at the airways but do not migrate to the draining lymph node. In contrast, DCs are induced to migrate to the draining LN in response to inflammatory stimuli or in the context of adaptive immune responses. 


\section{Discussion}

This work focused on the cell types involved in antigen surveillance at the airways in the steady state to understand the early events that initiate allergic airway inflammation in sensitized mice. By specifically depleting $\mathrm{cDCs}$, we found that allergic recall responses at the airways did not require DCs for effector/memory T cell activation. Our analysis of APCs at the airways revealed an abundant $\mathrm{MHC}-\mathrm{II}^{\mathrm{hi}}$ macrophage population positioned under the bronchial airway epithelium that sampled soluble luminal antigen, which we term Bronchus-Associated Macrophages (BAMs). We found that BAMs were particularly enriched in collagen-rich regions near some airway branchpoints. In addition, we demonstrated that BAMs were capable of antigen presentation to $T$ cells and interacted with recruited $T$ cells near the airways in an allergic airway disease model. While DCs migrated to the draining lymph node, BAMs remained resident in the lung after antigen capture, even in the presence of inflammatory stimuli. These findings support a model in which BAMs activate recruited effector/memory T cells, thereby driving local allergic inflammation independently of migratory DCs.

While results based on CD11C-DTR experiments previously led to the conclusion that DCs are necessary for effector $T$ cell responses in the lung, our studies reported here indicate that DCs are not required in this context. We found that depletion of cDCs in zDC-DTR chimeras, sparing macrophages and monocytes, had a minimal impact on allergic airway inflammation in previously sensitized mice. We chose an OVA model of allergic airway disease that relied specifically on the adaptive immune response mediated by T cells, since the OVA itself was from a very low endotoxin preparation that would not trigger responses by epithelial cells or innate immune cells. Hence, in this model, allergic inflammation can only be initiated by the activation of previously sensitized T cells through antigen presentation by resident APCs. While some other allergens have intrinsic inflammatory properties, the small amounts of allergens inhaled physiologically would likely only induce significant allergic inflammation following the activation of antigen-specific T cells activated by APCs. In contrast to the results with zDC-DTR chimeras, depletion of all CD11 $c^{+}$cells in CD11c-DTR chimeras led to reduced allergic airway inflammation. The differences in these results suggest that other CD11 ${ }^{+}$APCs, that are not cDCs, may activate effector/memory T cells in the lung to induce allergic airway inflammation. Similar to studies in other tissues, we established that $\mathrm{CD} 11 \mathrm{C}^{+} \mathrm{MHC}-\mathrm{II}^{+}$macrophages were depleted in the CD11c-DTR chimeras. Our subsequent work presented here implicates BAMs as potential APCs that can activate effector/memory T cells in the lung to induce allergic inflammation.

In characterizing the localization of cDCs and BAMs, we found that in naïve mice, both cell types were rarely located near alveoli, yet were abundant around the major airways, and were especially enriched at some airway branchpoints in collagen-rich regions. This positioning likely facilitates the uptake of antigens that have deposited at airway branchpoints, where airflow changes directions, leading to the activation of adaptive immune responses at these locations. We found that these sites corresponded to the regions where inflammatory clusters form in allergic airway disease models. BALT has also been observed near airway bifurcations (Bienenstock and McDermott, 2005; Randall, 2010). Our observation that BAMs and DCs were enriched near airway branchpoints in the steady state, prior to immunization, suggests that airway branchpoints are ideal sites for continuous immunosurveillance of the bronchial airway lumen, enabling the rapid local activation of antigen-specific $T$ cells and the generation of an inflammatory response. While most of the lung is filled with alveolar space to support gaseous exchange, these collagen-rich adventitial regions of connective tissue and interstitial space in the bronchovascular bundles represent a site where immune cells may be recruited. Recent work indicates that similar interstitial spaces may be found in other organs and 
that the adventitial "cuff" regions may generally be important sites for tissue immunity (Benias et al., 2018; Dahlgren and Molofsky, 2019).

During inflammatory exposures, BAMs stay resident near the bronchial airways, whereas some DCs migrate to the draining lymph node. Consequently, BAMs may play an important role in the local activation of effector/memory T cells recruited to the lung. After initial sensitization, effector T cells were recruited to the airway interstitium where BAMs were abundant and as early as 4-6 $h$ after allergen challenge and formed long interactions with BAMs, reminiscent of activating interactions previously observed between T cells and DCs in the lymph node (Mempel et al., 2004). These interactions may lead to the production of chemotactic factors that recruit additional cells to these sites forming inflammatory foci. Thus, the recruitment and activation of T cells to the bronchial airway interstitium, where BAMs display captured antigen, would provide a basis for the initiation of allergic inflammation during allergen re-exposure in sensitized individuals. In the intestine and adipose tissue, resident macrophages were also reported to activate effector T cells and shape local immunity (Cho et al., 2014; Kamada et al., 2009; Schreiber et al., 2013); BAMs may be the functional equivalent of these macrophages at the airways.

Consistent with previous imaging studies of CD11c-YFP mice (Thornton et al., 2012; Veres et al., 2011), we observed minimal fluorescent antigen uptake by CD11C-YFP+ DCs near the airways by microscopy. Our flow cytometric analysis revealed that CD11c-YFP+ DCs were nevertheless taking up soluble antigen at levels likely below the limit of detection by microscopy. In contrast, BAMs took up higher amounts of antigen that were readily detectable by imaging. In a similar manner, intestinal macrophages are superior at capturing soluble antigen from the intestinal lumen compared to DCs (Mazzini et al., 2014; Schulz et al., 2009). Considering that BAMs look more dendritic than DCs and are $\mathrm{MHC}-\mathrm{II}^{\mathrm{hi}}$, it is likely that $\mathrm{MHC}-\mathrm{Il}^{+}$dendritiform cells identified in rodent airways in earlier studies (Huh et al., 2003; von Garnier et al., 2007) were actually BAMs rather than DCs. The stellate shape of BAMs is reminiscent of recent imaging studies of IMs in other tissues, such as in the kidney (Stamatiades et al., 2016), and may facilitate antigen sampling.

Here we reported the rapid and efficient uptake of soluble antigen across a range of sizes by BAMs, with the magnitude of antigen uptake inversely proportional to antigen size. We did not readily observe dendrite extension through the epithelial barrier by live microscopy, making this unlikely to account for the widespread antigen uptake by BAMs, and therefore suggesting that BAMs capture soluble antigens by alternative mechanism(s). Soluble antigens may instead be captured after diffusing across the airway epithelial barrier. This model may account for the reduced uptake of larger molecular weight antigens, which would be less effective at diffusing across the epithelium. In the intestine, it was reported that low molecular weight soluble antigens passed through goblet cells (McDole et al., 2012). Although few goblet cells are present in the murine lung in the steady state, whether soluble antigens could also pass through the more abundant club cells remains to be determined. The increase in goblet cells that occurs in allergic airway disease might also facilitate the passage of soluble antigens and thus further promote the inflammatory response. At sites of BALT formation, the follicle associated epithelium containing microfold (M) cells has also been reported to facilitate the uptake of soluble antigens (Bienenstock and Befus, 1984). Alternatively, soluble antigen may pass through gaps in the epithelium, such as tri-junctional complexes located where three epithelial cells meet (Patton, 1992). The $200 \mathrm{~nm}$ bead particles that we tested would be too large to pass through the gaps in tri-junctional complexes that average $27 \mathrm{~nm}$. The selective passage of soluble antigens across the epithelium would explain why we did not observe bead particle uptake around the airways by either BAMs or DCs, whereas we found beads captured primarily at the alveoli by alveolar macrophages, which reside within the alveolar space. Another study 
using beads as model antigens also observed uptake at the alveoli rather than at the airways (Thornton et al., 2012) but reported that beads were captured by DCs. In that study, sensitized mice were rechallenged with the sensitizing antigen while beads were administered, creating an inflammatory state where monocyte-derived cells and DCs (Jenkins and Hume, 2014; Rodero et al., 2015) were likely to be recruited to the alveolar regions and capture antigen at the alveoli. In the steady state, DCs are largely restricted to the regions near bronchial airways, yet monocytes have also been reported to patrol the alveoli and capture beads (Rodero et al., 2015). Overall, our work reveals that at the bronchial interstitium, small soluble antigens are preferentially captured by BAMs.

The form and size of an antigen was recently reported to affect the type of $T$ cell responses induced, as type 2 allergic responses were primarily directed to small soluble antigens whereas regulatory $T$ cell responses were primarily directed to particulate antigens (Bacher et al., 2016), though the mechanism was not explored. Our finding that soluble and particulate antigens are preferentially captured in different regions of the lung leads us to propose that the anatomic location of antigen uptake ultimately influences the final $\mathrm{T}$ cell response. The tissue signals inherent in different anatomic environments may prime divergent immune responses. In the alveoli, the abundant alveolar macrophages have been proposed in several studies to dampen allergic responses (Bang et al., 2011; Mathias et al., 2013; Tang et al., 2001; Zaslona et al., 2014). Macrophages that were earlier found in the alveolar interstitium were also reported to produce IL-10 and reduce inflammation in an allergic airway disease model (Bedoret et al., 2009). The tissue environment at the alveoli thus appears to favor reduced inflammation in the delicate alveolar tissue, in the absence of overt infection in this region. Instead, the airways may be more permissive to the induction of inflammation as indicated by the concentration of immune responses at airway adjacent regions. Future work on the functional capacities or cytokine profiles of BAMs would further inform our understanding of the inflammatory milieu at the airway microenvironment.

We propose that BAMs represent a subset of IMs specialized for sampling the bronchial airway lumen. This work extends the findings of Gibbings et al. (2017) and Rodero et al. (2015) who first observed CX3CR1-GFP+ IMs localized near the bronchial airways. IM populations near the alveoli have also been reported in microscopy studies (Bedoret et al., 2009; Schyns et al., 2019; Tan and Krasnow, 2016). Multiple subsets of IMs have also been described based on different combinations of surface markers by flow cytometric analysis, as well as distinct transcriptional profiles (Chakarov et al., 2019; Gibbings et al., 2017; Sabatel et al., 2017; Schyns et al., 2019). There is a lack of consensus on the identification and localization of the IM subsets, and it seems likely that diverse pathogen exposures in different mouse facilities may affect baseline inflammation and the relative abundance of different subsets. Of note, most of our mice for this study were bred in a 'super-barrier' mouse facility that excludes additional pathogens compared to standard SPF facilities. Here we have focused specifically on the subpopulation of IMs localized near the bronchial airway epithelium that we found readily captures soluble inhaled antigens in naïve mice. We propose that the field consider referring to these macrophages as BAMs based on their anatomic localization near the bronchial airways, much as it has been useful to classify alveolar macrophages based on their anatomic location. We found that BAMs expressed high amounts of MHC-II, were efficient at antigen capture, processing and presentation, and interacted with effector T cells in vivo, suggesting that BAMs serve as APCs near the bronchial airways. Our finding that BAMs expressed high amounts of surface MHC-II differs from a recent study by Schyns et al (2019), which reported MHC-II+ CX3CR1-GFP+ IMs were primarily localized near the alveoli. This difference is likely due to technical differences in our imaging approaches. We imaged native GFP fluorescence in unfixed tissue allowing us to preferentially visualize CX3CR1-GFPbright BAMs, whereas Schyns et al. used anti-GFP antibody 
amplification of CX3CR1-GFP signal in fixed tissue, which would have likely resulted in the visualization of a much larger population of cells with varying expression of CX3CR1-GFP, including monocytes and DCs. We also imaged thick tissue vibratome sections by two-photon microscopy whereas Schyns et al. imaged thin cryosections by confocal microscopy. We found the analysis of thick sections to be particularly useful to try to discern the cellular distribution of BAMs in unimmunized mice, whereas in thin sections the cells were too sparse.

While our manuscript was being finalized, a recent study described a population of nerve and airway associated macrophages (NAMs) (Ural et al., 2020) which bear some resemblance to the population of BAMs we have defined here based on expression of CX3CR1-GFP and morphology. However, this population of NAMs was notable for high CD169 expression, whereas the BAMs we identified had a range of relatively low CD169 expression, appearing as a bell-shaped curve overlapping with our fluorescence minus one control. Another difference in our findings is that the antigen-capturing BAMs were CD11 $\mathrm{c}^{\text {int }} \mathrm{MHC}-\mathrm{II}^{\mathrm{hi}}$, whereas NAMs were reported to be $C D 11 \mathrm{C}^{-}$and have a range of $\mathrm{MHC}$-II expression, although we cannot exclude the possibility that these distinct results could be due to technical differences in antibody staining techniques or reagents. It seems plausible that these subsets of cells may be overlapping, but clearly some features are distinct. Indeed, in DT-treated CD169-DTR mice, we observed minimal depletion of CD11 $\mathrm{c}^{\text {int }} \mathrm{MHC}-\mathrm{II}^{+} \mathrm{CD} 64^{+} \mathrm{MerTK}^{+}$cells, which is the population we defined that correlated with BAMs, whereas the CD169-DTR was apparently used to efficiently deplete NAMs. Since bronchovascular bundles contain bronchi, arteries, lymphatic vessels, and nerves, presumably the BAMs we have visualized in collagen-rich regions near airway branchpoints are routinely found proximal to all of these structures. While we have focused on the potential role of BAMs as APCs in immune surveillance of the bronchial airways, our findings do not exclude other potential functions of these cells. For example, BAMs might be involved in the clearance of epithelial cells or in the production of molecules involved in tissue homeostasis. It will be interesting for future studies to resolve the potential distinctions and functions of the various subsets of IMs recently defined in the lung.

Emerging data from microarray and RNAseq analyses have highlighted the distinct gene expression patterns of IMs, alveolar macrophages and DCs in the lung (Chakarov et al., 2019; Gautier et al., 2012; Gibbings et al., 2017; Schlitzer et al., 2013; Schyns et al., 2019), and functional studies in other tissues such as the intestine have revealed distinct contributions of macrophages and DCs to immunity (Chang et al., 2013; Kamada et al., 2009; Mazzini et al., 2014; Schreiber et al., 2013; Schulz et al., 2009; Shaw et al., 2012). Here we have shown that BAMs, as a subset of IMs, are distinct from classical lung DCs in morphology, antigen uptake capacity and the ability to migrate to the draining lymph node. It is important to note that under inflammatory conditions, including in mouse models of allergic airway disease, monocytes rapidly enter lung tissue and differentiate into monocyte-derived cells that express surface markers that bear some resemblance to resident DCs and macrophages (Guilliams et al., 2013; Jakubzick et al., 2008; Plantinga et al., 2013). Although the MAR-1 antibody to FceRI was thought to be a marker of these monocyte-derived cells, we recently established that this antibody also binds to CD64 and FcyRIV (Tang et al., 2019), and thus would also detect resident $\mathrm{CD} 64^{+}$macrophages. One study used an extensive analysis of the ratio of expression of CX3CR1-GFP and CD11c-mCherry reporters to determine the relative differentiation state of infiltrating monocytes (Sen et al., 2016). This paper showed an increase in the abundance of cells with high expression of both CX3CR1-GFP and CD11c-mCherry reporters in allergic airway inflammation models. These cells were proposed to represent differentiated monocytederived cells, and we speculate that the rare cells we observed that were bright for CX3CR1GFP and CD11c-YFP reporters in the naïve state may also represent cells that had recently differentiated from monocytes. One challenge, however, in relating this study to our findings 
presented here is that the high expression of CX3CR1-GFP in resident BAMs versus the lower expression in monocytes was not considered in the analysis of the ratio of CX3CR1-GFP to CD11c-mCherry expression, which formed the basis of the monocyte differentiation model (Sen et al., 2016). Similar to BAMs and DCs, monocyte-derived cells have been reported to activate T cells and drive allergic inflammation (Plantinga et al., 2013). Conversely, monocyte-derived cells and IMs have also been reported to promote tolerance and dampen inflammation in the lung (Sabatel et al., 2017). Although all these APCs may exhibit some overlap in their ability to activate $T$ cells, it seems likely that these different cell types may skew $T$ cell responses at the airways in distinct ways. We found here that DCs and monocyte-derived cells were not critical for allergic airway inflammation to occur, suggesting that BAMs may be sufficient as APCs to activate $T$ cells near the airways. Further studies with selective tools for manipulation are needed to elucidate the specific contributions of BAMs, DCs, and monocyte-derived cells to lung immunity.

In summary, our study demonstrates that the bronchial airways are a major site of soluble antigen capture where BAMs serve as resident sentinel immune cells. Compared to DCs, BAMs exhibited distinct morphology and enhanced antigen uptake abilities. In addition, DCs migrated to the draining lymph nodes whereas BAMs remained resident near the airways. This disparity in migratory behavior suggests a division of labor where DCs may prime naïve T cells in the lymph nodes while BAMs mediate local airway immunity. Our data demonstrate that BAMs are able to activate effector Th2 cells and interact with CD4 T cells recruited to the airways in mouse models of allergic airway disease. We propose that BAMs may play a similar role in the local activation of T cells in context of infection. Overall, BAMs are strategically positioned as sentinel APCs underlying the bronchial airway epithelium. BAMs were enriched at collagen-rich regions near some airway branchpoints, which may ultimately develop inflammatory foci when an adaptive immune response is initiated. 


\section{Methods}

Mice and chimeras

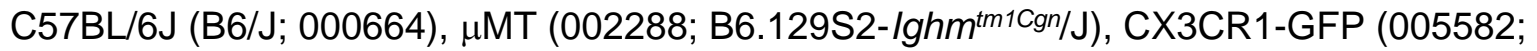

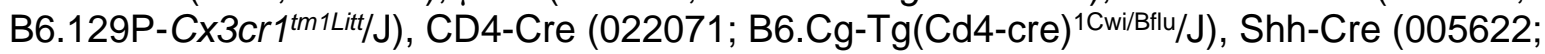

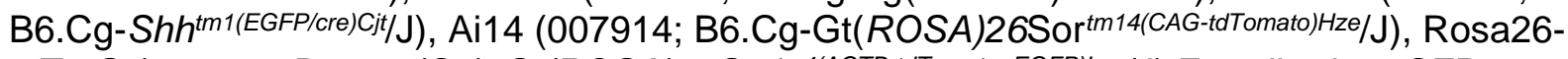
mTmG (007676; B6.129(Cg)-Gt(ROSA)26Sortm4(ACTB-tdTomato,-EGFP)Luo/J) E-cadherin-mCFP (016933; B6.129P2(Cg)-Cdh1tm1Cle/J), Prox1-tdTomato (022766; C57BL/6-Tg(Prox1tdTomato)12 Nrud/J), Thy1.1 (000406; B6.PL-Thy1a/CyJ) and Zbtb46-GFP (018534; $129 \mathrm{~S}$ -

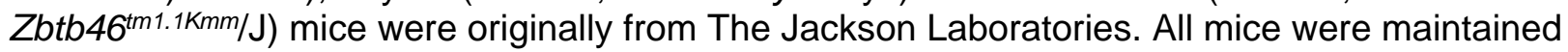
on B6 background except Zbtb46-GFP, which was obtained on a 129 background and crossed one generation to B6/J. MacGreen (CSF1R-GFP, Tg(Csf1r-EGFP) $1^{\text {Hume }}$ ) (Sasmono et al., 2003), CD11c-YFP (Tg(Itgax-Venus) $1^{\mathrm{Mnz}}$ ) (Lindquist et al., 2004), $\beta$-actin-CFP (Tg(CAGECFP)CK6 ${ }^{\text {Nagy }}$ ) (Hadjantonakis et al., 2002), OT-Il (Y-chromosome insertion; Tg(TcraTcrb)426$6^{\mathrm{Cbn}}$ ) (Barnden et al., 1998), CD11c-DTR (Tg(Itgax-DTR/EGFP)57 Lan) (Jung et al., 2002), zDC-

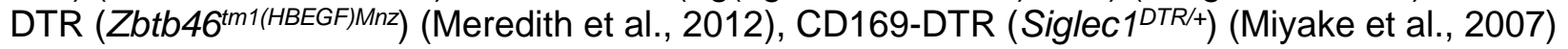
and $\mathrm{Ccr}^{-1-}\left(\mathrm{Ccr}^{\text {tm1lfc}}\right)$ (Boring et al., 1997) mice were maintained on a B6 background. B6CD45.1 congenic mice, which were used as wild-type mice in some experiments, were bred from the Boy/J line (002014; B6.SJL-Ptprc ${ }^{\mathrm{a}} P$ epc/BoyJ) from The Jackson Laboratories or purchased from Charles River (National Cancer Institute Model 01B96; B6-Ly5.2/Cr, later renamed to B6-Ly5.1/Cr). All mice were maintained in specific-pathogen-free facilities and protocols were approved by the Institutional Animal Care and Use Committee of the University of California San Francisco. MacGreen mice were crossed to $\mu \mathrm{MT}$ mice to generate a faithful reporter of myeloid cells because some B cells were also GFP+ (unpublished observations). Fluorescent OT-II T cells were obtained by crossing OT-II mice to $\beta$-actin-CFP mice or CD4-Cre $X$ Ai14 mice. To generate age-matched CD11C-DTR and zDC-DTR chimeras, B6-CD45.1 congenic mice were irradiated with two doses of 525-595 rads, $3 \mathrm{~h}$ apart, and then injected intravenously (i.v.) with 3-4 x $10^{6}$ bone marrow cells from C57BL/6J, CD11c-DTR or zDC-DTR mice. Chimeras were rested for 8 weeks to allow bone marrow reconstitution before immunization.

\section{Antigen administration}

To induce allergic airway inflammation with a classical OVA model (Daubeuf and Frossard, 2013), mice were sensitized by intraperitoneal (i.p.) injections with $100 \mu$ g Endograde OVA (Hyglos) mixed with $100 \mu$ alum (Alhydrogel, Grade A 1.3\%, Accurate Chemical and Scientific) once a week for a total of three times. One week after the last sensitization, mice were challenged intranasally (i.n.) with $50 \mu$ Endograde OVA in $50 \mu$ PBS daily over three days. Bronchoalveolar lavages (BAL) and lungs (see details below) were assessed two days after the last challenge. For Fig. 1C, 104 OT-II cells were adoptively transferred i.v. and then mice were primed i.p. with $100 \mu \mathrm{g}$ OVA grade VII (Sigma-Aldrich) in $200 \mu \mathrm{l}$ alum on d0 and d9, and then challenged i.n. with $100 \mu \mathrm{g}$ OVA in $50 \mu \mathrm{l}$ PBS on d16, 17, and 18, and then imaged on d20. In repeats of this particular experiment, the mice were primed once rather than twice with OVA/alum, as this led to greater recovery of OT-II cells and a similar inflammatory response. To deplete antigen presenting cells, B6, CD11c-DTR and zDC-DTR bone marrow chimeras were treated with $500 \mathrm{ng}$ Diphtheria toxin (Millipore) i.p. every other day beginning one day before the three i.n. OVA challenges. CD169-DTR mice were treated with $1 \mathrm{ng}$ Diphtheria toxin (Millipore) i.n. one day before the 3 i.n. OVA challenges. To induce allergic airway inflammation with HDM, mice received 10-100 $\mu \mathrm{g}$ of HDM extract (Greer) reconstituted in PBS i.n. once a week for a total of four times (Kohl et al., 2006). Lungs were imaged 2 days after the last exposure. Some experiments used an abbreviated intranasal model of OVA allergic airway 
inflammation (Eisenbarth et al., 2002) to study early events after allergen challenge.

Specifically, mice were sensitized intranasally with $100 \mu \mathrm{g}$ Endograde OVA mixed with low-dose (100 ng) LPS (ultrapure LPS, O55:B5, List Biologicals) in $50 \mu \mathrm{l}$ of PBS and then challenged intranasally with $50 \mu \mathrm{g}$ OVA in $50 \mu \mathrm{l}$ of PBS 9-10 days later, followed by excision of lungs 4-6h after challenge.

For microscopy, fluorescent ovalbumin (OVA) conjugated to Texas Red, TAMRA or Alexa 647 (Life Technologies) were administered in 20-50 $\mu$ PBS intranasally. Smaller volumes were found to somewhat favor labeling at the larger airways rather than at the alveoli, but also led to a more heterogeneous distribution of antigen throughout the lung. To produce HDM conjugated to Texas Red or OVA conjugated to TAMRA, $100 \mu \mathrm{g}$ of HDM or OVA were reconstituted in PBS with $0.1 \mathrm{M}$ sodium bicarbonate at $1 \mathrm{mg} / \mathrm{ml}$ and mixed with $18 \mu \mathrm{g}$ Texas Red-succinimidyl ester or $36 \mu \mathrm{g}$ 5,(6)-TAMRA-succinimidyl ester (Life Technologies), respectively. Excess free Texas Red or TAMRA were removed with Bio-spin $6 \mathrm{kDa}$ size exclusion columns (Bio-Rad Laboratories) equilibrated with PBS according to manufacturer's instructions. We noted that Texas Red-labeled antigens bound nonspecifically to dead epithelial cells at the cut site of the vibratome sections, but this was not observed with TAMRA- or Alexa 647-labeled antigens. However, we observed similar capture of all types of fluorophore-labeled antigens by BAMs, confirming this result was not fluorophore-dependent. TRITC-Dextran and FITC-Dextran were from Life Technologies (10 kDa) or Sigma-Aldrich (all other molecular weights). R-Phycoerythrin (PE) (Life Technologies) was dialyzed for $48 \mathrm{~h}$ at $4^{\circ} \mathrm{C}$ into PBS using $10 \mathrm{kDa}$ MWCO Slide-alyzer cassettes (Thermo Fisher) before intranasal administration. $0.2 \mu \mathrm{m}$ Sky Blue fluorescent beads (Spherotech) were administered i.n. at $0.025-0.05 \% \mathrm{w} / \mathrm{v}$ in $30 \mu \mathrm{l} \mathrm{PBS}$. To induce CCR7 upregulation and track lymphatic migration (Fig 7), mice received either $1 \mu \mathrm{g}$ ultrapure LPS or $100 \mu \mathrm{g}$ HDM in 30-50 $\mu$ l of PBS i.n., or were primed and challenged with the abbreviated lowdose LPS intranasal OVA model described above, and lungs were analyzed 4-6 h later.

To generate OVA-E $\alpha$, an E $\alpha$ peptide (Murphy et al., 1992) synthesized with an added terminal cysteine residue (New England Peptide) was dissolved in ultrapure water with $5 \mathrm{mM}$ EDTA and mixed with maleimide-activated OVA (Thermo Fisher Scientific) at room temperature for $2 \mathrm{~h}$. Excess E $\alpha$ peptide was removed with Bio-spin $30 \mathrm{kDa}$ size exclusion columns (Bio-Rad Laboratories) equilibrated with PBS according to the manufacturer's instructions. $20 \mu \mathrm{g}$ OVA-E $\alpha$ was administered i.n. together with $2.5 \mu \mathrm{g}$ of OVA-Alexa 647 (Life Technologies) in 30-50 $\mu \mathrm{l}$ PBS and lungs were analyzed 17-18 $\mathrm{h}$ later. For imaging of T cell activation, $5 \times 10^{5}$ fluorescent OT-II T cells (see Mice and Chimeras above) were adoptively transferred i.v. into the retroorbital plexus of anesthetized CX3CR1-GFP X CD11c-YFP recipient mice, which were then sensitized and challenged with the abbreviated low-dose LPS intranasal OVA model described above, and lungs were excised for imaging 4-6 $\mathrm{h}$ after challenge.

\section{Cryosection and immunofluorescence microscopy}

Mouse lungs were inflated with $1 \mathrm{~mL}$ of Tissue-Tek optimum cutting temperature compound (OCT, Sakura), then placed in a cryomold with OCT and "snap-frozen" in dry ice and ethanol. Frozen tissue blocks were stored at $-80^{\circ} \mathrm{C}$. Acetone-fixed cryosections were prepared as described (Allen et al., 2004). Slides were stained as described (Yang et al., 2018) in PBS or TBS containing $0.1 \%$ BSA (Roche), $1 \%$ normal mouse serum (Jackson Immunoresearch) and a diluted mixture of purified Siglec-F PE (E50-2440, BD) and SMA-FITC (1A4, Abcam) for $2 \mathrm{~h}$. Slides were washed for 3 min in PBS or TBS and mounted in Fluoromount G with DAPI (SouthernBiotech). Slides were imaged on the Axio Scan.Z1 slide scanner equipped with an HXP120 fluorescence microscope illuminator as well as $38 \mathrm{HE}$ and $20 \mathrm{HE}$ filter sets for FITC and PE visualization (Carl Zeiss Microscopy). A Chroma filter set (GT370/60x, T425lpxr, 
ET460/50m) was used for DAPI visualization. Images were collected and analyzed with Zen Blue (Carl Zeiss Microscopy).

\section{2-photon microscopy}

In preparation for 2-photon microscopy, mouse lungs were inflated with $1 \mathrm{~mL}$ of $2 \%$ low melt agarose, and $600 \mu \mathrm{m}$ thick sections were precision cut using a vibratome (Leica VT1200 or Oxford Laboratories Model G) as described (Sullivan et al., 2011). Airways could be identified by transmitted light based on the presence of a columnar epithelial lining and active ciliary beating. For antibody staining, 250-300 $\mu \mathrm{m}$ lung slices were incubated at room temperature in PBS with TruStain FcX (Biolegend) and mouse gamma globulin (Jackson Immunoresearch) for $2 \mathrm{~h}$ and then stained with the antibodies CD64-PE and I-A ${ }^{\mathrm{b}}$-Alexa 647 (Biolegend) overnight at $4^{\circ} \mathrm{C}$. Lung slices were then washed in excess PBS before imaging. For time-lapse microscopy, lung slices were incubated as described (Sullivan et al., 2011). Briefly, lungs slices were mounted in a heated chamber (JG-23W/HP, Warner Instruments) with warm RPMI (Gibco) supplemented with $1 \mathrm{X}$ Penicillin, Streptomycin, and L-Glutamine (Life Technologies) flowing over it at a rate of $1.5 \mathrm{~mL} / \mathrm{min}$. Media temperature in the imaging chamber was maintained at $35-37^{\circ} \mathrm{C} .5 \% \mathrm{CO}_{2} / 95 \% \mathrm{O}_{2}$ was bubbled into $\mathrm{RPMI}$ to maintain physiologic $\mathrm{pH}$.

Lung slices were imaged on an LSM 7 MP INDIMO two-photon laser scanning microscope (Carl Zeiss Microscopy) equipped with two Chameleon Ultra II lasers (Coherent), a Compact Optical Parametric Oscillator (OPO, Coherent) and a W Plan-Apochromat 20x/1.0 objective. Images were collected on non-descanned detectors consisting of four gallium arsenide phosphide (GaAsP) detectors and one far-red sensitive detector. Emission filters used to record fluorescence signals are listed in Supplementary Table 1. Sequential laser excitation at different wavelengths was used to enhance the spectral separation of fluorophores, similar to our previous approach (Sullivan et al., 2011) with CFP and GFP. Samples were imaged with multiple tracks, with rapid line switching of laser emissions by acousto-optical modulators in order to separate the excitation and detection of different fluorophores and for second harmonic generation. For example, in order to improve the separation of GFP and YFP: in the first track, one laser was tuned to $860-870 \mathrm{~nm}$ to excite CFP and GFP with minimal excitation of YFP; and then in the second track, the other laser was tuned to $1020-1040 \mathrm{~nm}$ to strongly excite YFP with minimal excitation of CFP and GFP. SkyBlue beads were excited at $850 \mathrm{~nm}$. PE was excited at 1040-1050 nm on the Chameleon laser or at $1100 \mathrm{~nm}$ on the OPO. Alexa 647 was excited at $1200 \mathrm{~nm}$ on the OPO. Second harmonic generation results in an emission at half the incident laser wavelength and the signal was collected in various filters (Supplementary Table 1); the separation of the second harmonic from fluorophore emissions was assisted by tuning lasers to particular wavelengths and the use of multiple tracks. For experiments in which enhanced spectral separation was not needed, or for fast imaging for time-lapse recordings, fluorophores were excited simultaneously at wavelengths of $890-1040 \mathrm{~nm}$ with one or more laser lines. Zstacks were collected every $30 \mathrm{~s}$ for 20-45 min. $x y$ planes were collected at variable zoom and pixel sizes, with a typical resolution of $512 \times 512$ pixels. Bidirectional scanning was typically used for faster image acquisition. The spacing between planes in the $z$ dimension was set to three to five times the $x y$ pixel size for a given zoom setting. Images were collected with Zen Black (Carl Zeiss Microscopy) and images were analyzed with Zen Black, Volocity (PerkinElmer) and Imaris software (Bitplane). Videos were prepared with Volocity and then annotated in Adobe After Effects CC.

\section{Flow Cytometry}

To collect bronchoalveolar lavages (BAL), mice were euthanized with an overdose of isoflurane and lungs were deflated and exposed by thoracotomy. A $20 \mathrm{G}$ x 1" SurFlash catheter (Terumo) 
was inserted into the trachea and secured with a suture. Lungs were flushed twice with a syringe with $1 \mathrm{~mL}$ of DPBS (Gibco) and then the lavage was added to $200 \mu$ of PBS with $50 \%$ FBS and 0.1 M EDTA (Gibco) and kept on ice. BALs were centrifuged at $350 \mathrm{~g}$ for $7 \mathrm{~min}$ at $4{ }^{\circ} \mathrm{C}$ and resuspended in PBS with $2 \%$ FBS, 1 mM EDTA (Gibco) and $0.1 \%$ sodium azide (Gibco) (FACS buffer) for antibody staining. Lungs were excised into $1 \mathrm{~mL}$ DMEM media supplemented with HEPES (Gibco), Penicillin, Streptomycin and L-Glutamine (Life Technologies). For lung digestion, $25 \mu \mathrm{g}$ of DNase I (Sigma) and 0.28 Wunitz Units of Liberase TM (Roche) were added to each $\mathrm{mL}$ of digest. Lungs were snipped into small pieces with scissors in a $1.7 \mathrm{~mL}$ eppendorf tube and incubated on a $37^{\circ} \mathrm{C}$ shaker for $30-45 \mathrm{~min}$ at $700 \mathrm{rpm}$ on a ThermoMixer F1.5 (Eppendorf). The digestion reaction was quenched by adding FBS and EDTA to a final concentration of $5 \%$ FBS and 10 mM EDTA. Digested lungs were then gently dissociated and passed through a $70 \mu \mathrm{m}$ strainer to yield single cell suspensions that were then centrifuged and resuspended in DMEM supplemented with $5 \%$ FBS, HEPES, Penicillin, Streptomycin and LGlutamine. For FACS staining, $3 \times 10^{6}$ lung cells were added to a 96 -well plate and washed with $150 \mu$ of ACK Lysing Buffer (Quality Biological) before antibodies were added for staining. Flow cytometric staining of BAL and lung cells was done as described (Allen et al., 2004; Yang et al., 2012), except CCR7 was stained for $15 \mathrm{~min}$ at $37^{\circ} \mathrm{C}$. Antibodies used for staining are listed in Table 2. Flow cytometric data was acquired on a BD LSRFortessa with 405nm, 488nm, and $640 \mathrm{~nm}$ lasers, using BD FACS DiVa software and analyzed with FlowJo software (TreeStar).

\section{APC sorting}

Lungs were excised from CD45.1 congenic mice into DMEM media supplemented with HEPES, Penicillin, Streptomycin and L-Glutamine and digested and dissociated as above. Single cell suspensions of lung digests were combined and then a 2X volume of ACK Lysing Buffer (Quality Biological) was added and cells were centrifuged at $350 \mathrm{~g}$ for $7 \mathrm{~min}$ at $4^{\circ} \mathrm{C}$ and resuspended in PBS with 0.5\% BSA (Roche) and 1\% FBS (Sorting Buffer). Cells were incubated with CD11c BV650 antibody together with CD11c Mojosort Nanobeads (Biolegend), after which bead-labeled cells were purified with the Mojosort magnet (Biolegend) according to the manufacturer's instructions. Cells were then washed and stained with sorting antibodies (Viability dye eFluor780, CD45 Alexa 700, Ly6G PE-Cy7, Siglec-F BV421, CD19 PE-Dazzle

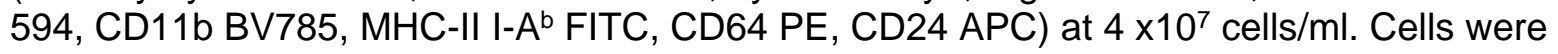
washed and diluted with Sorting Buffer, centrifuged through a $1 \mathrm{~mL}$ layer of $100 \% \mathrm{FBS}$, resuspended in Sorting Buffer and passed through a $40 \mu \mathrm{m}$ cell strainer. Cells were sorted on the FACSAria III (BD) into Advanced RPMI (Gibco) with 20\% FBS.

\section{T cell culture}

Inguinal, brachial, axillary and cervical lymph nodes were excised from OT-II mice with a Thy 1.1 congenic marker. The tissues were then gently dissociated and passed through $40 \mu \mathrm{m}$ strainers to yield single cell suspensions that were centrifuged at $350 \mathrm{~g}$ for $7 \mathrm{~min}$ at $4^{\circ} \mathrm{C}$ and resuspended in DMEM supplemented with 5\% FBS, HEPES, Penicillin, Streptomycin and L-Glutamine. To purify CD4 T cells by negative selection, cells were resuspended at $1-2 \times 10^{8} \mathrm{cells} / \mathrm{ml}$ and incubated with biotinylated antibodies against B220, CD11b, CD11c, CD8, NK1.1 and MHC-II I$A^{b}$ for 30 min on ice. Cells were washed to remove excess antibodies and then incubated with $250 \mu$ l MyOne Streptavidin T1 Dynabeads (Thermo Fisher) per $10^{8}$ cells for 30 min, during which tubes were inverted and rotated at $4^{\circ} \mathrm{C}$. Tubes were placed in a Dynamag-2 magnet (Thermo Fisher) for 2 min for bead isolation and the negative fraction containing unlabeled cells was collected and washed. For Cell Trace Violet labeling, cells were centrifuged and resuspended in PBS with $2 \%$ FBS at $2-20 \times 10^{6} \mathrm{cells} / \mathrm{ml}$. A $10 \mathrm{mM}$ stock of Cell Trace Violet (Thermo Fisher) in DMSO was diluted to $10 \mu \mathrm{M}$ in PBS and added at 1:1 volumetric ratio to cells while vortexing. Cells were incubated with Cell Trace Violet for $20 \mathrm{~min}$ at $37^{\circ} \mathrm{C}$, then $100 \mu \mathrm{l}$ of 
$100 \%$ FBS was layered at the bottom of the tube and cells were then centrifuged and resuspended in Advanced RPMI (Gibco) culture media. 50,000 labelled naïve T cells were cocultured with 10,000 sorted APCs for 2.5 days in the presence or absence of $20 \mu \mathrm{g} / \mathrm{mL} \mathrm{OVA}_{323-}$ 339 peptide (Invivogen) before analysis.

For Th2 polarization, CD4 T cells were purified by negative selection with magnetic beads as described above and cultured in Advanced RPMI (Gibco) supplemented with 10\% FBS, HEPES, Penicillin, Streptomycin, L-glutamine, $1 \mathrm{mM}$ sodium pyruvate and $50 \mathrm{mM} 2-$ mercaptoethanol (culture media). Flat-bottom 96-well plates were coated with $2.5 \mu \mathrm{g} / \mathrm{mL}$ antimouse CD3e (eBioscience, functional grade purified, eBio500A2) in PBS for $3 \mathrm{~h}$ at $37^{\circ} \mathrm{C}$ and washed twice with PBS before use. T cells were added to anti-CD3 coated wells at $10^{6} \mathrm{cells} / \mathrm{mL}$ in the presence of $1 \mu \mathrm{g} / \mathrm{mL}$ anti-CD28 (Biolegend, LEAF purified, 37.51), $100 \mathrm{U} / \mathrm{ml} \mathrm{IL-2} \mathrm{(gift} \mathrm{from}$ K. Mark Ansel's lab), $50 \mathrm{ng} / \mathrm{mL}$ IL-4 (Peprotech) and $10 \mu \mathrm{g} / \mathrm{ml}$ anti-IFN $\gamma$ (Biolegend, LEAF purified) for 3 days. T cells were then transferred into uncoated wells and replenished with IL-2, IL-4 and anti-IFN $\gamma$ for another 3 days before co-culturing with sorted APCs. 50,000 T cells were co-cultured with 10,000 sorted APCs in 96-well V-bottom plates (Cellstar) in the presence or absence of $20 \mu \mathrm{g} / \mathrm{mL}_{\mathrm{OVA}} \mathrm{OV}_{323} 339$ peptide (Invivogen). To assess cytokine production, $3 \mu \mathrm{g} / \mathrm{mL}$ Brefeldin A (eBioscience) was added to cultures 1-2 $\mathrm{h}$ after the start of culture, for 14-18 $\mathrm{h}$ before flow cytometric analysis. T cells were analyzed by flow cytometry as described above. For intracellular cytokine staining, cells were fixed and permeabilized with Cytofix/cytoperm solution (BD) for 20 min on ice and then washed with Perm/Wash solution (BD) according to the manufacturer's instructions. Cells were stained with anti-cytokine antibodies (Table 2) in Perm/Wash solution for 20 min on ice. Cells were washed twice with Perm/Wash solution and resuspended in FACS buffer, acquired on LSR Fortessa (BD) using FACS DiVA software (BD) and analyzed with FlowJo software (Treestar).

\section{Statistical analysis}

Statistical analysis and graphical representations were done using GraphPad Prism v7. The appropriate tests were chosen based on experimental design after consulting the GraphPad Statistics Guide. All tests were two-tailed.

\section{Author Contributions}

X.T. designed, performed, and analyzed data from most experiments; L.S.M.K., C.C., R.J.M., and C.D.C.A. significantly contributed to experiments; R.J.M. provided critical insights into lung anatomy and visualization; C.D.C.A supervised the research; X.T. and C.D.C.A. conceived of the work, prepared figures, and wrote the manuscript; X.T., L.S.M.K, R.J.M., and C.D.C.A. revised the manuscript.

\section{Acknowledgments}

We thank A. Chawla for providing Ccr2-- mice; J. Cyster for providing zDC-DTR and CD169DTR mice; M. Tanaka for the use of CD169-DTR mice; D. Sheppard for providing CD11c-YFP mice; Z. Werb for providing $\beta$-actin-CFP, MacGreen, and CD11c-DTR mice; H. Chapman, J. Cyster, R. Locksley, J-S. Shin, D. Sheppard, and X. Huang for helpful advice; J. Gordon and the UCSF Laboratory for Cell Analysis (supported by National Cancer Institute Cancer Center Support Grant P30CA082103) for cell sorting; and M. Shenoy for contributions to some early experiments. Research reported in this publication was supported by the National Heart, Lung, and Blood Institute (DP2HL117752) and the National Institute of Allergy and Infectious Diseases 
(R21Al130495) of the National Institutes of Health, the UCSF Cardiovascular Research Institute, the UCSF Sandler Asthma Basic Research Center, and the UCSF Program for Breakthrough Biomedical Research, which is partially funded by the Sandler Foundation. X.T. was funded by the Agency for Science, Technology and Research (A*STAR) National Science Scholarship (PhD). L.S.M.K. was supported by a National Institute of Allergy and Infectious Diseases training grant (T32Al007334-31). The content is solely the responsibility of the authors and does not necessarily represent the official views of the funding agencies.

\section{Disclosures}

After completing experiments for this manuscript, C.C. subsequently became an employee and shareholder of RAPT therapeutics. The authors declare no other competing financial interests. 


\section{Figure Legends}

Figure 1: Myeloid cells are strategically positioned for surveillance of the airways (A) Representative immunofluorescence staining of thin cryostat sections of the lung from wildtype mice sensitized and challenged with OVA in a classical OVA model of allergic airway disease. Sections were stained with an antibody to smooth muscle actin (SMA, green) to differentiate between airways and blood vessels, and with an antibody to Siglec $F$ (red) to visualize tissue eosinophils (Siglec-Fright) and alveolar macrophages (Siglec-Fint). Sections were stained with DAPI (blue) to visualize all nuclei. Airways $\left({ }^{*}\right)$ and blood vessels (BV) are labeled. (B) Representative 3D rendering of branching airways $\left({ }^{*}\right)$ and blood vessels (BV). The image was collected by two-photon microscopy of a precision-cut thick vibratome slice of the lung from a naive Shh-Cre ROSA26-mTmG mouse. Bronchial airway and alveolar epithelial cells express membrane-bound GFP (green), whereas all other cells express tdTomato (red). Collagen (blue) was visualized by second harmonic generation (2HG). (C, D, E) Representative two-photon microscopy images of precision-cut thick vibratome slices of the lungs of CSF1R-GFP mice that were treated with OVA (C) or HDM (D) allergic airway disease models, or were untreated (E). Maximum Intensity Projections (MIPs) representing z-stacks of $165 \mu \mathrm{m}(\mathrm{C}), 122.5 \mu \mathrm{m}(\mathrm{D})$, and $127.5 \mu \mathrm{m}(\mathrm{E})$ are shown. The bronchial airways were visualized separately by brightfield microscopy and the approximate boundaries are denoted by dashed lines, with the airway lumen denoted by *. Collagen (blue) was visualized by $2 \mathrm{HG}$. (F) Representative two-photon microscopy images of thick lung slices from mice expressing CX3CR1-GFP (green) together with E-cadherin-mCFP (left, blue) or Shh-Cre Ai14 (right, blue) to label airway epithelial cells. Collagen (magenta) was visualized by 2HG. MIPs representing z-stacks of $210 \mu \mathrm{m}$ (left) and $142 \mu \mathrm{m}$ (right) are shown. (G) Quantification of the density of CX3CR1-GFPbright cells located in tissue regions near the bronchial airways (AW) or alveoli (alv). (H) Representative two-photon microscopy images of thick lung slices from mice expressing CD11c-YFP (green) together with E-cadherin-mCFP (left, blue) or Shh-Cre Ai14 (right, blue) to label airway epithelial cells. Collagen (magenta) was visualized by 2HG. MIPs representing z-stacks of $231 \mu \mathrm{m}$ (left) and $285 \mu \mathrm{m}$ (right) are shown. (I) Quantification of the density of CD11c-YFP+ cells in tissue regions near the bronchial airways (AW) or alveoli (alv). Data are representative of 3 experiments (A), 4 experiments (B), 3 experiments (C), 2 experiments (D), $>5$ experiments $(E)$, and $\geq 3$ experiments $(F, H)$. Images in $(B-H)$ are stitched from tiled images. Each data point in $(G, I)$ represents the quantification of cell density in one region of interest collected from 6 tiled images (AW) and 5 tiled images (alv) from 5 different lung lobes from 4 mice across 3 experiments. ${ }^{* \star \star *} \mathrm{p}<0.0001$ (ttest). Scale bars, $100 \mu \mathrm{m}$.

Figure 2: Antigen administered via the airways is captured by CX3CR1-GFPbright IMs (A-D) Fluorescent OVA (OVA-FL, red) was administered by intranasal droplet to naïve mice $45 \mathrm{~min}-2 \mathrm{~h}$ prior to lung isolation. Precision-cut, thick vibratome sections were then imaged by two-photon microscopy. Shown are representative images of regions near the bronchial airways from mice expressing CX3CR1-GFP (green) and E-cadherin-mCFP (blue) (A, B), CD11c-YFP (green) and E-cadherin-mCFP (blue) (C) and CX3CR1-GFP (blue) and CD11c-YFP (green) (D). In (B) and (D), single color and merged color images of the regions are shown. Collagen (magenta) was visualized in (A) by 2HG. MIPs representing z-stacks of $6 \mu \mathrm{m}$ (A, left), $21 \mu \mathrm{m}(\mathrm{A}$, right), $9 \mu \mathrm{m}$ (B), $24 \mu \mathrm{m}$ (C, left), $22 \mu \mathrm{m}$ (C, right), and $24 \mu \mathrm{m}$ (D) are shown. (E) Fluorescent HDM extract (HDM-FL, red) was instilled intranasally to naive mice expressing CX3CR1-GFP (blue), CD11c-YFP (green), and E-cadherin-mCFP (gray). MIPs representing z-stacks of 12-13 $\mu \mathrm{m}$ are shown. (F) Analysis of the shapes of CX3CR1-GFP+ and CD11C-YFP+ cells in naïve mice by quantifying sphericity (left) and the length of the longest cell axis (right). Each data point represents the average of measurements from one image across 4 experiments. (G, H) 
Representative flow cytometric analysis $(\mathrm{G})$ and quantification $(\mathrm{H})$ of the intensity of OVA uptake in CX3CR1-GFP+ versus CD11C-YFP+ cells. Each data point represents one mouse (naïve). Data are representative of 5 experiments $(A-B, D), 2$ experiments $(C, E)$, and 4 experiments $(G-$ H). ${ }^{* *} p<0.01,{ }^{* * *} p<0.001$ (t-test). Scale bars, $20 \mu \mathrm{m}$.

Figure 3: DCs are not necessary for allergic recall responses in the lung

(A) Timeline of the classical OVA allergic airway disease model used in (B). (B) Eosinophil counts in the broncho-alveolar lavage (BAL) fluid at the endpoint of the classical OVA model.

(C) Representative flow cytometry gating of $\mathrm{CD} 11 \mathrm{c}^{+} \mathrm{MHC}-\mathrm{II}^{+} \mathrm{APCs}$ and resolution into $\mathrm{CD} 24^{+}$ CD64- DCs and CD24- CD64+ cells in the lungs of naïve mice with the indicated genotypes after DT treatment. CD11 $\mathrm{C}^{+} \mathrm{MHC}-\mathrm{II}^{+}$APCs were pregated as CD19-Siglec-F- $\mathrm{Ly}-6 \mathrm{G}^{-}$to exclude $B$ cells, alveolar macrophages, eosinophils, and neutrophils. (D-F) Counts of the indicated APC subsets from the lungs of naïve mice with the indicated genotypes after DT treatment, gated as in (C). Data in (B) are representative of 3 experiments. The relative depletion of cell subsets shown in (D-F) was also observed at the endpoint of the classical OVA models as in (A-B), although the absolute number of cells was increased due to infiltrating monocytes after allergen challenge (data not shown). Each data point represents one mouse (B, D-F). ns, not significant ${ }^{\star *} p<0.01 ;{ }^{* * \star *} p<0.0001$ (one-way ANOVA with Tukey's post-test (B) Dunnett's post-test (D-F)).

Figure 4: Antigen-capturing CX3CR1-GFPbright cells are Bronchus-Associated Macrophages (BAMs)

(A) Representative flow cytometric analysis of CX3CR1-GFPbright OVA ${ }^{\text {bright }}$ cells (top) versus CD11c-YFPbright cells (bottom). Cells were pre-gated to exclude B cells, neutrophils, eosinophils, and alveolar macrophages (CD19- Ly6G- Siglec- $^{-}$). (B) Quantification of the frequency of CD24+ CD64- ("CD24+") or CD64+ CD24-/lo (“CD64+") cells among CX3CR1-GFPbright OVA bright cells (top) or CD11c-YFPbright cells (bottom) that were gated as in (A). (C-D) Representative twophoton microscopy of CD64 (red) and MHC-II (blue) antibody staining in precision-cut vibratome lung sections from CX3CR1-GFP mice, showing 3D rendering $(C)$ and single z-plane images (D). In (D), single color and merged images are shown. (E) Representative two-photon microscopy of CD64 antibody staining (red) in vibratome lung sections from CD11c-YFP mice, showing a MIP of a $15 \mu \mathrm{m}$ z-stack. (F) Representative flow cytometric analysis comparing the phenotypes of cDCs (red), CD64+ $\mathrm{MHC}-\mathrm{Il}^{+}$macrophages (blue) and alveolar macrophages (green). cDCs and BAMs were gated as CD19- Ly6G $^{-}$Siglec- $\mathrm{F}^{-} \mathrm{CD} 11 \mathrm{C}^{+} \mathrm{MHC}^{-\mathrm{II}^{+}}$then CD24+ (CDCs) versus $\mathrm{CD}^{+} 4^{+}$(BAMs) as in (A). Alveolar macrophages were gated as CD19- CD11C ${ }^{+}$ Siglec- $\mathrm{F}^{+}$. Mice in all panels were unimmunized. Each data point represents one mouse $(B)$. Data in all panels are representative of $\geq 2$ experiments. Scale bars, $20 \mu \mathrm{m}$.

Figure 5: Characteristics of molecules captured by BAMs versus cDCs

(A) Fluorescent OVA was administered by intranasal droplet to naïve mice $2 \mathrm{~h}$ before lung isolation and enzymatic digestion. Representative flow cytometry (left) and quantification (right) of the frequency of OVA ${ }^{+}$cells within each indicated cell subset. Cells were pre-gated to exclude $B$ cells, neutrophils, eosinophils, and alveolar macrophages (CD19- Ly6G- Siglec- $F^{-}$). CD11 ${ }^{+}$ $\mathrm{MHC}-\mathrm{Il}^{+}$cells were resolved into CD24+ CDCs versus CD64+ BAMs as in Fig 4A, and then the remaining cells that were not $\mathrm{CD} 11 \mathrm{c}^{+} \mathrm{MHC}-\mathrm{Il}^{+}$cells were gated as $\mathrm{CD} 11 \mathrm{~b}+$ to define monocytes (mono). cDC1s were gated as CD11 $\mathrm{b}^{-} \mathrm{CD}_{103^{+}}$and $\mathrm{cDC} 2 \mathrm{~s}$ were gated as CD11 $\mathrm{b}^{+}$CD103subsets of cDCs. Monocytes (mono) were gated as the remaining CD11b+ cells after excluding CD11 $\mathrm{C}^{+} \mathrm{MHC}-\mathrm{II}^{+}$cells. Mice were either CX3CR1-GFP or CD11c-YFP mice. In CX3CR1-GFP mice, monocytes appeared as two subsets with lo to intermediate GFP expression, consistent with classical and non-classical monocytes, respectively (data not shown). (B, C, D) The indicated fluorescent molecules were administered by intranasal droplet to naïve CX3CR1-GFP $\mathrm{X}$ CD11c-YFP mice 2-4 $\mathrm{h}$ before lung isolation and the preparation of precision-cut thick lung 
sections. Representative images depict cells that captured the indicated fluorescent molecules in renderings of $73 \mu \mathrm{m}(\mathrm{B}), 16 \mu \mathrm{m}(\mathrm{C})$, and $51 \mu \mathrm{m}(\mathrm{D}) \mathrm{z}$-stacks collected by two-photon microscopy. DX, dextran; scale bars, $20 \mu \mathrm{m}$. (E) FITC-dextran of a range of sizes was administered by intranasal droplet to naïve mice, and then 2-3 $\mathrm{h}$ later the lungs were isolated and enzymatically digested. The frequencies of FITC+ BAMs (left) and FITC+ CDC2s (right) were enumerated by flow cytometry as shown. To control for the possibility of FITC-dextran uptake during lung digestion and dissociation, the lungs from congenic mice that did not receive FITCdextran were co-digested ("control lung") with the lungs of mice that had received FITC-dextran ("host lung"). (F) Fluorescent beads were administered to naïve mice expressing CX3CR1-GFP and CD11c-YFP. Representative two-photon microscopy images of an airway branchpoint (left) and alveoli (right) are shown. Images are MIPs of $107 \mu \mathrm{m}$ (left) and $45 \mu \mathrm{m}$ (right) z-stacks. Beads were primarily captured by alveolar macrophages which appear dimly fluorescent in the YFP channel (note that the image of the alveoli [right] is adjusted to show the dimmer signal in the green channel). Collagen was visualized by $2 \mathrm{HG}$. Each data point represents one mouse (A, E). Data are representative of 2 experiments (A-D). Similar results to (F) were observed in other experiments with smaller and larger beads. Scale bars, $20 \mu \mathrm{m}$.

Figure 6: BAMs act as APCs and interact with CD4 effector T cells in the lung (A) Representative flow cytometric analysis of $\mathrm{Y}$-Ae antibody staining to detect the presentation of MHC-II:E $\alpha$ peptide complexes. OVA conjugated to E $\alpha$ peptide was administered intranasally together with OVA-Alexa647 to fluorescently label antigen-capturing cells, and then after 17-18 $\mathrm{h}$ to allow time for antigen processing and presentation, the lungs were isolated, followed by enzymatic digestion and analysis of Alexa647+ BAMs (blue) vs cDC2s (red). Control mice received OVA without the E $\alpha$ peptide (gray). (B) Representative flow cytometry (top) and quantification (bottom) of the surface expression of the co-stimulatory molecules CD80 and CD86 on BAMs (blue) and cDC2s (red) in the lungs of naïve mice in the steady state. FMO (gray), fluorescence minus one control. (C) Flow cytometric analysis of the proliferation of naïve OT-II T cells that were co-cultured for 2.5 days with sorted cDC2s or BAMs in the presence (red) or absence (black) of OVA peptide. Proliferation was assessed by dilution of CellTrace Violet. (D) Flow cytometric analysis of IL-13 production in Th2-polarized OT-II T cells that were cultured overnight with sorted CDC2s or BAMs, or no APCs as a control, in the presence (red) or absence (black) of OVA peptide, together with Brefeldin A. (E, F) Time-lapse images of CD4 T cell interactions with CX3CR1-GFP+ BAMs. OT-II T cells (red) expressing tdTomato (E) or CFP (F) were adoptively transferred to mice expressing CX3CR1-GFP (green) and CD11C-YFP (yellow) that had been sensitized with OVA and low-dose LPS, and then challenged with OVA alone intranasally 9-10 days later. Precision-cut thick vibratome sections of the lung were prepared for imaging 4-6 h after OVA challenge, and two-photon microscopy z-stacks of $15 \mu \mathrm{m}$ (E) and $22 \mu \mathrm{m}(\mathrm{F})$ are shown. Elapsed time is indicated as hh:mm:ss. Each data point represents one mouse (B). Data are representative of 3 experiments $(A, D), 2$ experiments $(B$, C), and 5 experiments (E-F). Scale bars, $20 \mu \mathrm{m}$.

Figure 7: BAMs remain lung resident whereas DCs migrate to the draining lymph node (A-D) Motility measurements derived from time-lapse imaging of CX3CR1-GFP+ BAMs and CD11c-YFP+ DCs by two-photon microscopy of precision-cut thick lung sections from naïve mice. (E) Flow cytometric analysis of the frequency of CCR7 ${ }^{+}$cells among BAMs and cDC2s in the lung $4 \mathrm{~h}$ after the indicated concentrations of LPS were administered intranasally. $(\mathrm{F})$ Representative flow cytometry showing CCR7 expression on BAMs (blue) and CDC2s (red) in the lung $6 \mathrm{~h}$ after intranasal HDM administration. (G) The frequency of CCR7+ cells among BAMs and cDC2s in the lung in mice that were naïve ("no prime") or had been primed $10 \mathrm{~d}$ earlier with OVA and 100 ng LPS ("prime"), and were challenged once with intranasal OVA (i.n. 
OVA) without adjuvant. Lungs were excised $6 \mathrm{~h}$ after OVA challenge, enzymatically digested, and analyzed by flow cytometry. $(\mathrm{H})$ Representative two-photon microscopy images of CD11cYFP+ DCs or CX3CR1-GFP+ BAMs migrating in lymphatic vessels (Prox1-tdTomato). Mice were administered intranasal LPS 2-4 h before lung isolation, and then precision-cut thick lung slices were imaged for several hours. Images are MIPs of $41 \mu \mathrm{m}$ (left) and $32 \mu \mathrm{m}$ (right) z-stacks. (I) Representative flow cytometry gating in the lung-draining mediastinal lymph node in mice that were untreated or had been given HDM and PE intranasally $1 \mathrm{~d}$ earlier. Left, gating of cDCs (DC, red) and monocyte-derived cells (Ly6C+, blue). Cells were pregated as CD19- CD11 ${ }^{+}$ MHC-II+ CD11 b+. Right, gating of PE+ cells. (J) Quantification of the frequency of $\mathrm{PE}^{+}$cells among DCs and monocyte-derived cells $\left(\mathrm{Ly}_{6 \mathrm{C}^{+}}\right)$gated as in (I) $1 \mathrm{~d}$ after HDM and PE were administered intranasally. Each data point represents an individual cell, pooled from four timelapse image sequences $(A)$; the average of all cells from one time-lapse image sequence $(B, C$, and $D$ ); or one mouse (E, G, J). Data are from 2 experiments (A-D) or are representative of 2 experiments $(E, F, I, J)$. Similar results to the primed mice shown in $(G)$ were observed $1 \mathrm{~d}$ after OVA challenge, and similar results for CD11c-YFP cells shown in $(H)$ were observed with HDM treatment. ${ }^{* * *} \mathrm{p}<0.001,{ }^{* \star * *} \mathrm{p}<0.0001$ (t-test). Scale bars, $20 \mu \mathrm{m}$.

Supplementary Figure 1: Alveolar macrophages in CX3CR1-GFP mice appear distinct from BAMs

Representative alveolar region in the lung slice from a mouse expressing CX3CR1-GFP (green) that was imaged by two-photon microscopy $2 \mathrm{~h}$ after the intranasal administration of fluorescent antigen (OVA, red). Single color and merged MIP images depicting an $80 \mu \mathrm{m} z$-stack are shown. Alveolar macrophages (white arrows) are visible with a round morphology and capture large amounts of fluorescent OVA, yet exhibit only punctate autofluorescence in the GFP channel at our imaging settings. Data are representative of $>5$ experiments. Scale bar, $50 \mu \mathrm{m}$.

Supplementary Figure 2: Characterization of the relative intensity of CX3CR1-GFP versus CD11c-YFP fluorescence.

(A) Two different contrast adjustments are depicted of the same original image, shown as merged versus single color images. In the 'normal' settings, the cells look exclusively CX3CR1$\mathrm{GFP}^{+}$(green) or CD11c-YFP+ (red), but when the contrast is increased ('bright' setting) then dim CX3CR1-GFP expression is observed in some bright CD11cYFP+ cells, and vice versa (white arrowheads). The MIP represents a $53 \mu \mathrm{m}$ z-stack collected by two-photon microscopy of a precision-cut thick vibratome section from a naïve mouse. (B) Three images are shown depicting rare cells that have bright expression of both CX3CR1-GFP (green) and CD11C-YFP (red) reporters, and thus appear yellow (white arrowheads). The MIPs represent $60 \mu \mathrm{m}$ (left) and $34 \mu \mathrm{m}$ (middle, right) z-stacks collected by two-photon microscopy of precision-cut thick vibratome sections. Images are from independent experiments. Scale bars, $20 \mu \mathrm{m}$.

Supplementary Figure 3: OVA-capturing BAMs do not express the CD11c-YFP reporter. Fluorescent OVA was administered by intranasal droplet to naïve mice $2-3 \mathrm{~h}$ before lung isolation and enzymatic digestion. (A) Representative flow cytometric analyses of CX3CR1-GFP (upper histogram) and CD11C-YFP (lower histogram) expression on OVA ${ }^{\text {bright }}\left(\mathrm{OVA}^{++}\right)$APCs. Note that the GFP and YFP reporters were analyzed in separate mice. Only the cells capturing the most OVA, and the cells with bright GFP or YFP expression were gated, corresponding to the cells visualized by microscopy. Cells were pre-gated to exclude alveolar macrophages, $B$ cells, and neutrophils. (B) Quantification of the frequency of CX3CR1-GFPbright or CD11CYFPbright cells among $\mathrm{OVA}^{++}$cells. Each data point represents one mouse, and data are representative of 3 experiments. 
Supplementary Figure 4: Alveolar macrophages and blood monocytes are not essential for the induction of allergic airway inflammation.

(A) Representative flow cytometric analysis of the depletion of alveolar macrophages in CD11CDTR (right) versus control chimeras (WT, left) injected intraperitoneally (i.p.) with DT. (B) Representative flow cytometric analysis of the depletion of alveolar macrophages in CD169DTR mice (right) versus control mice (WT, left) treated with DT intranasally (i.n.). (C, D) Representative flow cytometry analyses showing frequency of MHC-II+ Ly-6C+ monocytederived cells (C) and CD64+ MerTK ${ }^{+}$cells (D) in CD169-DTR mice versus control mice (WT) treated with DT intranasally. (C) Cells were pregated as CD19-Siglec- $\mathrm{F}^{-} \mathrm{Ly}^{-} 6 \mathrm{G}^{-}$to exclude B cells, alveolar macrophages, and neutrophils (C) or CD19-Siglec-F- $\mathrm{Ly}^{-6 \mathrm{G}^{-} \mathrm{CD} 11 \mathrm{C}^{+} \mathrm{MHC}-\mathrm{II}^{+} \mathrm{Ly}-}$ $6 \mathrm{C}^{\text {lo }}$ to exclude $\mathrm{B}$ cells, alveolar macrophages, neutrophils, and monocyte-derived cells (D). (E, F) Eosinophil counts in the BAL fluid of mice exposed to the allergic airway disease model shown in Fig 3A, comparing WT with CD11c-DTR chimeras and with CD169-DTR mice after DT treatment (E) or WT with Ccr2 ${ }^{--}$mice $(F)$. In (E) WT refers to mixture of WT chimeras and WT mice. Data shown in (E) and $(F)$ are compiled from two independent experiments, and each data point represents one mouse. ns, not significant; * $p<0.05$; ${ }^{* * *} p<0.0001$ (one-way ANOVA with Dunnett's post-test $(\mathrm{E})$, t-test $(\mathrm{F})$ ).

Supplementary Figure 5: CD11c antibody labeling, CD11C-YFP and CX3CR1-GFP expression on CD64+ IMs.

(A) Representative flow cytometric analysis of CD11c-YFP reporter expression (upper histogram) versus CD11c antibody surface staining (bottom histogram) in the same sample, comparing OVA ${ }^{\text {bright }}\left(\mathrm{OVA}^{++}\right)$BAMs (blue) to DCs (red) gated as shown (left). (B) Representative flow cytometric analysis comparing the fluorescence intensity of the CX3CR1-GFP reporter in cDC2s (red), MHC-II+ CD64+ MerTK+ cells (blue), and monocytes (green). Data are representative of 2 experiments $(A)$ and 4 experiments $(B)$.

Supplementary Figure 6: Phenotypic comparison of cDCs, BAMs and alveolar macrophages. Representative flow cytometric analysis of marker expression on all CD24+ DCs (red), CD64 ${ }^{+}$ MHC-II+ BAMs (blue) and alveolar macrophages (green). (A) GFP expression on cells from the lung of a Zbtb46-GFP mouse. Background signal in a GFP-negative control mouse is shown in gray. (B-E) Antibody surface staining for CD11b (B), MerTK (C), CD169 (D), and CD206 (E) on each cell population in a wild-type mouse. Background signals in Fluorescence Minus One (FMO) controls are shown in gray. Cells were gated as in Fig 4 . Data are representative of $\geq 2$ experiments.

Supplementary Figure 7: Alveolar macrophages do not efficiently process and present antigen on MHC-II.

Representative flow cytometric analysis of $\mathrm{Y}$-Ae antibody staining to detect the presentation of MHC-II:E $\alpha$ peptide complexes as in Fig 6A. OVA conjugated to E $\alpha$ peptide was administered intranasally together with OVA-Alexa647 to fluorescently label antigen-capturing cells, and then after 17-18 $\mathrm{h}$ to allow time for antigen processing and presentation, the lungs were isolated, followed by enzymatic digestion and analysis of Alexa647 ${ }^{+}$alveolar macrophages (AMs, Siglec$\left.\mathrm{F}^{+} \mathrm{CD} 11 \mathrm{C}^{+}\right)$. Control mice received OVA without the $\mathrm{E} \alpha$ peptide (gray). Data are representative of 3 experiments.

Supplementary Figure 8: Comparison of Ly-6C surface expression on BAMs, DCs, and monocytes.

Representative flow cytometric analysis, comparing Ly-6C surface expression on DCs (red) and monocytes (green) from the lung and right posterior mediastinal lymph node (LN) as well as lung CD64+ MHC-II+ BAMs (blue). Cells were from naïve mice except LN monocytes, which 
bioRxiv preprint doi: https://doi.org/10.1101/2020.09.18.247742; this version posted September 19,2020 . The copyright holder for this preprint (which was not certified by peer review) is the author/funder, who has granted bioRxiv a license to display the preprint in perpetuity. It is made available under aCC-BY-NC-ND 4.0 International license.

were analyzed $1 \mathrm{~d}$ after HDM was administered intranasally. Data are representative of 2 experiments. 


\section{Video Legends}

Video 1: Collagen-rich region at branchpoint. The video is a $3 D$ rendering of the image depicted in Fig 1B, showing branching airways and blood vessels (BV) in the lung of a naïve Shh-Cre ROSA26-mTmG mouse. The image was stitched from tiled images collected by two-photon microscopy of a precision-cut thick vibratome section. Bronchial airway and alveolar epithelial cells express membrane-bound GFP (green), whereas all other cells express tdTomato (red). Collagen (blue) was visualized by second harmonic generation.

Video 2: CX3CR1-GFPbright IMs are positioned under the bronchial airway epithelium and are enriched at collagen-rich regions near branchpoints. The video is a 3D rendering of the image depicted in Fig. 1F (left panel), showing branching airways and blood vessels (BV) in the lung of a naïve mouse expressing CX3CR1-GFP (green) to visualize IMs, together with E-cadherinmCFP (blue) to visualize epithelial cells. Collagen (magenta) was visualized by second harmonic generation. The image was stitched from tiled images collected by two-photon microscopy of a precision-cut thick vibratome section. The video begins by showing the lumen of the airways with opacity rendering and then the image rotates to show CX3CR1-GFPbright IMs positioned underneath the airway epithelium. Finally, a zoomed in view of CX3CR1-GFPbright IMs in the collagen-rich region at the branchpoint is shown.

Video 3: CD11C-YFPbright DCs are positioned near the bronchial airway epithelium and are enriched at collagen-rich regions near branchpoints. The video is a 3D rendering of the image depicted in Fig. $1 \mathrm{H}$ (right panel), showing branching airways in the lung of a naïve mouse expressing CD11c-YFP (green) to visualize DCs, together with Shh-Cre and the Ai14 (tdTomato) reporter to show airway and alveolar epithelial cells (blue). Collagen (magenta) was visualized by second harmonic generation. The image was stitched from tiled images collected by two-photon microscopy of a precision-cut thick vibratome section.

Video 4: CD4 T cell interaction with a BAM (1). The video is a time-lapse image sequence corresponding to Fig. 6E, showing the interactions of an OVA-specific OT-II CD4 T cell (red) with a CX3CR1-GFPbright BAM (green) in the proximity of CD11c-YFPbright DCs (yellow). The OTII T cell was visualized by the expression of CD4-Cre and the Ai14 reporter leading to tdTomato expression. The image sequence is rendered from a $15 \mu \mathrm{m}$ z-stack, collected by two-photon microscopy of a cultured precision-cut vibratome section of the lung isolated $4 \mathrm{~h}$ after intranasal OVA challenge. Elapsed time is shown as hh:mm:ss.

Video 5: CD4 T cell interaction with a BAM (2). The video is a time-lapse image sequence corresponding to Fig. 6F, showing the interactions of an OVA-specific OT-II CD4 T cell (red) with a CX3CR1-GFPbright BAM (green) in the proximity of CD11c-YFPbright DCs (yellow). The OTII T cell was visualized by the expression of a $\beta$-actin-CFP transgene. The image sequence is rendered from a $22 \mu \mathrm{m} z$-stack, collected by two-photon microscopy of a cultured precision-cut vibratome section of the lung isolated $6 \mathrm{~h}$ after intranasal OVA challenge. Elapsed time is shown as hh:mm:ss.

Video 6: Different motility characteristics of BAMs vs DCs. The video is a time-lapse image sequence showing the dynamics of CX3CR1-GFPbright BAMs versus CD11c-YFPbright DCs in a collagen-rich region proximal to an airway. Collagen (blue) was visualized by second harmonic generation. The MIP represents a $27 \mu \mathrm{m}$ z-stack collected by two-photon microscopy of a precision-cut vibratome section of the lung of a naïve mouse. Elapsed time is shown as hh:mm:ss. 
Video 7: Some DCs enter lymphatics. The video is a time-lapse image sequence showing CD11c-YFPbright DCs (green) migrating within a Prox1-tdTomato+ lymphatic vessel (red). One DC can be seen that is entering the lymphatic vessel. Collagen (blue) was visualized by second harmonic generation. The image sequence was rendered from a $58 \mu \mathrm{m}$ z-stack collected by two-photon microscopy. The mouse was administered intranasal LPS $2 \mathrm{~h}$ before lung isolation, and then various precision-cut thick lung slices were imaged over a period of several hours prior to this recording. Elapsed time is shown as hh:mm:ss.

Video 8 BAMs do not enter lymphatics. The video is a time-lapse image sequence corresponding to Fig. 7H, right panel. CX3CR1-GFPbright BAMs can be observed proximal to a Prox1-tdTomato+ lymphatic vessel (red), but do not enter the lymphatic. Collagen (blue) was visualized by second harmonic generation. The image sequence was rendered from a $32 \mu \mathrm{m} z-$ stack collected by two-photon microscopy. The mouse was administered intranasal LPS $3.5 \mathrm{~h}$ before lung isolation and then various precision-cut lung slices were imaged over the next few hours prior to this recording. Elapsed time is shown as hh:mm:ss. 


\section{References}

Allen, CD, Ansel, KM, Low, C, Lesley, R, Tamamura, H, Fujii, N, and Cyster, JG. 2004. Germinal center dark and light zone organization is mediated by CXCR4 and CXCR5. Nat Immunol 5: 943-952. doi:10.1038/ni1100

Bacher, P, Heinrich, F, Stervbo, U, Nienen, M, Vahldieck, M, Iwert, C, Vogt, K, Kollet, J, Babel, N, Sawitzki, B, Schwarz, C, Bereswill, S, Heimesaat, MM, Heine, G, Gadermaier, G, Asam, C, Assenmacher, M, Kniemeyer, O, Brakhage, AA, Ferreira, F, et al. 2016. Regulatory T Cell Specificity Directs Tolerance versus Allergy against Aeroantigens in Humans. Cell 167: 1067-1078 e1016. doi:10.1016/j.cell.2016.09.050

Bang, BR, Chun, E, Shim, EJ, Lee, HS, Lee, SY, Cho, SH, Min, KU, Kim, YY, and Park, HW. 2011. Alveolar macrophages modulate allergic inflammation in a murine model of asthma. Exp Mol Med 43: 275-280. doi:10.3858/emm.2011.43.5.028

Barnden, MJ, Allison, J, Heath, WR, and Carbone, FR. 1998. Defective TCR expression in transgenic mice constructed using cDNA-based alpha- and beta-chain genes under the control of heterologous regulatory elements. Immunol Cell Biol 76: 34-40. doi:10.1046/j.1440-1711.1998.00709.x

Bedoret, D, Wallemacq, H, Marichal, T, Desmet, C, Quesada Calvo, F, Henry, E, Closset, R, Dewals, B, Thielen, C, Gustin, P, de Leval, L, Van Rooijen, N, Le Moine, A, Vanderplasschen, A, Cataldo, D, Drion, PV, Moser, M, Lekeux, P, and Bureau, F. 2009. Lung interstitial macrophages alter dendritic cell functions to prevent airway allergy in mice. J Clin Invest 119: 3723-3738. doi:10.1172/JCI39717

Benias, PC, Wells, RG, Sackey-Aboagye, B, Klavan, H, Reidy, J, Buonocore, D, Miranda, M, Kornacki, S, Wayne, M, Carr-Locke, DL, and Theise, ND. 2018. Structure and Distribution of an Unrecognized Interstitium in Human Tissues. Sci Rep 8: 4947. doi:10.1038/s41598-01823062-6

Bienenstock, J, and Befus, D. 1984. Gut- and bronchus-associated lymphoid tissue. Am J Anat 170: 437-445. doi:10.1002/aja.1001700316

Bienenstock, J, and McDermott, MR. 2005. Bronchus- and nasal-associated lymphoid tissues. Immunol Rev 206: 22-31. doi:10.1111/j.0105-2896.2005.00299.x

Boring, L, Gosling, J, Chensue, SW, Kunkel, SL, Farese, RV, Jr., Broxmeyer, HE, and Charo, IF. 1997. Impaired monocyte migration and reduced type 1 (Th1) cytokine responses in C-C chemokine receptor 2 knockout mice. J Clin Invest 100: 2552-2561. doi:10.1172/JCl119798

Carvalho, TC, Peters, JI, and Williams, RO, 3rd. 2011. Influence of particle size on regional lung deposition--what evidence is there? Int $J$ Pharm 406: 1-10. doi:10.1016/j.ijpharm.2010.12.040

Chakarov, S, Lim, HY, Tan, L, Lim, SY, See, P, Lum, J, Zhang, XM, Foo, S, Nakamizo, S, Duan, K, Kong, WT, Gentek, R, Balachander, A, Carbajo, D, Bleriot, C, Malleret, B, Tam, JKC, Baig, S, Shabeer, M, Toh, SES, et al. 2019. Two distinct interstitial macrophage populations coexist across tissues in specific subtissular niches. Science 363: eaau0964. doi:10.1126/science.aau0964

Chang, SY, Song, JH, Guleng, B, Cotoner, CA, Arihiro, S, Zhao, Y, Chiang, HS, O'Keeffe, M, Liao, G, Karp, CL, Kweon, MN, Sharpe, AH, Bhan, A, Terhorst, C, and Reinecker, HC. 2013. Circulatory antigen processing by mucosal dendritic cells controls CD8(+) T cell activation. Immunity 38: 153-165. doi:10.1016/j.immuni.2012.09.018

Cho, KW, Morris, DL, DelProposto, JL, Geletka, L, Zamarron, B, Martinez-Santibanez, G, Meyer, KA, Singer, K, O'Rourke, RW, and Lumeng, CN. 2014. An MHC II-dependent activation loop between adipose tissue macrophages and CD4+ T cells controls obesityinduced inflammation. Cell Rep 9: 605-617. doi:10.1016/j.celrep.2014.09.004

Clarke, SW, and Yeates, D. 1994. Deposition and Clearance. In Murray, JF, and Nadel, JA, editors. Textbook of Respiratory Medicine. W.B. Saunders Company, p345-369. 
Dahlgren, MW, and Molofsky, AB. 2019. Adventitial Cuffs: Regional Hubs for Tissue Immunity. Trends Immunol 40: 877-887. doi:10.1016/j.it.2019.08.002

Daubeuf, F, and Frossard, N. 2013. Acute Asthma Models to Ovalbumin in the Mouse. Curr Protoc Mouse Biol 3: 31-37. doi:10.1002/9780470942390.mo120202

del Rio, ML, Rodriguez-Barbosa, JI, Kremmer, E, and Forster, R. 2007. CD103- and CD103+ bronchial lymph node dendritic cells are specialized in presenting and cross-presenting innocuous antigen to CD4+ and CD8+ T cells. J Immunol 178: 6861-6866. doi:10.4049/jimmunol.178.11.6861

Demedts, IK, Brusselle, GG, Vermaelen, KY, and Pauwels, RA. 2005. Identification and characterization of human pulmonary dendritic cells. Am J Respir Cell Mol Biol 32: 177-184. doi:10.1165/rcmb.2004-02790C

Eisenbarth, SC, Piggott, DA, Huleatt, JW, Visintin, I, Herrick, CA, and Bottomly, K. 2002. Lipopolysaccharide-enhanced, toll-like receptor 4-dependent T helper cell type 2 responses to inhaled antigen. J Exp Med 196: 1645-1651. doi:10.1084/jem.20021340

Farache, J, Koren, I, Milo, I, Gurevich, I, Kim, KW, Zigmond, E, Furtado, GC, Lira, SA, and Shakhar, G. 2013. Luminal bacteria recruit CD103+ dendritic cells into the intestinal epithelium to sample bacterial antigens for presentation. Immunity 38: 581-595. doi:10.1016/j.immuni.2013.01.009

Fleige, $\mathrm{H}$, and Forster, R. 2017. Induction and Analysis of Bronchus-Associated Lymphoid Tissue. Methods Mol Biol 1559: 185-198. doi:10.1007/978-1-4939-6786-5_13

Gautier, EL, Shay, T, Miller, J, Greter, M, Jakubzick, C, Ivanov, S, Helft, J, Chow, A, Elpek, KG, Gordonov, S, Mazloom, AR, Ma'ayan, A, Chua, WJ, Hansen, TH, Turley, SJ, Merad, M, Randolph, GJ, and Immunological Genome, C. 2012. Gene-expression profiles and transcriptional regulatory pathways that underlie the identity and diversity of mouse tissue macrophages. Nat Immunol 13: 1118-1128. doi:10.1038/ni.2419

Geissmann, F, Jung, S, and Littman, DR. 2003. Blood monocytes consist of two principal subsets with distinct migratory properties. Immunity 19: 71-82. doi:10.1016/s10747613(03)00174-2

Gibbings, SL, Thomas, SM, Atif, SM, McCubbrey, AL, Desch, AN, Danhorn, T, Leach, SM, Bratton, DL, Henson, PM, Janssen, WJ, and Jakubzick, CV. 2017. Three Unique Interstitial Macrophages in the Murine Lung at Steady State. Am J Respir Cell Mol Biol 57: 66-76. doi:10.1165/rcmb.2016-03610C

Guilliams, M, Lambrecht, BN, and Hammad, H. 2013. Division of labor between lung dendritic cells and macrophages in the defense against pulmonary infections. Mucosal Immuno/ 6: 464-473. doi:10.1038/mi.2013.14

Hadis, U, Wahl, B, Schulz, O, Hardtke-Wolenski, M, Schippers, A, Wagner, N, Muller, W, Sparwasser, T, Forster, R, and Pabst, O. 2011. Intestinal tolerance requires gut homing and expansion of FoxP3+ regulatory T cells in the lamina propria. Immunity 34: 237-246. doi:10.1016/j.immuni.2011.01.016

Hadjantonakis, AK, Macmaster, S, and Nagy, A. 2002. Embryonic stem cells and mice expressing different GFP variants for multiple non-invasive reporter usage within a single animal. BMC Biotechnol 2: 11.

Hammad, H, Plantinga, M, Deswarte, K, Pouliot, P, Willart, MA, Kool, M, Muskens, F, and Lambrecht, BN. 2010. Inflammatory dendritic cells--not basophils--are necessary and sufficient for induction of Th2 immunity to inhaled house dust mite allergen. J Exp Med 207: 2097-2111. doi:10.1084/jem.20101563

Harfe, BD, Scherz, PJ, Nissim, S, Tian, H, McMahon, AP, and Tabin, CJ. 2004. Evidence for an expansion-based temporal Shh gradient in specifying vertebrate digit identities. Cell 118: 517-528. doi:10.1016/j.cell.2004.07.024

Hashimoto, D, Chow, A, Noizat, C, Teo, P, Beasley, MB, Leboeuf, M, Becker, CD, See, P, Price, J, Lucas, D, Greter, M, Mortha, A, Boyer, SW, Forsberg, EC, Tanaka, M, van Rooijen, 
N, Garcia-Sastre, A, Stanley, ER, Ginhoux, F, Frenette, PS, et al. 2013. Tissue-resident macrophages self-maintain locally throughout adult life with minimal contribution from circulating monocytes. Immunity 38: 792-804. doi:10.1016/j.immuni.2013.04.004

Haspeslagh, E, Debeuf, N, Hammad, H, and Lambrecht, BN. 2017. Murine Models of Allergic Asthma. Methods Mol Biol 1559: 121-136. doi:10.1007/978-1-4939-6786-5_10

Holgate, ST. 2012. Innate and adaptive immune responses in asthma. Nat Med 18: 673-683. doi:10.1038/nm.2731

Huh, JC, Strickland, DH, Jahnsen, FL, Turner, DJ, Thomas, JA, Napoli, S, Tobagus, I, Stumbles, PA, Sly, PD, and Holt, PG. 2003. Bidirectional interactions between antigenbearing respiratory tract dendritic cells (DCs) and T cells precede the late phase reaction in experimental asthma: DC activation occurs in the airway mucosa but not in the lung parenchyma. J Exp Med 198: 19-30. doi:10.1084/jem.20021328

Hume, DA. 2008. Macrophages as APC and the dendritic cell myth. $J$ Immunol 181: 5829-5835. doi:10.4049/jimmunol.181.9.5829

Jakubzick, C, Tacke, F, Ginhoux, F, Wagers, AJ, van Rooijen, N, Mack, M, Merad, M, and Randolph, GJ. 2008. Blood monocyte subsets differentially give rise to CD103+ and CD103pulmonary dendritic cell populations. J Immunol 180: 3019-3027. doi:10.4049/jimmunol.180.5.3019

Jeffery, PK. 1992. Histological features of the airways in asthma and COPD. Respiration 59 Suppl 1: 13-16. doi:10.1159/000196096

Jenkins, SJ, and Hume, DA. 2014. Homeostasis in the mononuclear phagocyte system. Trends Immuno/ 35: 358-367. doi:10.1016/j.it.2014.06.006

Jung, S, Aliberti, J, Graemmel, P, Sunshine, MJ, Kreutzberg, GW, Sher, A, and Littman, DR. 2000. Analysis of fractalkine receptor CX(3)CR1 function by targeted deletion and green fluorescent protein reporter gene insertion. Mol Cell Biol 20: 4106-4114. doi: $10.1128 / \mathrm{mcb} .20 .11 .4106-4114.2000$

Jung, S, Unutmaz, D, Wong, P, Sano, G, De los Santos, K, Sparwasser, T, Wu, S, Vuthoori, S, Ko, K, Zavala, F, Pamer, EG, Littman, DR, and Lang, RA. 2002. In vivo depletion of CD11C+ dendritic cells abrogates priming of CD8+ T cells by exogenous cell-associated antigens. Immunity 17: 211-220. doi:10.1016/s1074-7613(02)00365-5

Kamada, N, Hisamatsu, T, Honda, H, Kobayashi, T, Chinen, H, Kitazume, MT, Takayama, T, Okamoto, S, Koganei, K, Sugita, A, Kanai, T, and Hibi, T. 2009. Human CD14+ macrophages in intestinal lamina propria exhibit potent antigen-presenting ability. $J$ Immunol 183: 1724-1731. doi:10.4049/jimmunol.0804369

Kim, Y, Sung, S, Kuziel, WA, Feldman, S, Fu, SM, and Rose, CE, Jr. 2001. Enhanced airway Th2 response after allergen challenge in mice deficient in CC chemokine receptor-2 (CCR2). J Immunol 166: 5183-5192. doi:10.4049/jimmunol.166.8.5183

Kohl, J, Baelder, R, Lewkowich, IP, Pandey, MK, Hawlisch, H, Wang, L, Best, J, Herman, NS, Sproles, AA, Zwirner, J, Whitsett, JA, Gerard, C, Sfyroera, G, Lambris, JD, and Wills-Karp, M. 2006. A regulatory role for the C5a anaphylatoxin in type 2 immunity in asthma. J Clin Invest 116: 783-796. doi:10.1172/jci26582

Lambrecht, BN, Hammad, H, and Fahy, JV. 2019. The Cytokines of Asthma. Immunity 50: 975991. doi:10.1016/j.immuni.2019.03.018

Lambrecht, BN, Salomon, B, Klatzmann, D, and Pauwels, RA. 1998. Dendritic cells are required for the development of chronic eosinophilic airway inflammation in response to inhaled antigen in sensitized mice. J Immunol 160: 4090-4097.

Lindquist, RL, Shakhar, G, Dudziak, D, Wardemann, H, Eisenreich, T, Dustin, ML, and Nussenzweig, MC. 2004. Visualizing dendritic cell networks in vivo. Nat Immunol 5: 12431250. doi:10.1038/ni1139

Madisen, L, Zwingman, TA, Sunkin, SM, Oh, SW, Zariwala, HA, Gu, H, Ng, LL, Palmiter, RD, Hawrylycz, MJ, Jones, AR, Lein, ES, and Zeng, H. 2010. A robust and high-throughput Cre 
reporting and characterization system for the whole mouse brain. Nat Neurosci 13: 133-140. doi:10.1038/nn.2467

Mathias, LJ, Khong, SM, Spyroglou, L, Payne, NL, Siatskas, C, Thorburn, AN, Boyd, RL, and Heng, TS. 2013. Alveolar macrophages are critical for the inhibition of allergic asthma by mesenchymal stromal cells. J Immunol 191: 5914-5924. doi:10.4049/jimmunol.1300667

Mazzini, E, Massimiliano, L, Penna, G, and Rescigno, M. 2014. Oral tolerance can be established via gap junction transfer of fed antigens from CX3CR1(+) macrophages to CD103(+) dendritic cells. Immunity 40: 248-261. doi:10.1016/j.immuni.2013.12.012

McDole, JR, Wheeler, LW, McDonald, KG, Wang, B, Konjufca, V, Knoop, KA, Newberry, RD, and Miller, MJ. 2012. Goblet cells deliver luminal antigen to CD103+ dendritic cells in the small intestine. Nature 483: 345-349. doi:10.1038/nature10863

Mempel, TR, Henrickson, SE, and Von Andrian, UH. 2004. T-cell priming by dendritic cells in lymph nodes occurs in three distinct phases. Nature 427: 154-159. doi:10.1038/nature02238

Meredith, MM, Liu, K, Darrasse-Jeze, G, Kamphorst, AO, Schreiber, HA, Guermonprez, P, Idoyaga, J, Cheong, C, Yao, KH, Niec, RE, and Nussenzweig, MC. 2012. Expression of the zinc finger transcription factor zDC (Zbtb46, Btbd4) defines the classical dendritic cell lineage. J Exp Med 209: 1153-1165. doi:10.1084/jem.20112675

Metzger, RJ, Klein, OD, Martin, GR, and Krasnow, MA. 2008. The branching programme of mouse lung development. Nature 453: 745-750. doi:10.1038/nature07005

Miyake, Y, Asano, K, Kaise, H, Uemura, M, Nakayama, M, and Tanaka, M. 2007. Critical role of macrophages in the marginal zone in the suppression of immune responses to apoptotic cell-associated antigens. J Clin Invest 117: 2268-2278. doi:10.1172/JCI31990

Murphy, DB, Rath, S, Pizzo, E, Rudensky, AY, George, A, Larson, JK, and Janeway, CA, Jr. 1992. Monoclonal antibody detection of a major self peptide. MHC class II complex. $J$ Immunol 148: 3483-3491.

Muzumdar, MD, Tasic, B, Miyamichi, K, Li, L, and Luo, L. 2007. A global double-fluorescent Cre reporter mouse. Genesis 45: 593-605. doi:10.1002/dvg.20335

Patton, JS. 1992. Mechanisms of macromolecule absorption by the lungs. Adv Drug Deliv Rev 19: 3-36. doi:10.1016/0169-409X(95)00113-L

Plantinga, M, Guilliams, M, Vanheerswynghels, M, Deswarte, K, Branco-Madeira, F, Toussaint, W, Vanhoutte, L, Neyt, K, Killeen, N, Malissen, B, Hammad, H, and Lambrecht, BN. 2013. Conventional and monocyte-derived $\mathrm{CD} 11 \mathrm{~b}(+)$ dendritic cells initiate and maintain $\mathrm{T}$ helper 2 cell-mediated immunity to house dust mite allergen. Immunity 38: 322-335. doi:10.1016/j.immuni.2012.10.016

Purnama, C, Ng, SL, Tetlak, P, Setiagani, YA, Kandasamy, M, Baalasubramanian, S, Karjalainen, K, and Ruedl, C. 2014. Transient ablation of alveolar macrophages leads to massive pathology of influenza infection without affecting cellular adaptive immunity. Eur $J$ Immuno/ 44: 2003-2012. doi:10.1002/eji.201344359

Randall, TD. 2010. Bronchus-associated lymphoid tissue (BALT) structure and function. Adv Immunol 107: 187-241. doi:10.1016/B978-0-12-381300-8.00007-1

Rodero, MP, Poupel, L, Loyher, PL, Hamon, P, Licata, F, Pessel, C, Hume, DA, Combadiere, C, and Boissonnas, A. 2015. Immune surveillance of the lung by migrating tissue monocytes. Elife 4: e07847. doi:10.7554/eLife.07847

Roozendaal, R, Mempel, TR, Pitcher, LA, Gonzalez, SF, Verschoor, A, Mebius, RE, von Andrian, UH, and Carroll, MC. 2009. Conduits mediate transport of low-molecular-weight antigen to lymph node follicles. Immunity 30: 264-276. doi:10.1016/j.immuni.2008.12.014 Sabatel, C, Radermecker, C, Fievez, L, Paulissen, G, Chakarov, S, Fernandes, C, Olivier, S, Toussaint, M, Pirottin, D, Xiao, X, Quatresooz, P, Sirard, JC, Cataldo, D, Gillet, L, Bouabe, H, Desmet, CJ, Ginhoux, F, Marichal, T, and Bureau, F. 2017. Exposure to Bacterial CpG DNA Protects from Airway Allergic Inflammation by Expanding Regulatory Lung Interstitial Macrophages. Immunity 46: 457-473. doi:10.1016/j.immuni.2017.02.016 
Sasmono, RT, Oceandy, D, Pollard, JW, Tong, W, Pavli, P, Wainwright, BJ, Ostrowski, MC, Himes, SR, and Hume, DA. 2003. A macrophage colony-stimulating factor receptor-green fluorescent protein transgene is expressed throughout the mononuclear phagocyte system of the mouse. Blood 101: 1155-1163. doi:10.1182/blood-2002-02-1569

Satpathy, AT, Kc, W, Albring, JC, Edelson, BT, Kretzer, NM, Bhattacharya, D, Murphy, TL, and Murphy, KM. 2012. Zbtb46 expression distinguishes classical dendritic cells and their committed progenitors from other immune lineages. J Exp Med 209: 1135-1152. doi:10.1084/jem.20120030

Schlitzer, A, McGovern, N, Teo, P, Zelante, T, Atarashi, K, Low, D, Ho, AW, See, P, Shin, A, Wasan, PS, Hoeffel, G, Malleret, B, Heiseke, A, Chew, S, Jardine, L, Purvis, HA, Hilkens, CM, Tam, J, Poidinger, M, Stanley, ER, et al. 2013. IRF4 transcription factor-dependent CD11b+ dendritic cells in human and mouse control mucosal IL-17 cytokine responses. Immunity 38: 970-983. doi:10.1016/j.immuni.2013.04.011

Schreiber, HA, Loschko, J, Karssemeijer, RA, Escolano, A, Meredith, MM, Mucida, D, Guermonprez, P, and Nussenzweig, MC. 2013. Intestinal monocytes and macrophages are required for T cell polarization in response to Citrobacter rodentium. $J$ Exp Med 210: 20252039. doi:10.1084/jem.20130903

Schulz, O, Jaensson, E, Persson, EK, Liu, X, Worbs, T, Agace, WW, and Pabst, O. 2009. Intestinal CD103+, but not CX3CR1+, antigen sampling cells migrate in lymph and serve classical dendritic cell functions. J Exp Med 206: 3101-3114. doi:10.1084/jem.20091925

Schyns, J, Bai, Q, Ruscitti, C, Radermecker, C, De Schepper, S, Chakarov, S, Farnir, F, Pirottin, D, Ginhoux, F, Boeckxstaens, G, Bureau, F, and Marichal, T. 2019. Non-classical tissue monocytes and two functionally distinct populations of interstitial macrophages populate the mouse lung. Nat Commun 10: 3964. doi:10.1038/s41467-019-11843-0

Sen, D, Jones, SM, Oswald, EM, Pinkard, H, Corbin, K, and Krummel, MF. 2016. Tracking the Spatial and Functional Gradient of Monocyte-To-Macrophage Differentiation in Inflamed Lung. PLoS One 11: e0165064. doi:10.1371/journal.pone.0165064

Shaw, MH, Kamada, N, Kim, YG, and Nunez, G. 2012. Microbiota-induced IL-1beta, but not IL6 , is critical for the development of steady-state TH17 cells in the intestine. J Exp Med 209: 251-258. doi:10.1084/jem.20111703

Snippert, HJ, van der Flier, LG, Sato, T, van Es, JH, van den Born, M, Kroon-Veenboer, C, Barker, N, Klein, AM, van Rheenen, J, Simons, BD, and Clevers, H. 2010. Intestinal crypt homeostasis results from neutral competition between symmetrically dividing Lgr5 stem cells. Cell 143: 134-144. doi:10.1016/j.cell.2010.09.016

Stamatiades, EG, Tremblay, ME, Bohm, M, Crozet, L, Bisht, K, Kao, D, Coelho, C, Fan, X, Yewdell, WT, Davidson, A, Heeger, PS, Diebold, S, Nimmerjahn, F, and Geissmann, F. 2016. Immune Monitoring of Trans-endothelial Transport by Kidney-Resident Macrophages. Cell 166: 991-1003. doi:10.1016/j.cell.2016.06.058

Sullivan, BM, Liang, HE, Bando, JK, Wu, D, Cheng, LE, McKerrow, JK, Allen, CD, and Locksley, RM. 2011. Genetic analysis of basophil function in vivo. Nat Immunol 12: 527-535. doi:10.1038/ni.2036

Tan, SY, and Krasnow, MA. 2016. Developmental origin of lung macrophage diversity. Development 143: 1318-1327. doi:10.1242/dev.129122

Tang, C, Inman, MD, van Rooijen, N, Yang, P, Shen, H, Matsumoto, K, and O'Byrne, PM. 2001. Th type 1-stimulating activity of lung macrophages inhibits Th2-mediated allergic airway inflammation by an IFN-gamma-dependent mechanism. J Immunol 166: 1471-1481. doi:10.4049/jimmunol.166.3.1471

Tang, XZ, Jung, JB, and Allen, CDC. 2019. A case of mistaken identity: The MAR-1 antibody to mouse FceRla cross-reacts with FcyRI and FcyRIV. J Allergy Clin Immunol 143: 16431646.e1646. doi:10.1016/j.jaci.2018.11.045 
Thornton, EE, Looney, MR, Bose, O, Sen, D, Sheppard, D, Locksley, R, Huang, X, and Krummel, MF. 2012. Spatiotemporally separated antigen uptake by alveolar dendritic cells and airway presentation to T cells in the lung. J Exp Med 209: 1183-1199. doi:10.1084/jem.20112667

Townsley, MI. 2012. Structure and composition of pulmonary arteries, capillaries, and veins. Compr Physiol 2: 675-709. doi:10.1002/cphy.c100081

Truman, LA, Bentley, KL, Smith, EC, Massaro, SA, Gonzalez, DG, Haberman, AM, Hill, M, Jones, D, Min, W, Krause, DS, and Ruddle, NH. 2012. ProxTom lymphatic vessel reporter mice reveal Prox1 expression in the adrenal medulla, megakaryocytes, and platelets. Am J Pathol 180: 1715-1725. doi:10.1016/j.ajpath.2011.12.026

Ural, BB, Yeung, ST, Damani-Yokota, P, Devlin, JC, de Vries, M, Vera-Licona, P, Samji, T, Sawai, CM, Jang, G, Perez, OA, Pham, Q, Maher, L, Loke, P, Dittmann, M, Reizis, B, and Khanna, KM. 2020. Identification of a nerve-associated, lung-resident interstitial macrophage subset with distinct localization and immunoregulatory properties. Sci Immunol 5: eaax8756. doi:10.1126/sciimmunol.aax8756

van Rijt, LS, Jung, S, Kleinjan, A, Vos, N, Willart, M, Duez, C, Hoogsteden, HC, and Lambrecht, BN. 2005. In vivo depletion of lung CD11C+ dendritic cells during allergen challenge abrogates the characteristic features of asthma. J Exp Med 201: 981-991. doi:10.1084/jem.20042311

Veres, TZ, Voedisch, S, Spies, E, Tschernig, T, and Braun, A. 2011. Spatiotemporal and functional behavior of airway dendritic cells visualized by two-photon microscopy. Am J Pathol 179: 603-609. doi:10.1016/j.ajpath.2011.04.039

von Garnier, C, Wikstrom, ME, Zosky, G, Turner, DJ, Sly, PD, Smith, M, Thomas, JA, Judd, SR, Strickland, DH, Holt, PG, and Stumbles, PA. 2007. Allergic airways disease develops after an increase in allergen capture and processing in the airway mucosa. J Immunol 179: 57485759. doi:10.4049/jimmunol.179.9.5748

Wikstrom, ME, and Stumbles, PA. 2007. Mouse respiratory tract dendritic cell subsets and the immunological fate of inhaled antigens. Immunol Cell Biol 85: 182-188. doi:10.1038/sj.icb.7100039

Yang, Z, Jung, JB, and Allen, CDC. 2018. Study of IgE-Producing B Cells Using the Verigem Fluorescent Reporter Mouse. Methods Mol Biol 1799: 247-264. doi:10.1007/978-1-49397896-0_19

Yang, Z, Sullivan, BM, and Allen, CD. 2012. Fluorescent in vivo detection reveals that $\lg E(+) B$ cells are restrained by an intrinsic cell fate predisposition. Immunity 36: 857-872. doi:10.1016/j.immuni.2012.02.009

Zaslona, Z, Przybranowski, S, Wilke, C, van Rooijen, N, Teitz-Tennenbaum, S, Osterholzer, JJ, Wilkinson, JE, Moore, BB, and Peters-Golden, M. 2014. Resident alveolar macrophages suppress, whereas recruited monocytes promote, allergic lung inflammation in murine models of asthma. J Immunol 193: 4245-4253. doi:10.4049/jimmunol.1400580 
bioRxiv preprint doi: https://doi.org/10.1101/2020.09.18.247742; this version posted September 19, 2020. The copyright holder for this preprint

(which was not certified by peer review) is the author/funder, who has granted bioRxiv a license to display the preprint in perpetuity. It is made available under aCC-BY-NC-ND 4.0 International license.

\section{Figure 1}
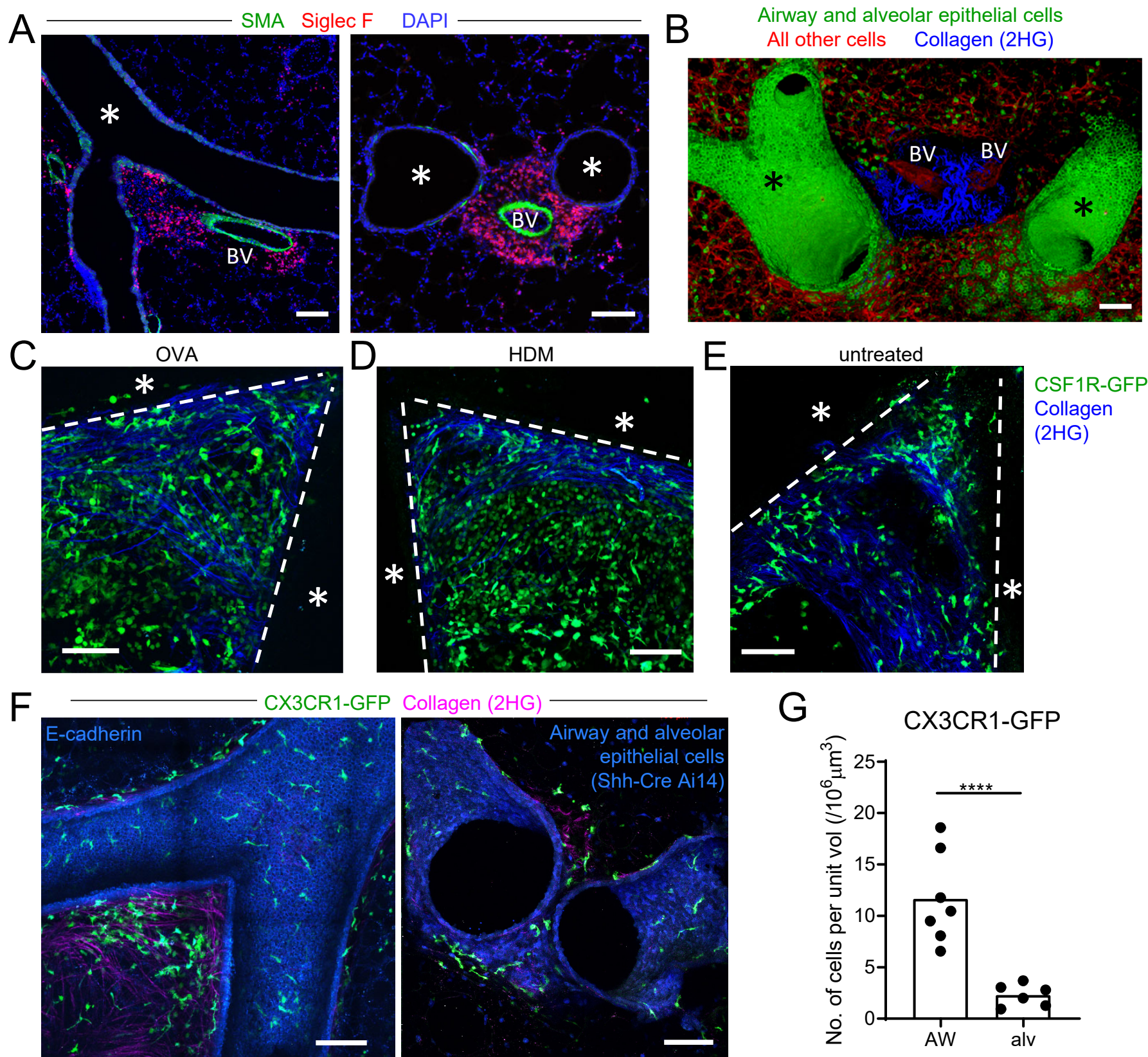

F


$\mathrm{H}$
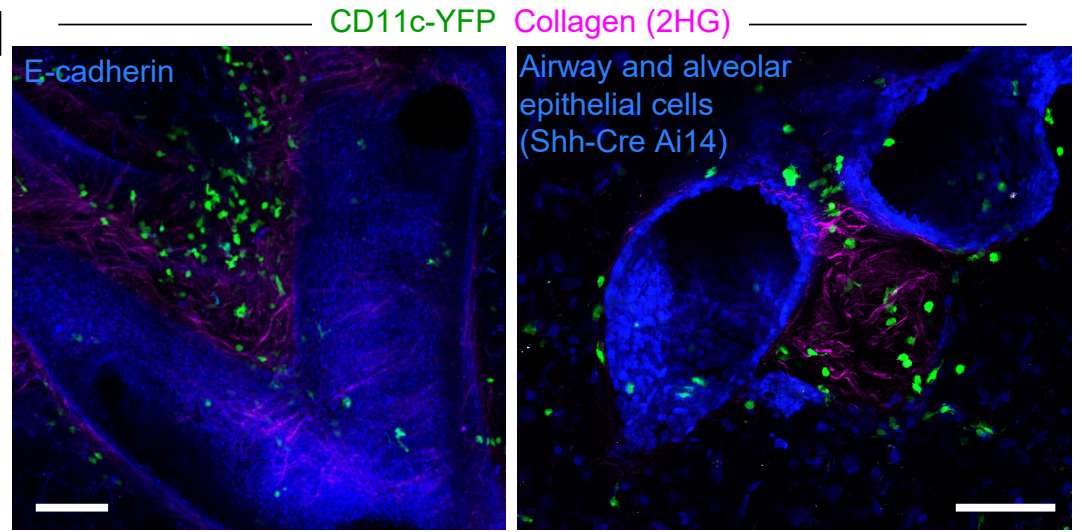

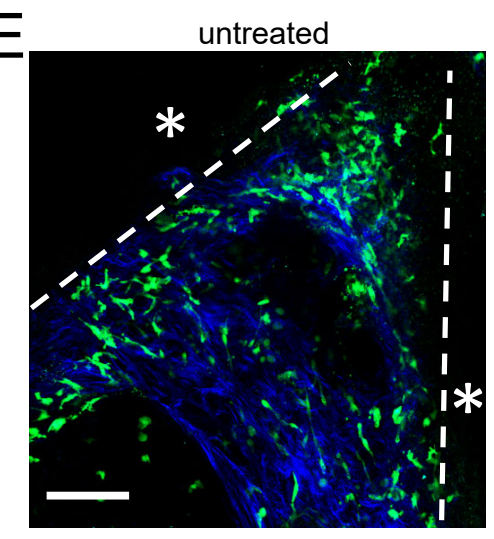

G
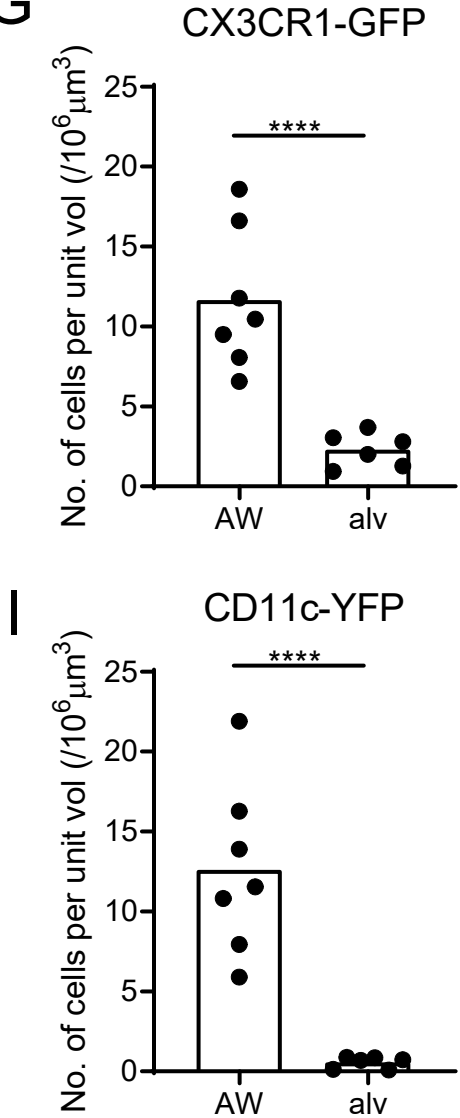
bioRxiv preprint doi: https://doi.org/10.1101/2020.09.18.247742; this version posted September 19, 2020. The copyright holder for this preprint

(which was not certified by peer review) is the author/funder, who has granted bioRxiv a license to display the preprint in perpetuity. It is made available under aCC-BY-NC-ND 4.0 International license.

\section{Figure 2}
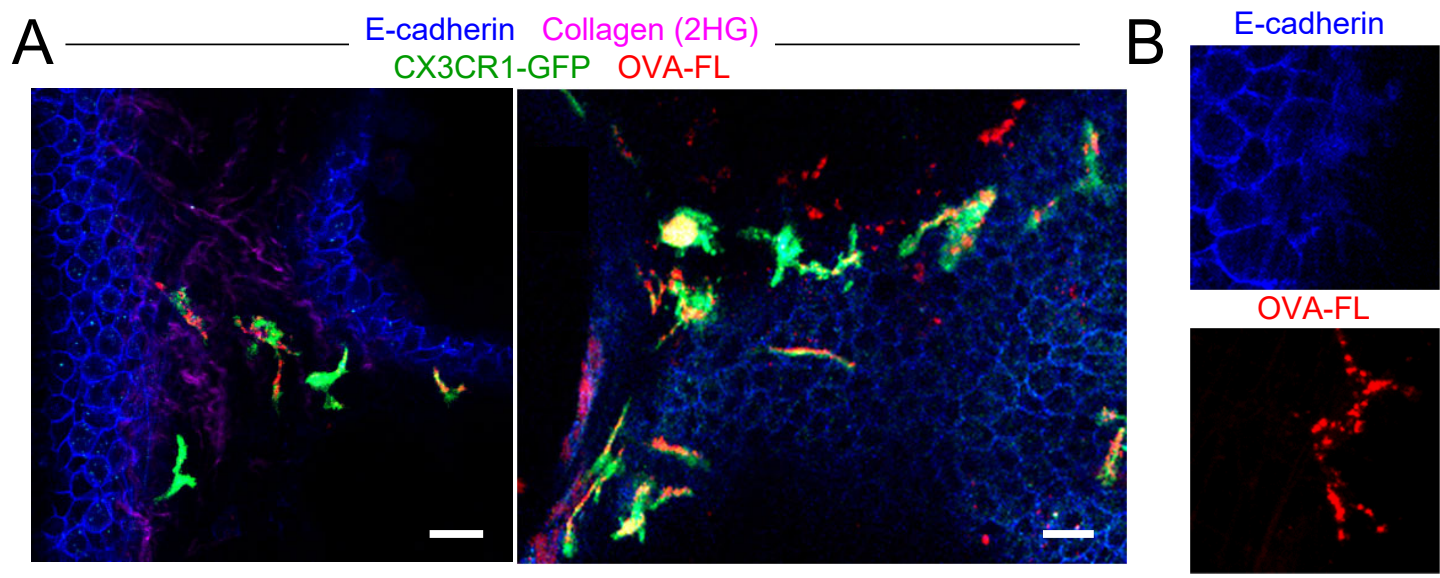

OVA-FL

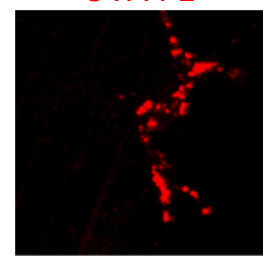

CX3CR1-GFP

D

C CD11C-YFP

OVA-FL

E-cadherin


OVA-FL

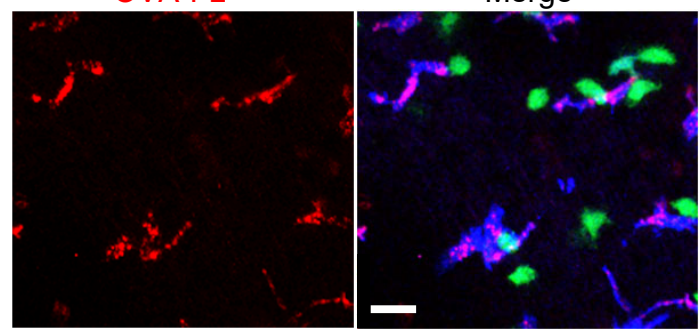

$E$

CX3CR1-GFP HDM-FL CD11C-YFP E-cadherin
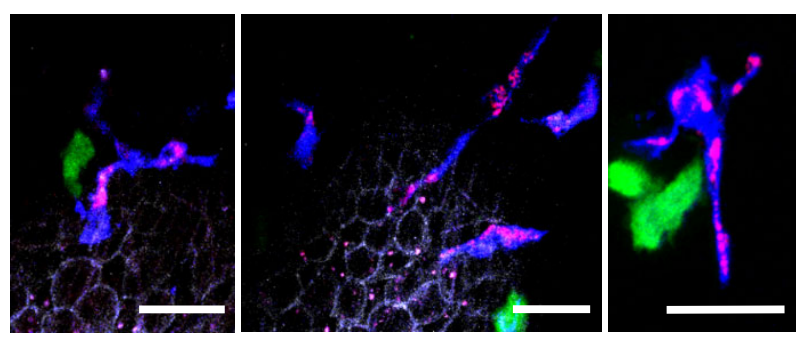

$\mathrm{F}$
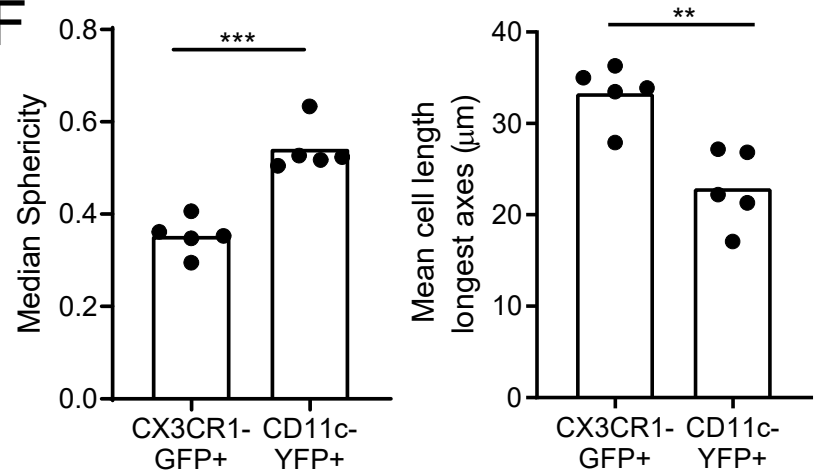

G

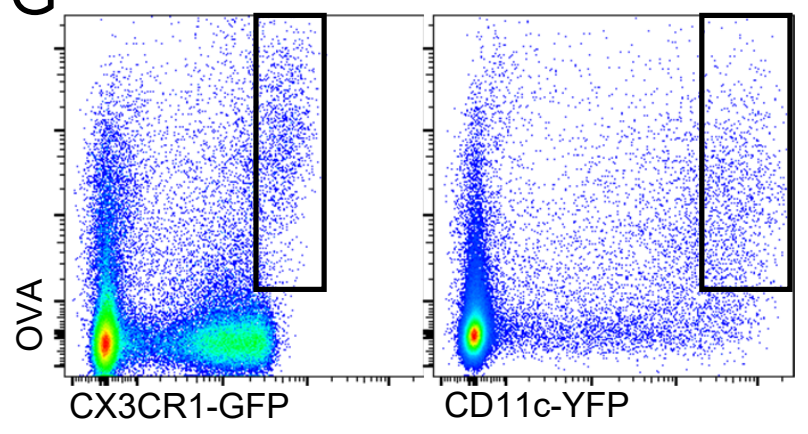

$\mathrm{H}$

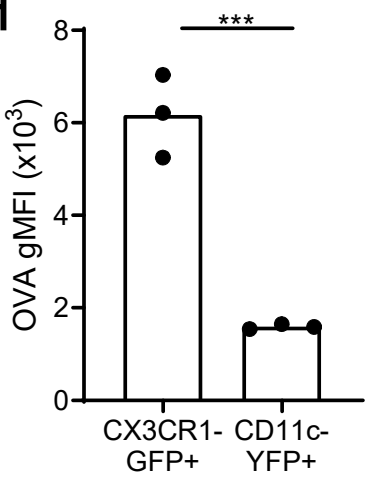

CX3CR1-GFP

Merge

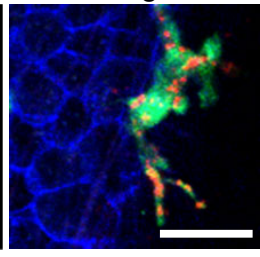

CD11C-YFP

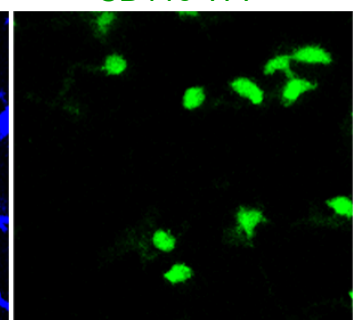

Merge

GFP+ YFP+

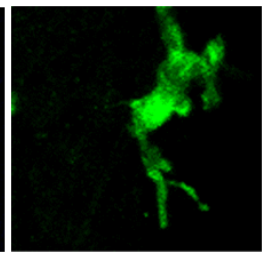


bioRxiv preprint doi: https://doi.org/10.1101/2020.09.18.247742; this version posted September 19, 2020. The copyright holder for this preprint (which was not certified by peer review) is the author/funder, who has granted bioRxiv a license to display the preprint in perpetuity. It is made available under aCC-BY-NC-ND 4.0 International license.

\section{Figure 3}

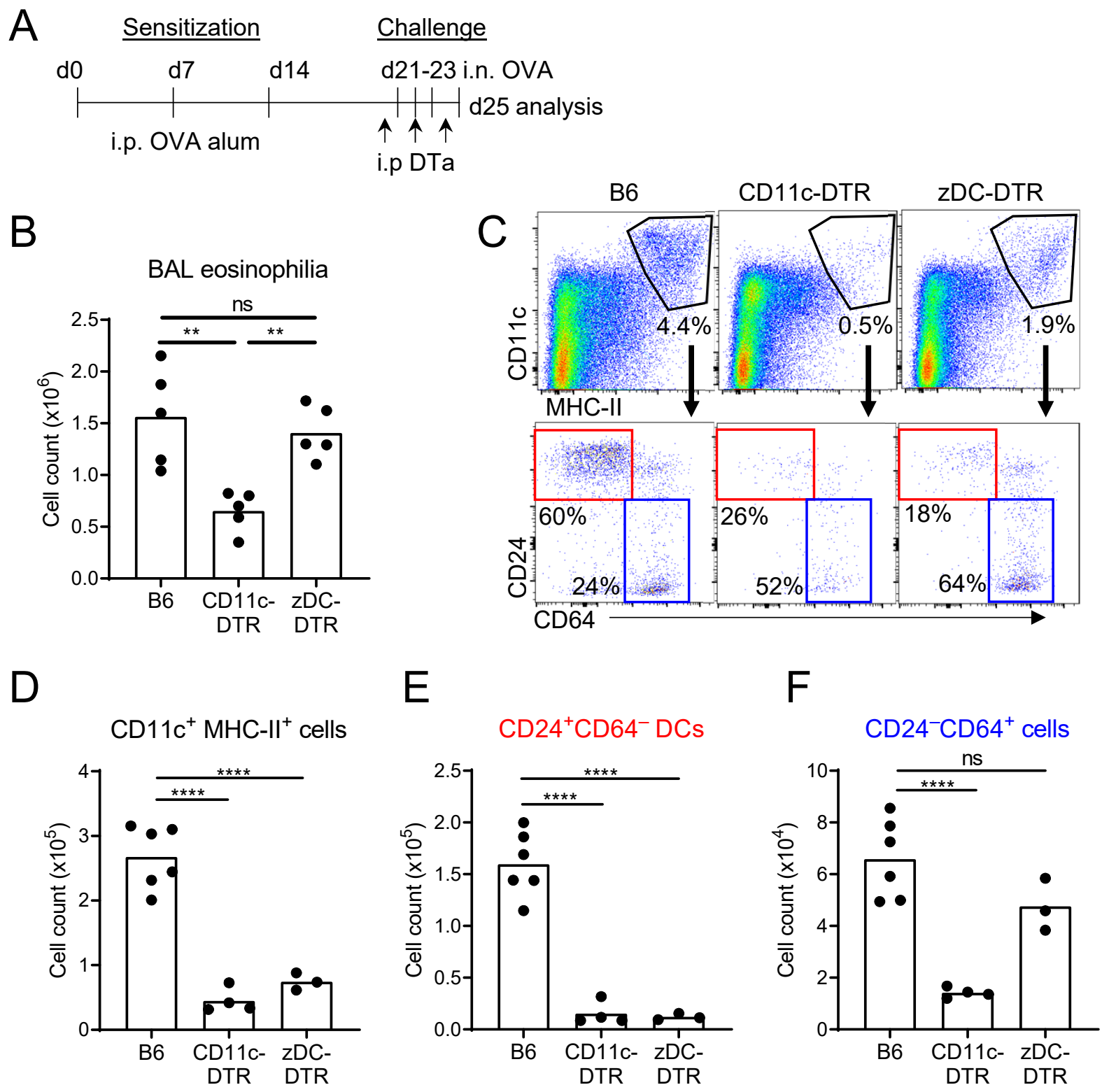


bioRxiv preprint doi: https://doi.org/10.1101/2020.09.18.247742; this version posted September 19, 2020. The copyright holder for this preprint

(which was not certified by peer review) is the author/funder, who has granted bioRxiv a license to display the preprint in perpetuity. It is made available under aCC-BY-NC-ND 4.0 International license.

\section{Figure 4}

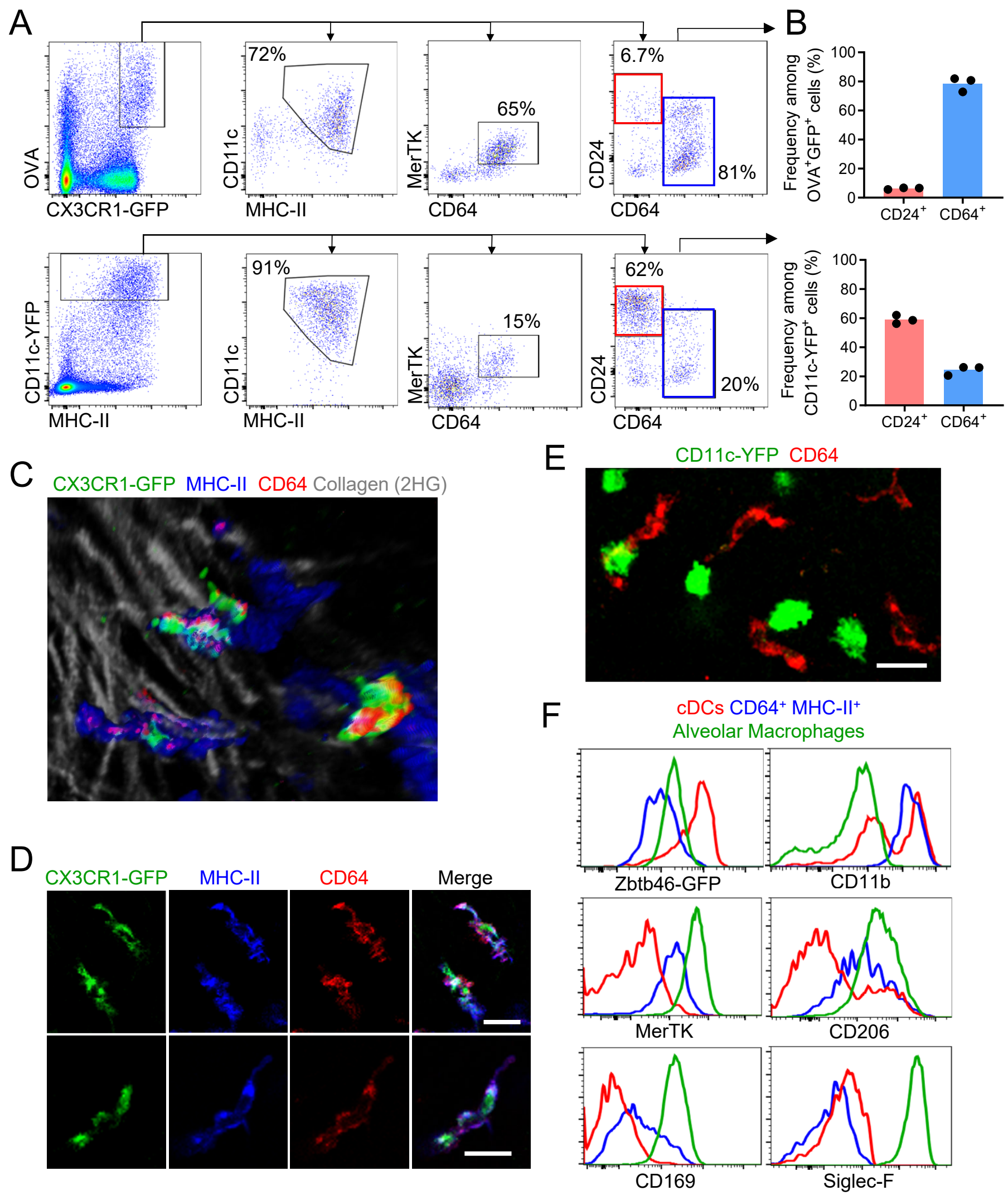


bioRxiv preprint doi: https://doi.org/10.1101/2020.09.18.247742; this version posted September 19, 2020. The copyright holder for this preprint

(which was not certified by peer review) is the author/funder, who has granted bioRxiv a license to display the preprint in perpetuity. It is made available under aCC-BY-NC-ND 4.0 International license.

\section{Figure 5}

A

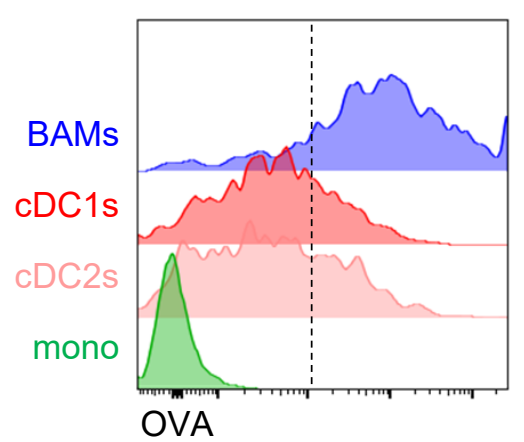

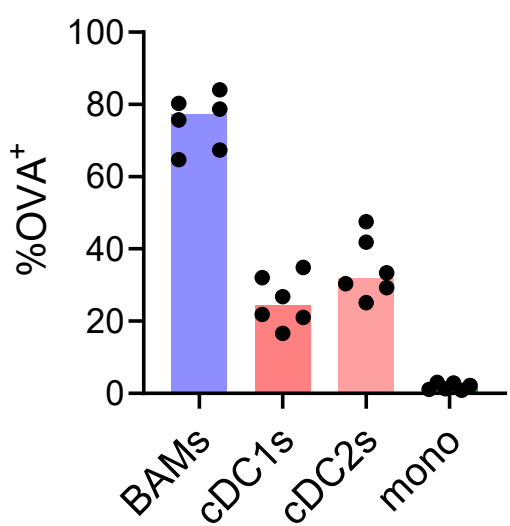

B TRITC-DX $10 \mathrm{kDa}$ C TRITC-DX $155 \mathrm{kDa}$ D PE $240 \mathrm{kDa}$
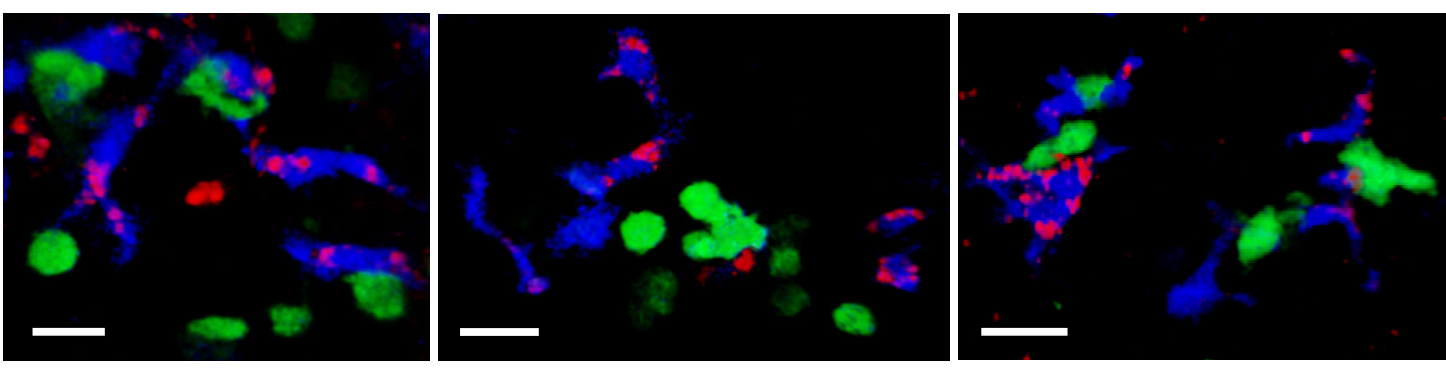

CX3CR1-GFP

CD11C-YFP

Antigen

E

BAMs
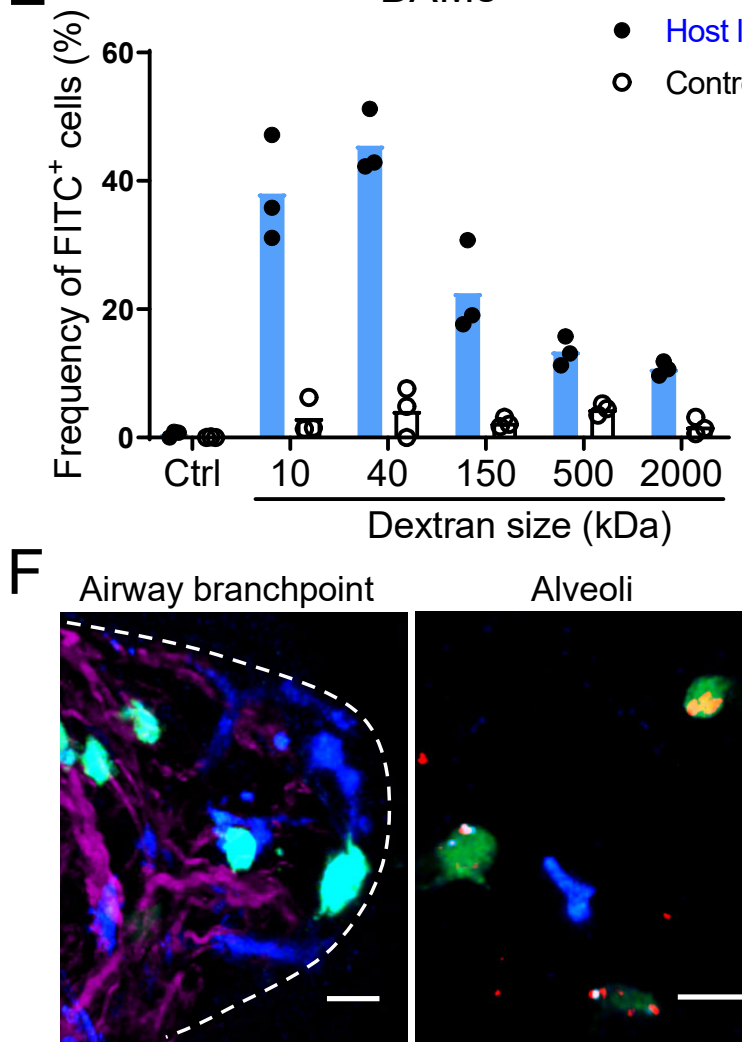

Alveoli

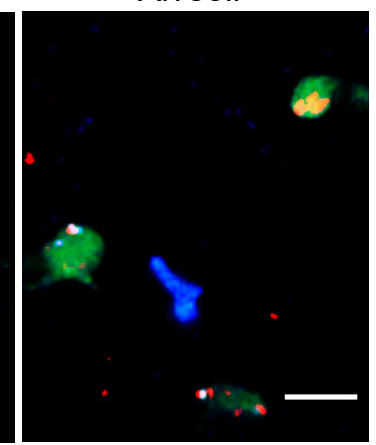

CX3CR1-GFP

CX3CR1-GFP

CD11C-YFP

Beads

CD11C-YFP

Collagen

Beads

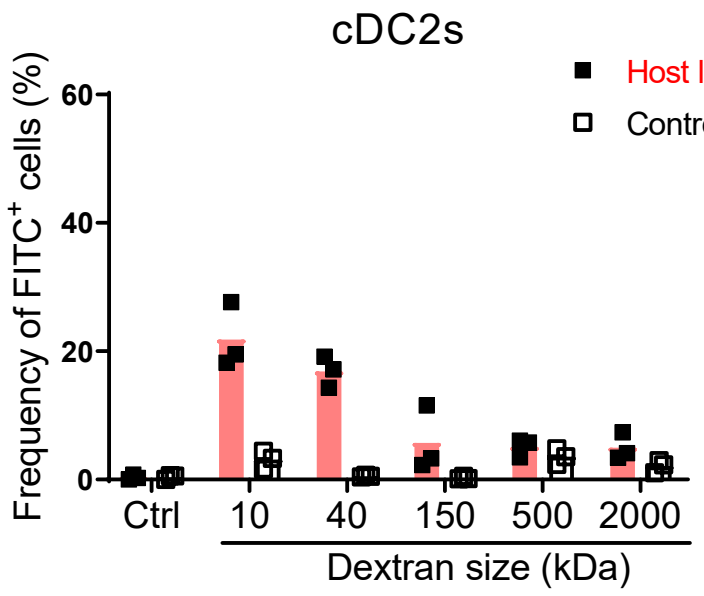


bioRxiv preprint doi: https://doi.org/10.1101/2020.09.18.247742; this version posted September 19, 2020. The copyright holder for this preprint (which was not certified by peer review) is the author/funder, who has granted bioRxiv a license to display the preprint in perpetuity. It is made available under aCC-BY-NC-ND 4.0 International license.

\section{Figure 6}

A

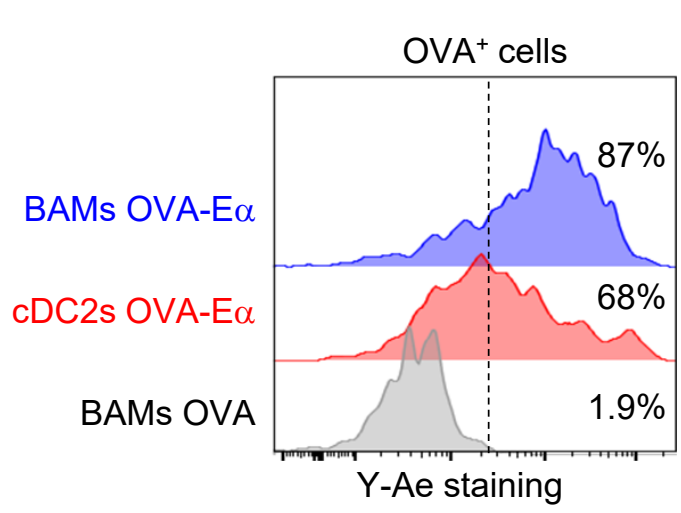

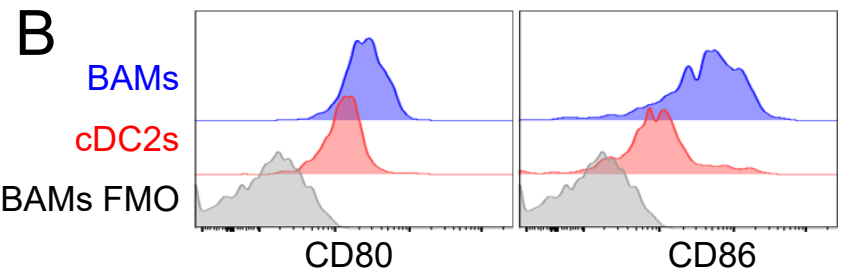

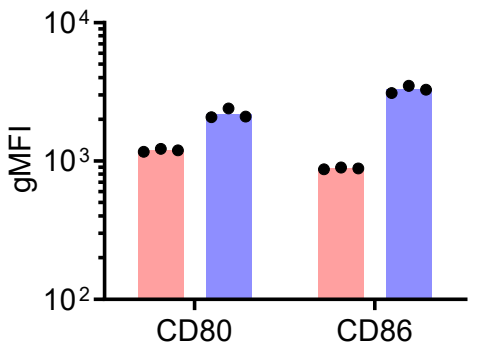

cDC2s

BAMs


No peptide

OVA peptide

IL-13

E
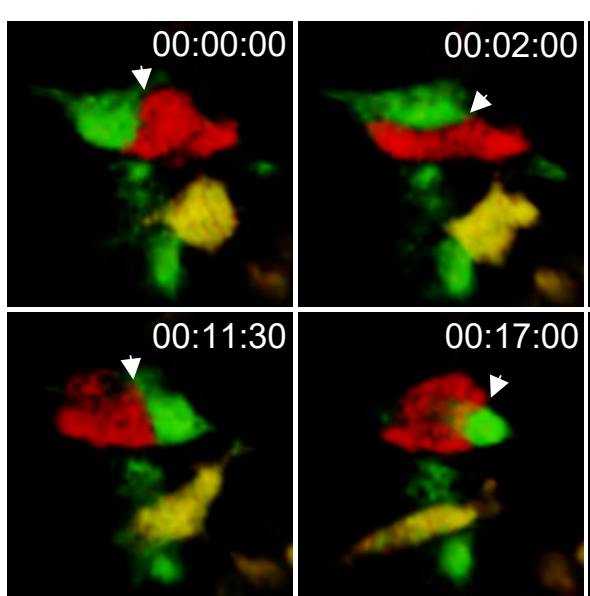

$F$
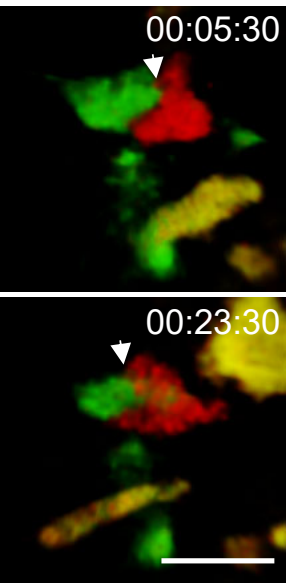
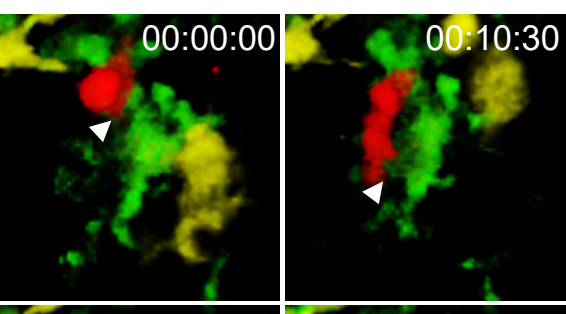

CX3CR1-GFP

CD11C-YFP

OT-II T cell
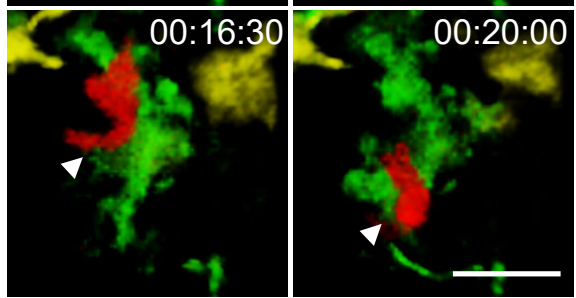
bioRxiv preprint doi: https://doi.org/10.1101/2020.09.18.247742; this version posted September 19, 2020. The copyright holder for this preprint

(which was not certified by peer review) is the author/funder, who has granted bioRxiv a license to display the preprint in perpetuity. It is made available under aCC-BY-NC-ND 4.0 International license.

\section{Figure 7}

\section{Lung}
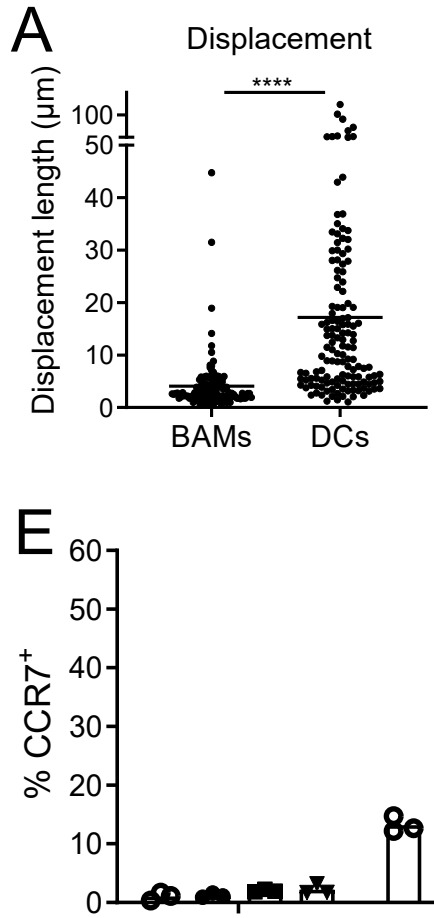

BAMs

G



B Mean Displacement

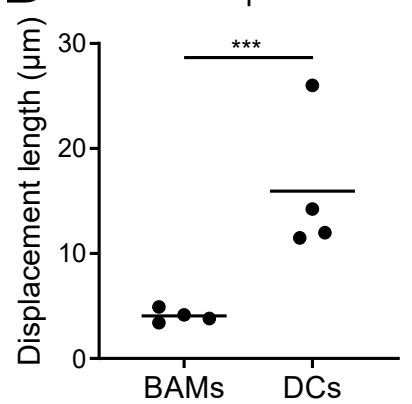

C Mean Track Speed

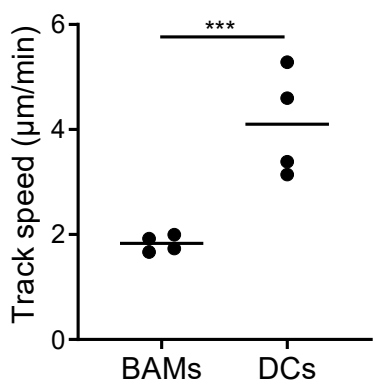

Naïve



$\mathrm{H}$
D Mean Track Length

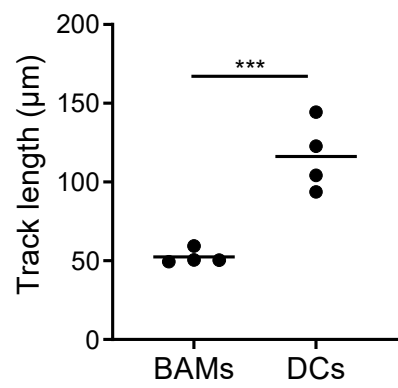

HDM

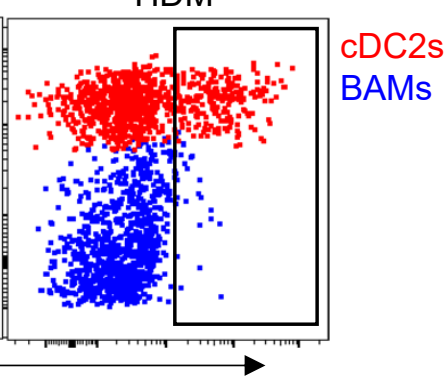

Prox1 (lymphatic vessels)
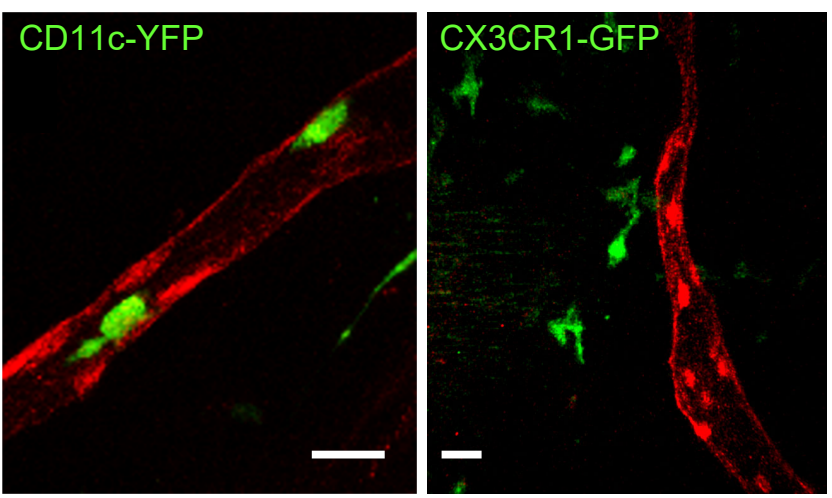

\section{Lymph Node}

bioRxiv preprint doi: https://doi.org/10.1101/2020.09.18.247742; this version posted September 19, 2020. The copyright holder for this preprint (which was not certified by peer review) is the author/funder, who has granted bioRxiv a license to display the preprint in perpetuity. It is made available under aCC-BY-NC-ND 4.0 International license.

\section{Supplementary Figure 1}

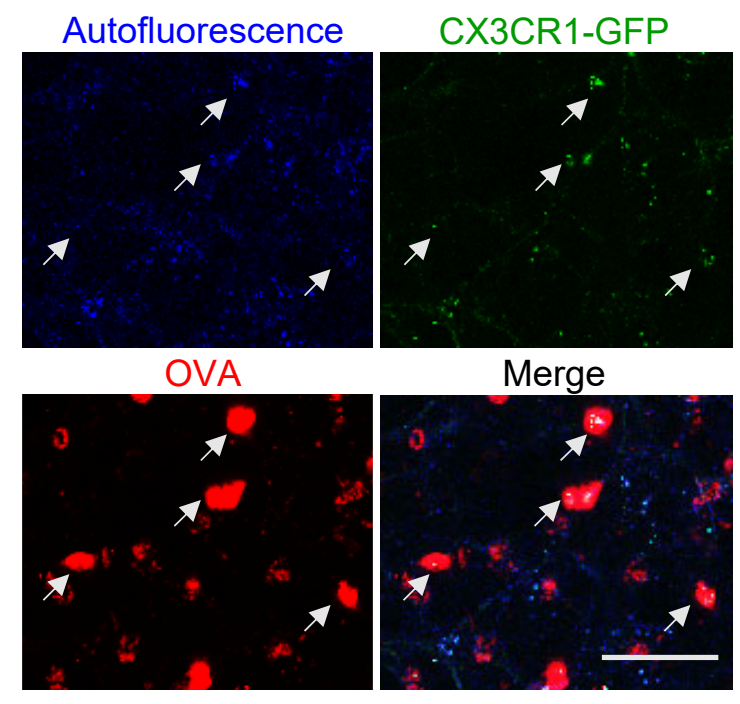


bioRxiv preprint doi: https://doi.org/10.1101/2020.09.18.247742; this version posted September 19, 2020. The copyright holder for this preprint (which was not certified by peer review) is the author/funder, who has granted bioRxiv a license to display the preprint in perpetuity. It is made available under aCC-BY-NC-ND 4.0 International license.

\section{Supplementary Figure 2}

A

Merged

CX3CR1-GFP CD11c-YFP

CX3CR1-GFP
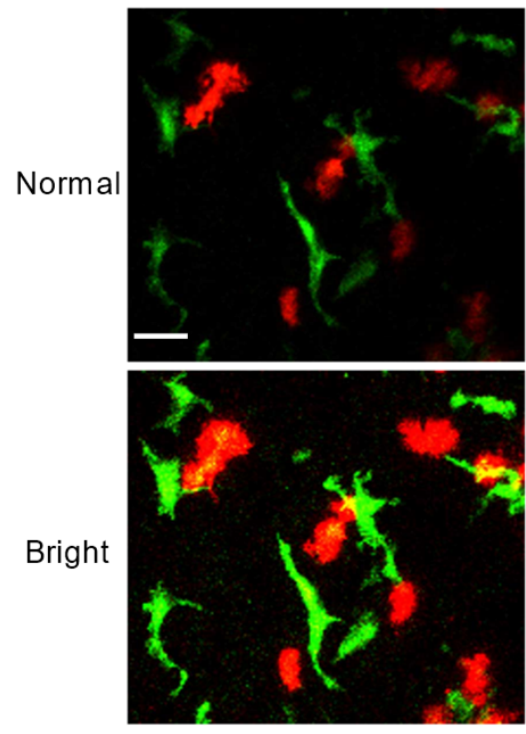

E-cadherin-CFP

B

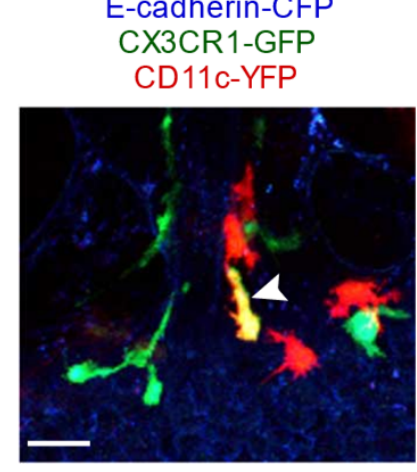


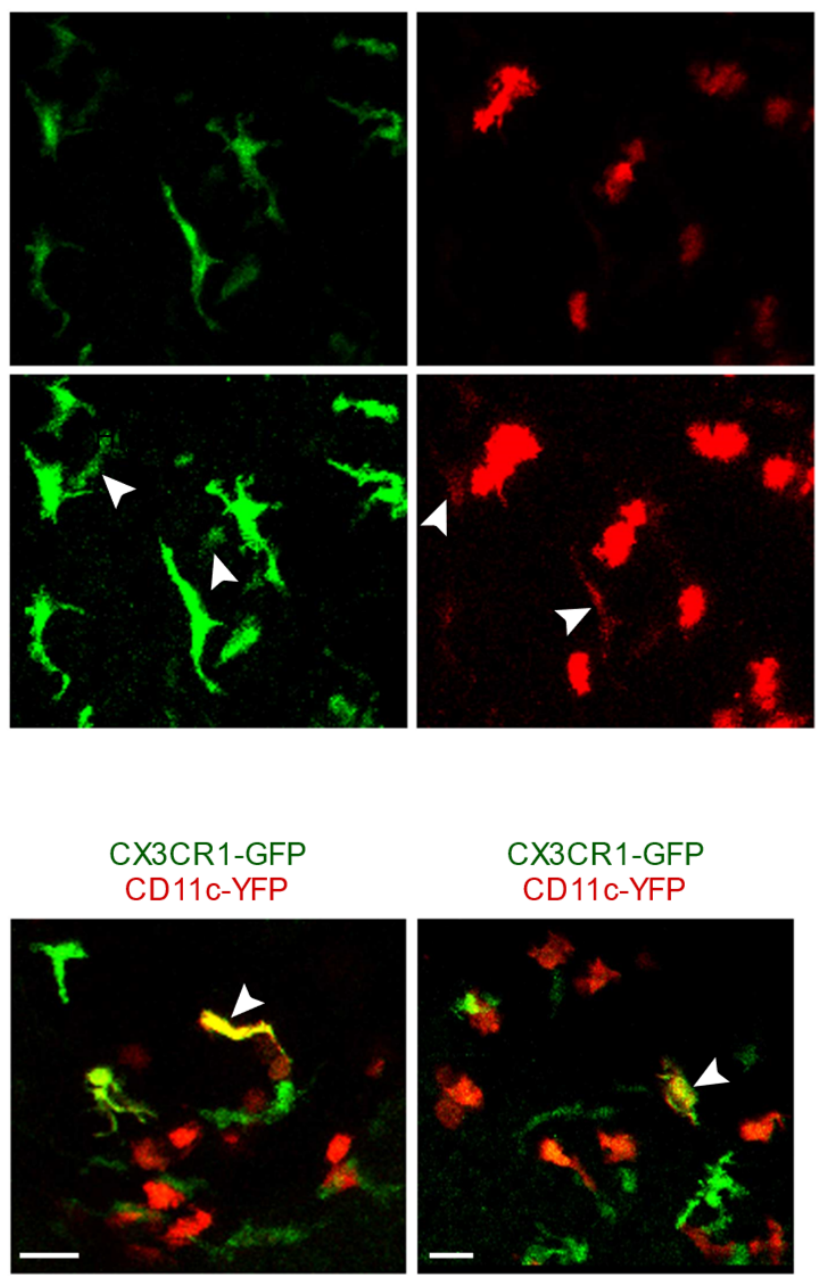
bioRxiv preprint doi: https://doi.org/10.1101/2020.09.18.247742; this version posted September 19, 2020. The copyright holder for this preprint (which was not certified by peer review) is the author/funder, who has granted bioRxiv a license to display the preprint in perpetuity. It is made available under aCC-BY-NC-ND 4.0 International license.

\section{Supplementary Figure 3}

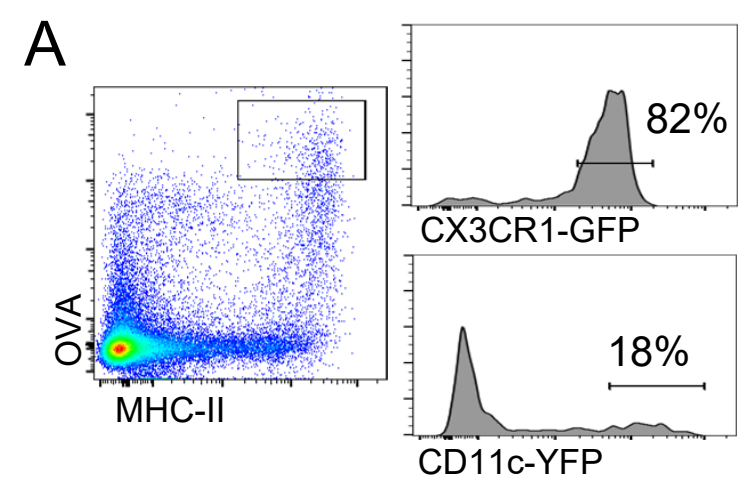

B

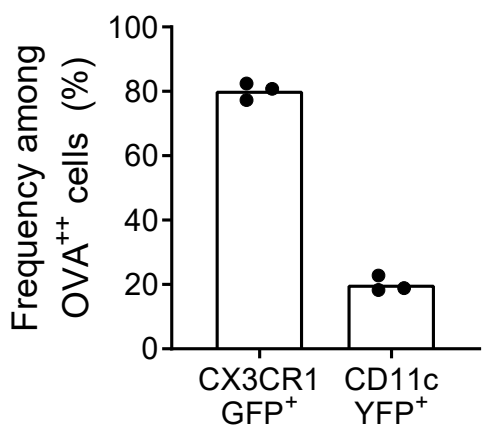


bioRxiv preprint doi: https://doi.org/10.1101/2020.09.18.247742; this version posted September 19,2020 . The copyright holder for this preprint (which was not certified by peer review) is the author/funder, who has granted bioRxiv a license to display the preprint in perpetuity. It is made available under aCC-BY-NC-ND 4.0 International license.

\section{Supplementary Figure 4}
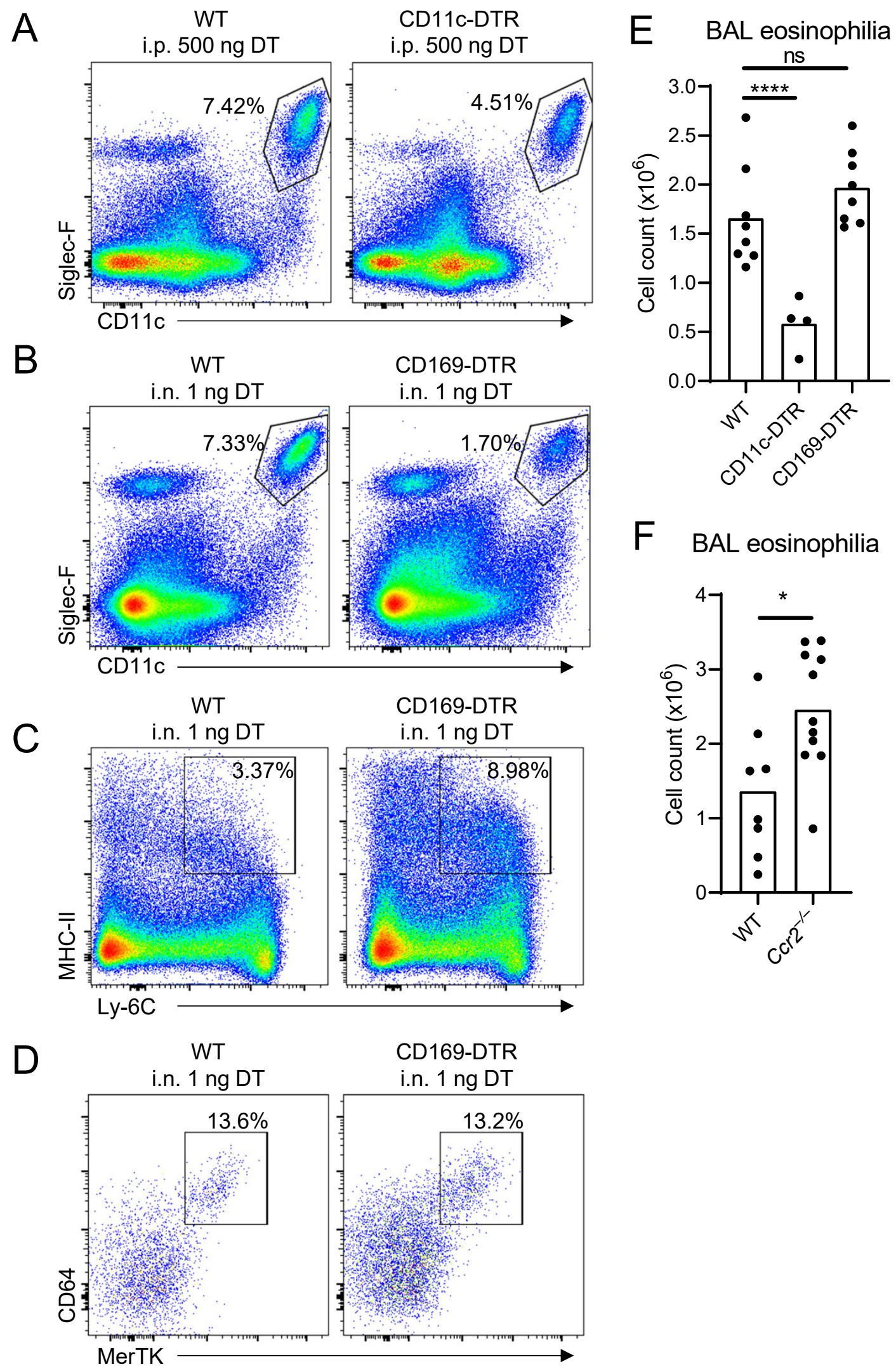

F BAL eosinophilia

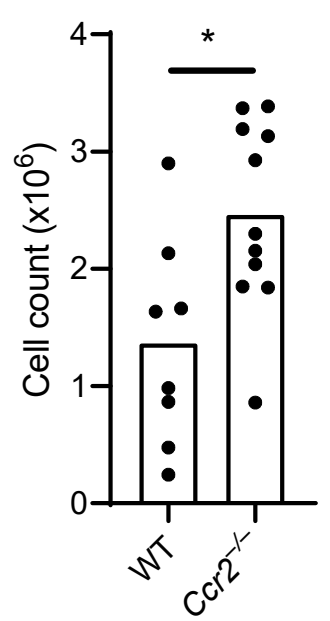


bioRxiv preprint doi: https://doi.org/10.1101/2020.09.18.247742; this version posted September 19, 2020. The copyright holder for this preprint (which was not certified by peer review) is the author/funder, who has granted bioRxiv a license to display the preprint in perpetuity. It is made available under aCC-BY-NC-ND 4.0 International license.

\section{Supplementary Figure 5}

A $\mathrm{CD} 11 \mathrm{C}^{+} \mathrm{MHC}-\mathrm{II}^{+}$

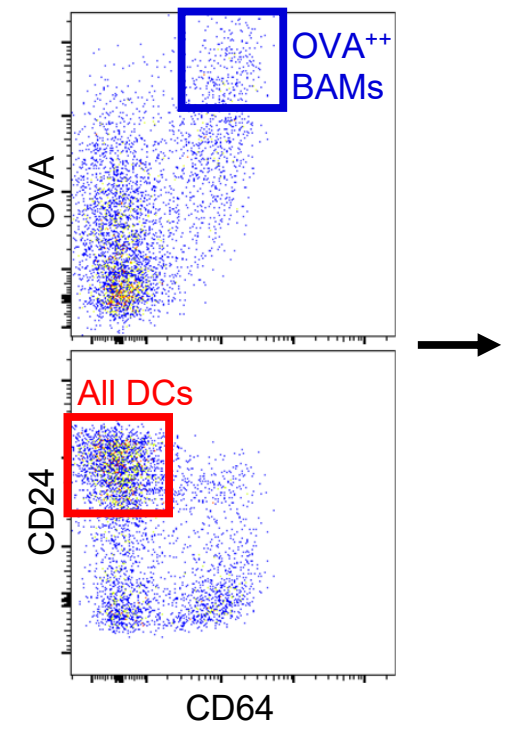

B $\mathrm{CDC2s}$

$\mathrm{MHC}-\mathrm{II}^{+} \mathrm{CD}^{+} 4^{+} \mathrm{MerTK}^{+}$

Monocytes

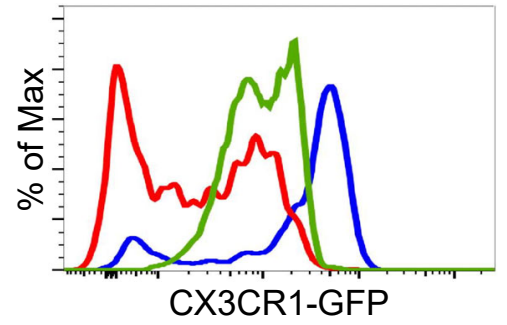

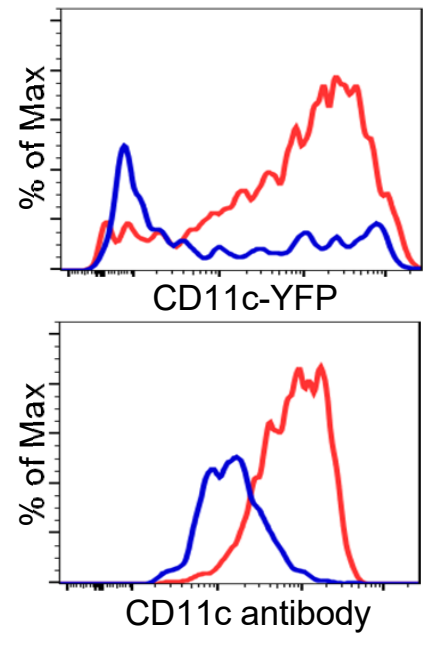


bioRxiv preprint doi: https://doi.org/10.1101/2020.09.18.247742; this version posted September 19, 2020. The copyright holder for this preprint (which was not certified by peer review) is the author/funder, who has granted bioRxiv a license to display the preprint in perpetuity. It is made available under aCC-BY-NC-ND 4.0 International license.

\section{Supplementary Figure 6}

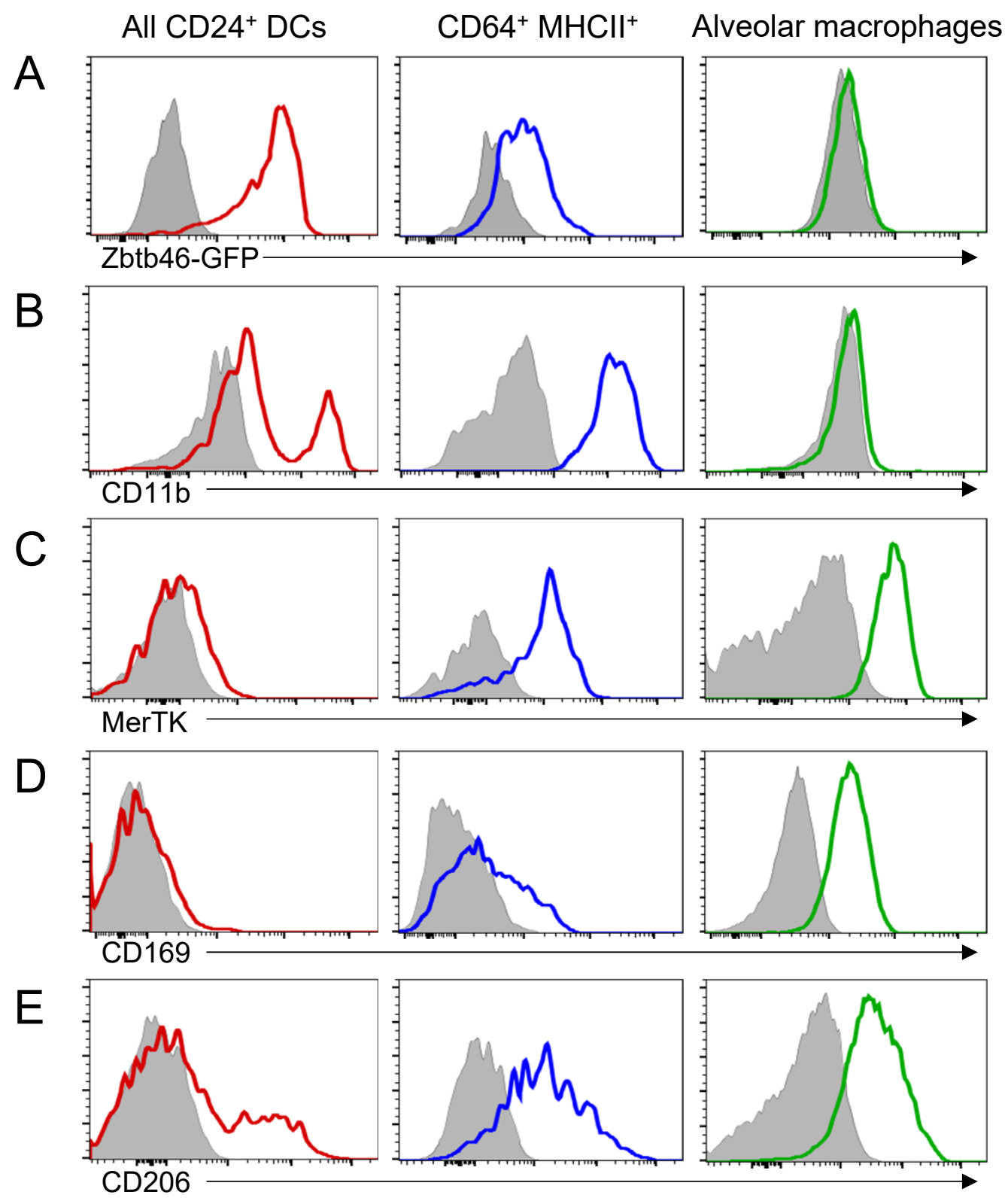


bioRxiv preprint doi: https://doi.org/10.1101/2020.09.18.247742; this version posted September 19,2020 . The copyright holder for this preprint (which was not certified by peer review) is the author/funder, who has granted bioRxiv a license to display the preprint in perpetuity. It is made available under aCC-BY-NC-ND 4.0 International license.

\section{Supplementary Figure 7}

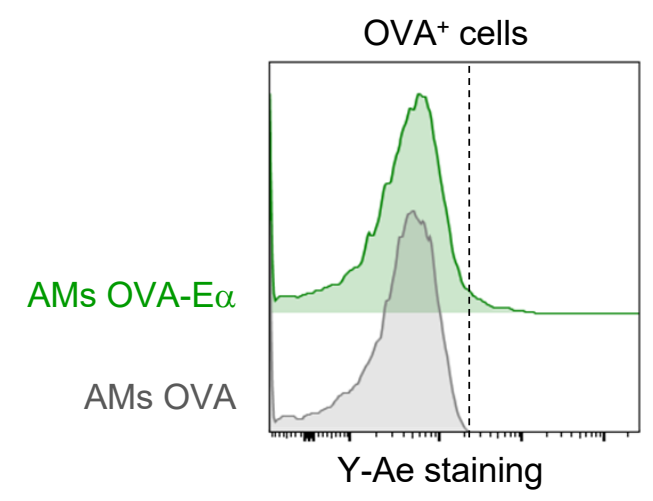


bioRxiv preprint doi: https://doi.org/10.1101/2020.09.18.247742; this version posted September 19,2020 . The copyright holder for this preprint (which was not certified by peer review) is the author/funder, who has granted bioRxiv a license to display the preprint in perpetuity. It is made available under aCC-BY-NC-ND 4.0 International license.

\section{Supplementary Figure 8}

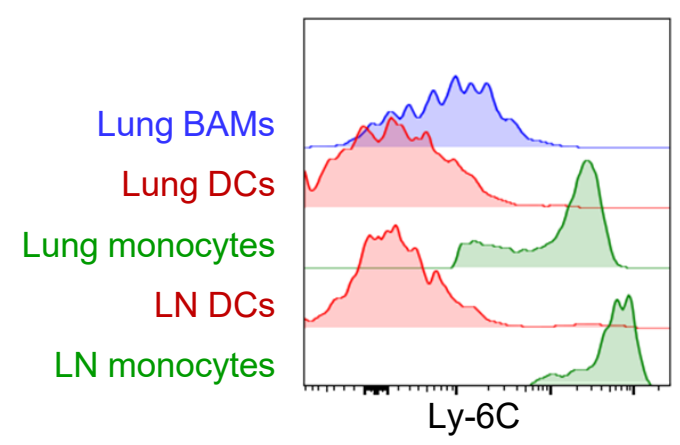


Supplementary Table 1: Emission filters for 2-photon microscopy

\begin{tabular}{lll}
\hline Emission/Fluorophore & Filter & Vendor \\
\hline Second harmonic & 450 short-pass & Chroma \\
(half of incident laser & $460 / 60$ & Semrock \\
wavelength) & $469 / 35$ & Semrock \\
& $470 / 40$ & Chroma \\
& $510 / 20$ & Chroma \\
& $539 / 30$ & Semrock \\
\hline CFP & $469 / 35$ & Semrock \\
& $472 / 30$ & Semrock \\
\hline GFP & $525 / 50$ & Chroma \\
& $510 / 20$ & Chroma \\
& $510 / 20$ & Semrock \\
\hline YFP & $525 / 50$ & Chroma \\
& $525 / 40$ & Semrock \\
& $535 / 30$ & Chroma \\
\hline PE & $539 / 30$ & Semrock \\
& $588 / 45$ & Zeiss \\
\hline tdTomato & $610 / 75$ & Chroma \\
& $588 / 45$ & Zeiss \\
& $605 / 70$ & Chroma \\
& $610 / 75$ & Chroma \\
\hline Tetramethylrhodamine & $625 / 30$ & Chroma \\
(TRITC, TAMRA) & $610 / 75$ & Chroma \\
\hline Texas Red & $625 / 30$ & Chroma \\
& $605 / 70$ & Chroma \\
\hline Alexa 647 & $610 / 75$ & Chroma \\
\hline Sky Blue beads & $625 / 30$ & Chroma \\
\hline & $670 / 50$ & Chroma \\
\hline & $690 / 50$ & Zeiss \\
\hline
\end{tabular}


Supplementary Table 2: List of antibodies and reagents used for flow cytometric analyses

\begin{tabular}{|c|c|c|c|}
\hline Antigen/reagent & Fluorophores & Vendor & Clone \\
\hline CCR7 & Biotin & Biolegend & 4B12 \\
\hline CD103 & PerCP-Cy5.5 & Biolegend & $2 \mathrm{E} 7$ \\
\hline CD11b & BV785 & Biolegend & $\mathrm{M} 1 / 70$ \\
\hline CD11b & FITC & Caltag & M1/70.15 \\
\hline CD11c & BV650, PE-Cy7 & Biolegend & N418 \\
\hline CD169 & eFluor660 & eBioscience & Ser-4 \\
\hline CD19 & PE-Dazzle594 & Biolegend & $6 \mathrm{D5}$ \\
\hline CD19 & PE-Cy7 & $\mathrm{BD}$ & 1D3 \\
\hline CD206 & Biotin & Biolegend & C068C2 \\
\hline CD24 & BV421 & Biolegend & M1/69 \\
\hline CD24 & APC & eBioscience & $\mathrm{M} 1 / 69$ \\
\hline CD4 & APC-H7 & BD & GK1.5 \\
\hline CD4 & Pacific Blue & Biolegend & RM4-5 \\
\hline CD4 & PE-Cy7 & eBioscience & GK1.5 \\
\hline CD45 & Alexa 700 & Biolegend & $30-F 11$ \\
\hline CD45.1 & Pacific Blue, Alexa 700 & Biolegend & A20 \\
\hline CD45.1 & $\mathrm{PE}$ & $\mathrm{BD}$ & A20 \\
\hline CD45.2 & Alexa 700 & Biolegend & 104 \\
\hline CD64 & PE, PE-Cy7 & Biolegend & $\times 54-5 / 7.1$ \\
\hline CD80 & Biotin & UCSF MAb core & 16.10.A1 \\
\hline CD86 & Biotin & UCSF MAb core & GL-1 \\
\hline$I-A^{b}$ & Biotin, FITC & Biolegend & $\mathrm{KH} 74$ \\
\hline IFN $\gamma$ & Alexa 488 & Biolegend & XMG1.2 \\
\hline IL-13 & PE & eBioscience & eBio13A \\
\hline Ly6C & BV711 & Biolegend & HK1.4 \\
\hline Ly6G & BV510, PE-Cy7 & Biolegend & $1 \mathrm{~A} 8$ \\
\hline MerTK & Biotin & $R \& D$ & polyclonal \\
\hline MerTK & PE & Biolegend & 2B10C42 \\
\hline Siglec-F & BV421, PE, PE-CF594 & $\mathrm{BD}$ & E50-2440 \\
\hline Streptavidin & Qdot605 & Life Technologies & \\
\hline TCR $\beta$ & APC & Biolegend & H57-597 \\
\hline Thy1.1 & PE-Cy7 & Biolegend & OX-7 \\
\hline Viability dye & eFluor780 & eBioscience & \\
\hline$V_{\alpha 2}$ & PE & $\mathrm{BD}$ & B20.1 \\
\hline$V \beta 5.1 / .2$ & FITC & $\mathrm{BD}$ & MR9-4 \\
\hline $\mathrm{V} \beta 5.1 / .2$ & PerCP-e710 & eBioscience & MR9-4 \\
\hline $\mathrm{Y}-\mathrm{Ae}$ & Biotin & eBioscience & eBioY-Ae \\
\hline
\end{tabular}

